\title{
MAY 11964
}

Do not remove this sheet

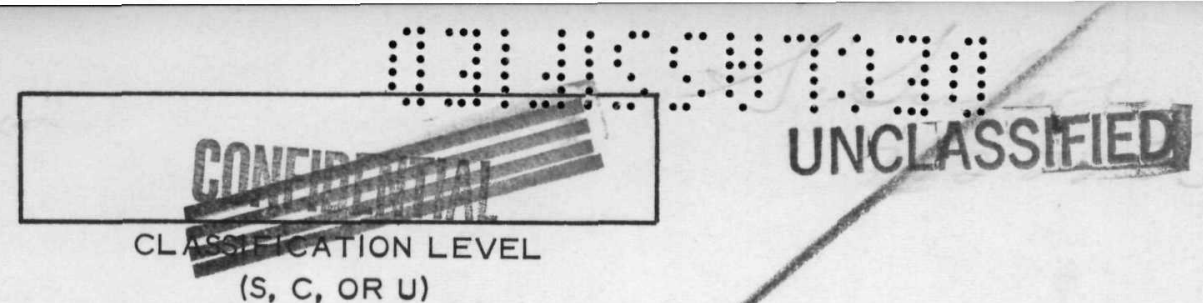

ATOMICS INTERNATIONAL

A Division of North American Aviation, IDC.

NAA-SR-MEMO

9ook

This document contains 124 pages

This is copy 60 of series

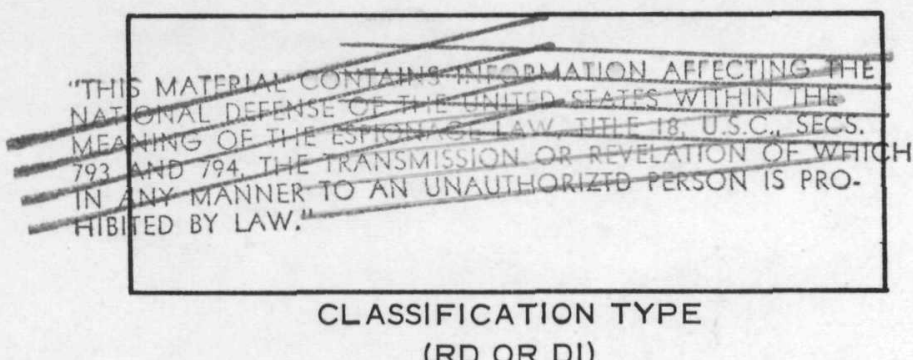

$N A A-S R-M E M O s$ are working papers and may be expanded, modified, or withdrawn at any time, and are intended for internal use only.

GROUP I

EXCLUDED FROM AUTOMATIC

DOWNGRADING \& DECLASSIFICATION

This report may not be published without the approval of the Patent Branch, AEC.

\section{LEGAL NOTICE}

This report was prepared as an account of Government sponsored work. Neither the United States, nor the Commission, nor any person acting on behalf of the Commission:

A. Makes any warranty or representation, express or implied, with respect to the accuracy, completeness, or usefulness of the information contained in this report, or that the use of any information, apparatus, method, or process disclosed in this report may not infringe privately owned rights; or

B. Assumes any liabilities with respect to the use of, or for damages resulting from the use of information, apparatus, method, or process disclosed in this report.

As used in the above, "person acting on behalf of the Commission" includes any amployee or contractor of the Commission to the extent that such employee or contractor prepares, handles or distributes, or provides access to, any information pursuant to his omployment or contract with the Commission.

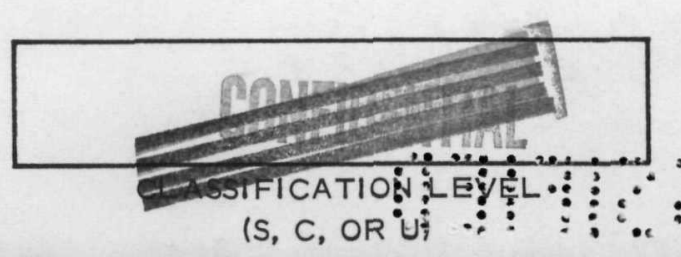

BISTRAUTHON Of THIS BOCUMENI IS UNLMHTE

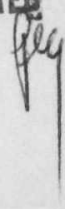




\section{DISCLAIMER}

This report was prepared as an account of work sponsored by an agency of the United States Government. Neither the United States Government nor any agency Thereof, nor any of their employees, makes any warranty, express or implied, or assumes any legal liability or responsibility for the accuracy, completeness, or usefulness of any information, apparatus, product, or process disclosed, or represents that its use would not infringe privately owned rights. Reference herein to any specific commercial product, process, or service by trade name, trademark, manufacturer, or otherwise does not necessarily constitute or imply its endorsement, recommendation, or favoring by the United States Government or any agency thereof. The views and opinions of authors expressed herein do not necessarily state or reflect those of the United States Government or any agency thereof. 


\section{DISCLAIMER}

Portions of this document may be illegible in electronic image products. Images are produced from the best available original document. 


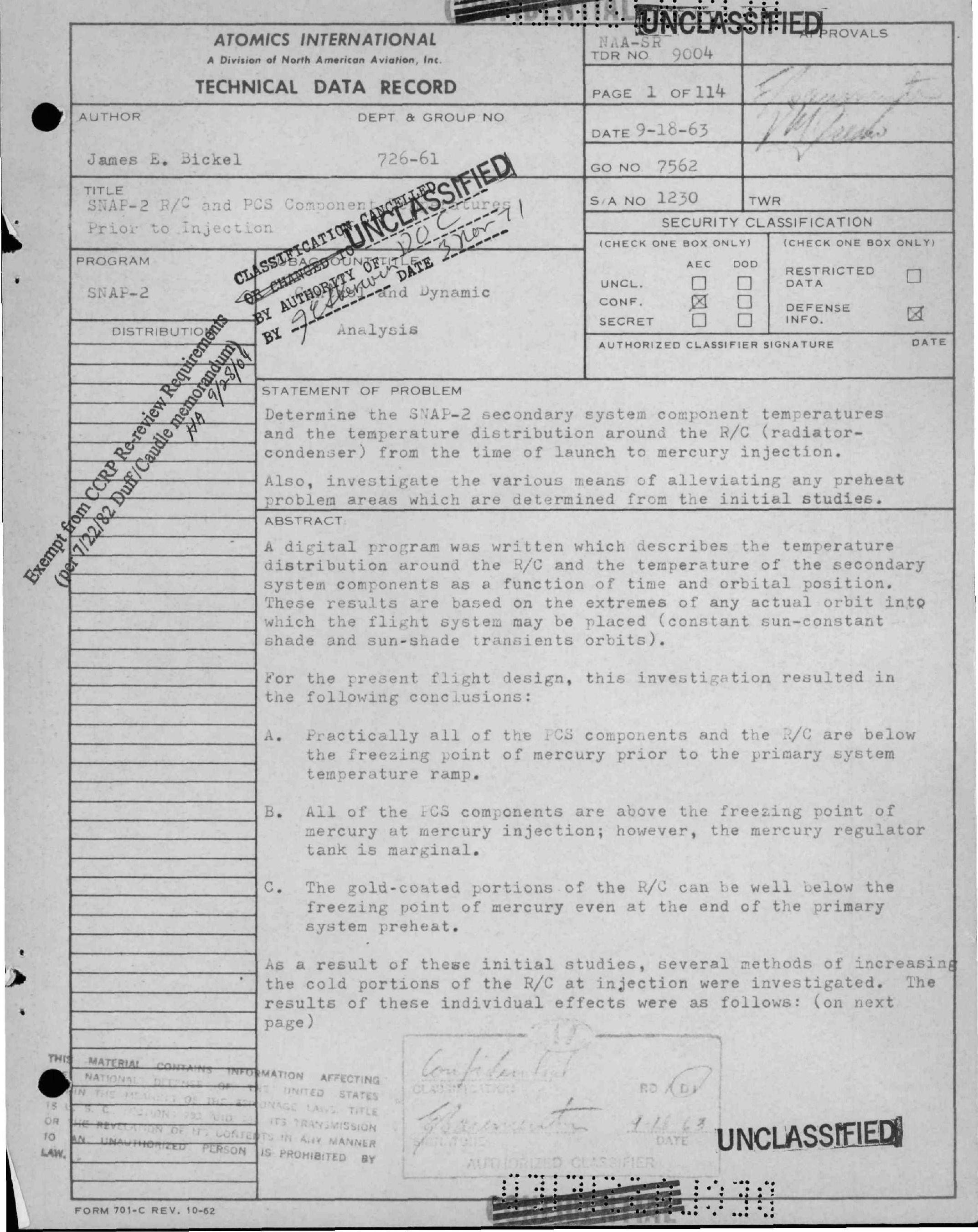




\section{ATOMICS INTERNATIONAL}

A Division of North American Aviation, Ine.

NO. NAA-SR-IDR 9004

Abstract- Continued

\section{Minimum $F / C$ Node-Temperature at End of Preheat}

Fresent flight design

Removal of gold-coating

Removal of gold-coating from NaK cold leg

Half of preheat ramp rate

Soak period after preheat prior to injection

$$
\begin{aligned}
& -120^{\circ} \mathrm{F} \\
& -39^{\circ} \mathrm{F} \\
& -84^{\circ} \mathrm{F}
\end{aligned}
$$$$
-105^{\circ} \mathrm{F}
$$$$
-84^{\circ} \mathrm{F}
$$

From these results, the best approach is to remove the gold-coating from the $R / C$ and the next best method being the high temperature soak (about one hour). If both methods were employed, the coldest $\mathrm{R} / \mathrm{C}$ node temperature would be $-8^{\circ} \mathrm{F}$.

Additional studies are needed to determine the penalties associated with these approaches. 


\section{ATOMICS INTERNATIONAL}

A Division of North American Aviation, Inc.

DATE Sectember 18,1963

PAGE 2 OF

114

\section{TABLE OF CONTENTS}

\section{STATEMENT OF PROBLEM}

II. ABSTRACT

III. RESULTS AND RECOMIENDATIONS

A. Cases Investigated and Results

Case 1 - Reference Case

a) transient orbit

b) constant sun-constant shade orbit

Case 2 - Reference case, except half of preheat ramprate

a) transient orbit

b) constant sun-constant shade orbit

Case 3 - Removal of R/C coating

a) transient orbit

b) constant sun-constant shade orbit

Case 4 - Removal of $\mathrm{R} / \mathrm{C}$ coating with half of preheat ramp rate

a) transient orbit

b) constant sun-constant shade orbit

Case 5 - Removal of coating on Nak cold leg

a) transient orbit

b) constant sun-constant shade orbit

Case 6 - Removal of coating on NaK cold leg and half of preheat ramp rate

a) Pransient orbit

b) Constant sun-constant shade orbit

Case 7 - Removal of coating from $R / C$ and NaK

Cold leg

a) Transient orbit

b) Constant sun-constant shade orbit

Case 8 - Removal of coating from $R / C$ and NaK cold leg 11 also half of preheat ramp rate

a) Transient orbit

b) Constant sun-constant shade orbit

Case 9 - Reference case with temperature soak at end of Naǩ ramp

a) Transient orbit

b) Constant sun-constant shade orbit

Case 10 - Removal of coating from NaK cold leg with temperature soak

a) Transient orbit

b) Constant sun-constant shade orbit

.




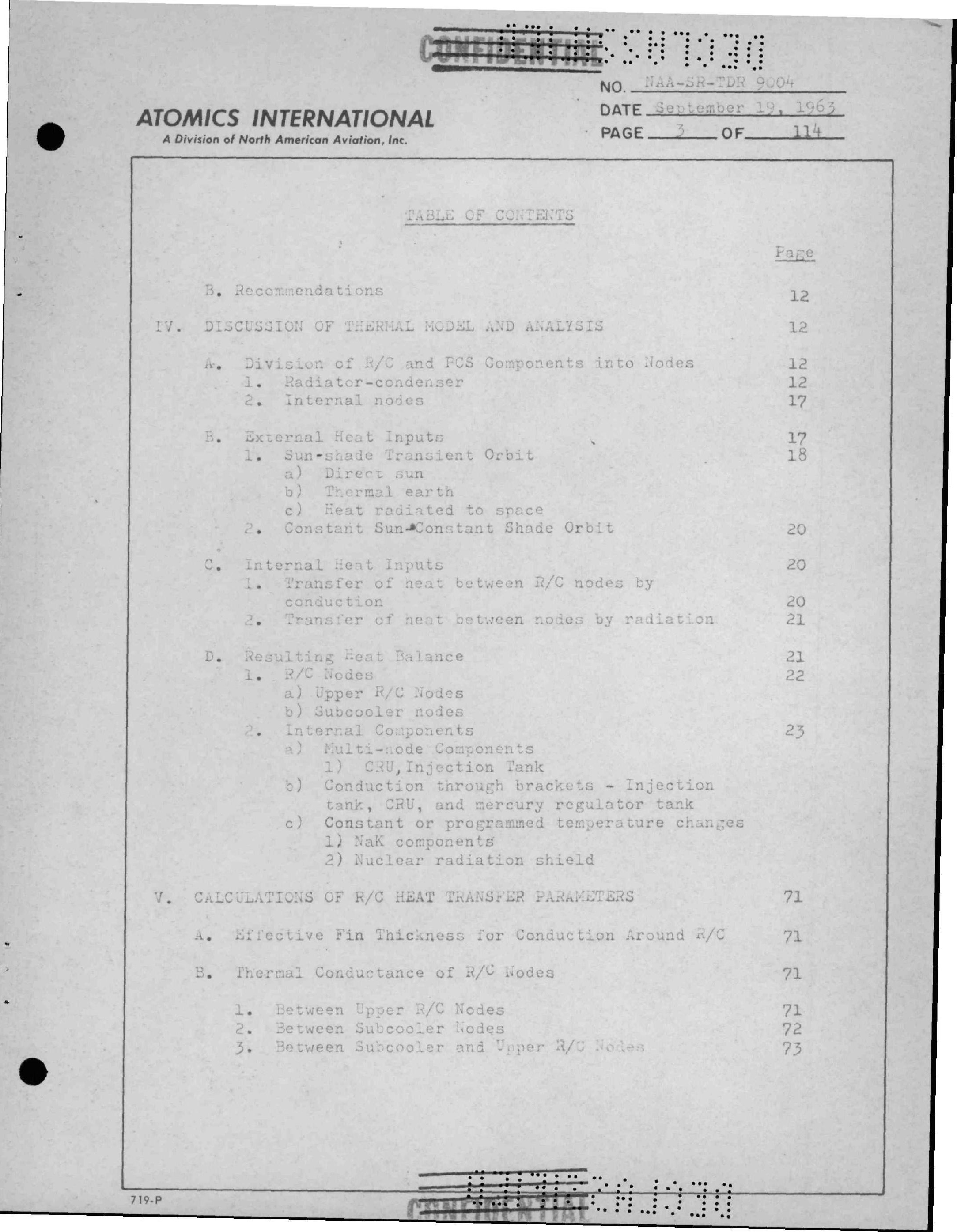




\section{ATOMICS INTERNATIONAL}

A Division of North American Aviation, Inc.

NO. NAA-SR-TDR 9004
DATE September 18,1963
PAGE 4 OF $\quad 114$

\section{TABLE OF CONTENTS}

C. Product of Mass Times Specific Heat for R/ C Nodes

VII APPENDIX

A. Interchange factors

B. Mean $\mathrm{R} / \mathrm{C}$ Temperature

C. Program Description

D. Method of Predicting Temperature Extremes of Any Component 


\section{RESULTS AND RECONIENDATIONS}

The analysis of this problem was made by utilizing a digital computer program written by J. Temple. The results discussed in this section are based on the results of this digital program.

\section{Initial conditions for all cases}

1. Sun-Shade Transient Orbit In order to evaluate the flight system under the most severe conditions (coldest system temperatures at mercury injection), the vehicle was launched toward the sun $(\rho=0$ in Figure 3$)$ and was in orbit at least 15 hours before the initiation of the startup sequence. Except when stated, mercury injection was assumed to occur immediately after the primary system temperature ramp. At injection, the coldest component and $\mathrm{R} / \mathrm{C}$ temperature are experienced when the vehicle is in the orbital position $\rho=270-\theta$ (Figure 3 ). This represents the case where the vehicle is in the shade for the longest period of time prior to injection.

The orientation of the bracketed components, boiler, and CRU at an orbital position $f=90^{\circ} \mathrm{F}$ is shown by Figure 4 .

2. Constant Sun-Constant Shade Orbit The initial conditions for this orbit were identical to the transient orbit's except the orbital position was constant at $\mathcal{S}=90^{\circ}$. The vehicle was again in orbit for at least 15 hours before the initiation of the startup sequence.

The results of the various cases are presented according to changes made in the emissivity of certain nodes, the slope of the primary system temperature ramp, and the time of injection after the end of the NaK ramp.

The description of each case is included with the results and the coldest $R / C$ node temperature for all of these cases are summarized by Graphs 1 and 2. Graph 1 gives the coldest R/C node temperature from sensible heat for the various cases investigated which have a normal preheat ramp rate. Graph 2 gives the coldest R/C node temperature for the current vehicle configuration with a nomal and half of the normal preheat ramp rate. 


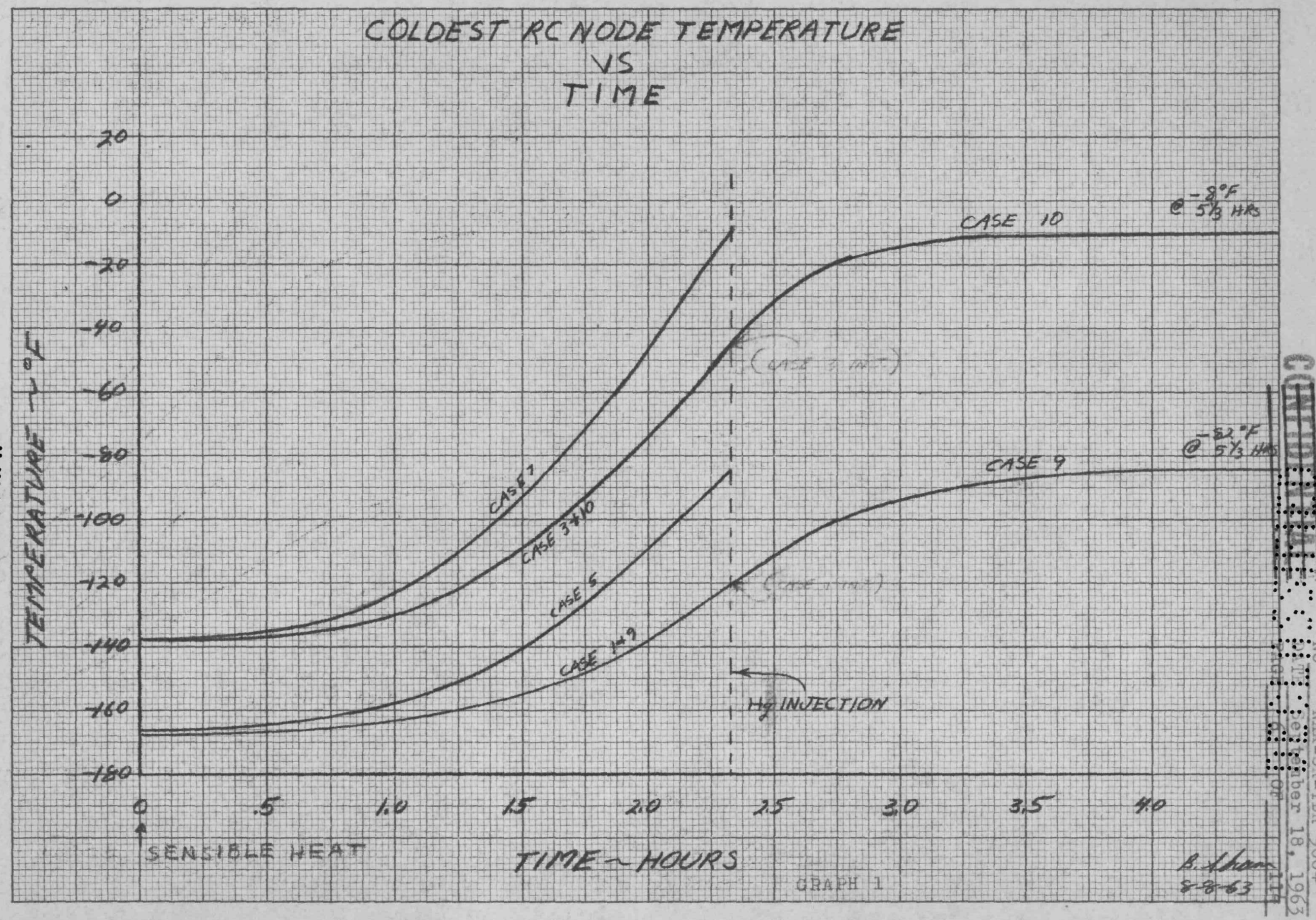




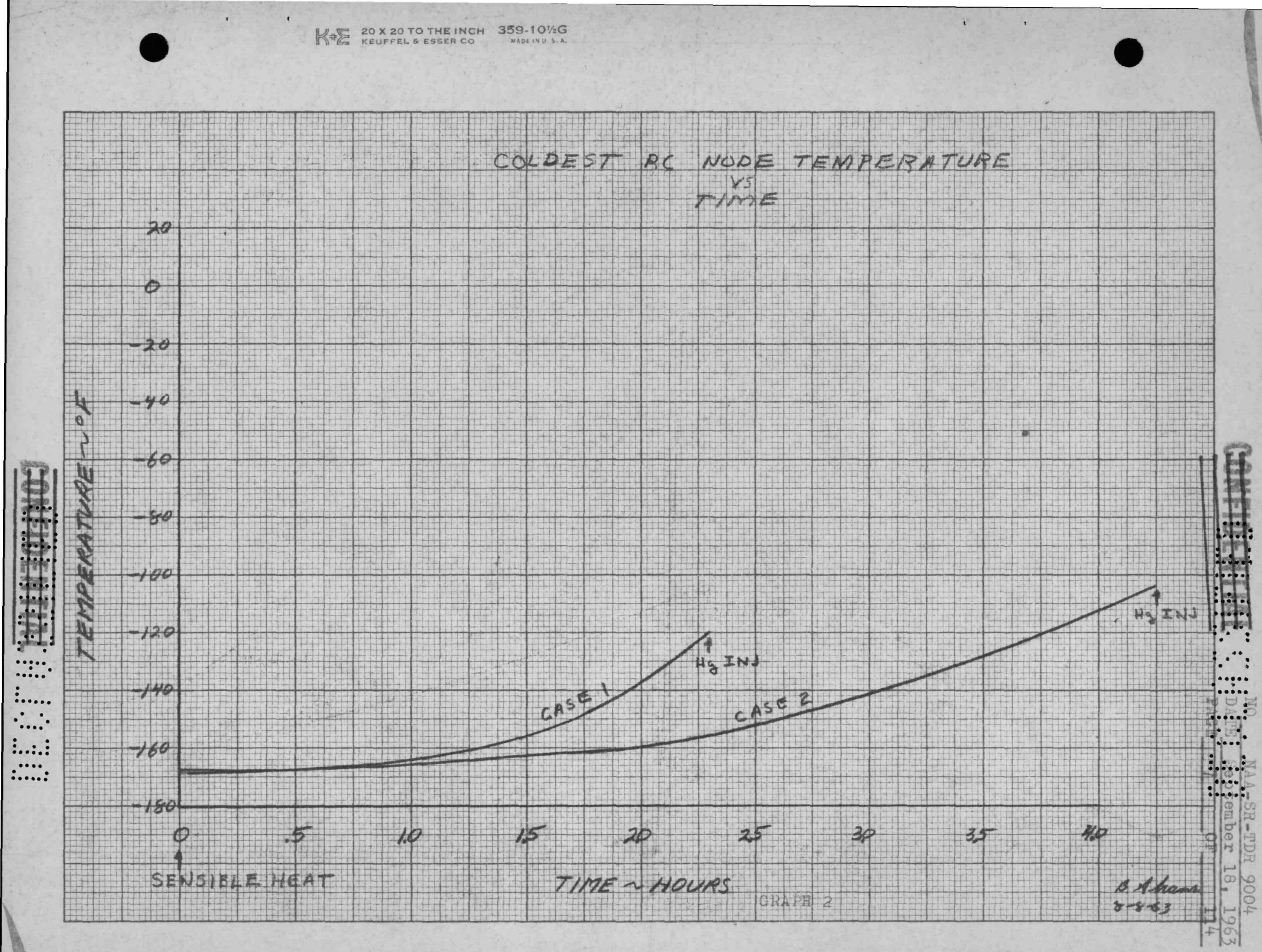




\section{Case 1 - Reference Case}

The emissivities of the R/C nodes and the slope of the primary system temperature ramp for this case were the same as the current values which are being considered for the flight design. Two of the upper $\mathrm{R} / \mathrm{C}$ nodes and all of the subcooler nodes were gold-coated. The primary system temperature ramp simulated the results obtained with a control drum stepping rate of one pulse per 100 seconds. All of the primary system nodes were gold-coated $(\varepsilon=.05)$.

\section{A. Transient Orbit}

The temperatures as a function of orbital position of the secondary system components listed in Table I are summarized by Graphs 9 through 13. From these results, the only PCS component which appeared to be marginal at injection from mercury freezing considerations was the mercury regulator tank. The temperature of this component at injection was $-32^{\circ} \mathrm{F}$. At injection, the mean $\mathrm{R} / \mathrm{C}$ temperature was $-38^{\circ} \mathrm{F}$ (Graph 3 ) and the coldest $\mathrm{R} / \mathrm{C}$ node temperature was $-100^{\circ} \mathrm{F}$. The temperature distributions for the upper $R / C$ and subcooler nodes for this orbit are given by Graphs 4 and 5 .

\section{B. Constant Sun-Constant Shade Orbit}

The mean $R / C$ temperature at injection was $11^{\circ} \mathrm{F}$. The mercury regulator was the coldest PCS component for this orbit also and was $3^{\circ} \mathrm{F}$ at injection. Although the mean $\mathrm{R} / \mathrm{C}$ and component temperatures are warmer in this orbit, the coldest individual R/C node temperature $\left(-120^{\circ} \mathrm{F}\right)$ was experienced on the shade side of the $R / C$ during the constant sun-constant shade orbit. (Graphs 7 and 8 )

Therefore, the coldest node temperature for the constant sunconstant shade orbit, and the mean R/C temperature at injection during the transient case were the main source of concern on all future cases.

\section{Case 2 - Reference Case Except Half of Preheat Ramp Rate}

The system was given a longer period to respond to the primary system temperature changes by reducing the slope of the NaK ramp to half of the predetermined value which was used in Case I. (This represents a stepping rate of approximately one pulse per 200 seconds, compared to one pulse per 100 seconds for Case 1)

\section{A. Transient Orbit}

The mean $\mathrm{R} / \mathrm{C}$ temperature at injection was $-22^{\circ} \mathrm{F}$ which represents an increase of approximately $20^{\circ}$ from the results obtained with the normal temperature ramp (Graph 3 ). 


\section{B. Constant Sun-Constant Shade Orbit}

The temperature distribution around the upper $\mathrm{R} / \mathrm{C}$ and subcooler nodes are shown by Graphs 14 and 15. The coldest individual node temperature was $-105^{\circ} \mathrm{F}$.

Case 3 - Removal of $\mathrm{R} / \mathrm{C}$ Coatin:

The gold-coating which was on two of the upper R/C nodes and all of the subcooler nodes during Cases I and 2 was removed by assigning these nodes an emissivity of 0.21 . Again, all of the primary system components were gold-coated and a normal NaK ramp was programmed into the analysis.

\section{A. Transient Orbit}

The temperatures of the secondary components were about $15^{\circ} \mathrm{F}$ less for this case. This decrease was due to the removal of the goldcoating from the $\mathrm{R} / \mathrm{C}$ and subcooler nodes since these nodes represent an adiitional heat sink on the system with any increase in emissivity. The mean $R / C$ temperature as a function of orbital position is shown by Graph 16.

\section{B. Constant Sun-Constant Shade Orbit}

The coldest $\mathrm{R} / \mathrm{C}$ node temperature at injection was $-45^{\circ} \mathrm{F}$. The temperature distribution around the upper $R / C$ and subcooler nodes are summarized in Graphs 17 and 18.

\section{Case 4 - Removal of $\mathrm{R} / \mathrm{C}$ Coating and Half of Preheat Ramp Rate}

This case is identical to Case 3, except the primary system temperature ramp was half of the normal ramp.

\section{A. Transient Orbit.}

From graph 19, the mean $\mathrm{R} / \mathrm{C}$ temperature at injection was found to be $-12^{\circ} \mathrm{F}$.

\section{B. Constant Sun-Constant Shade}

The temperature distributions around the two sets of $\mathrm{R} / \mathrm{C}$ nodes at injection are given by Graphs 20 and 21 . The coldest $R / C$ node temperature at injection was $-28^{\circ} \mathrm{F}$. 


\section{Case 5 - Removal of Coating on NaK Cold Leg}

In order to allow more heat to be radiated to the system during the prinary system temperature ramp, the coating on the cold NaK leg was removed for this case. The upper $R / C$ and subcooler nodes were gold-coated in the manner described by Case 1. The slope of the NaK temperature ramp was for the current stepping rate.

\section{A. Transient Orbit}

A mean $R / C$ temperature at mercury injection of $8^{\circ} \mathrm{F}$ was obtained for this case (Graph 22). Again, the mercury regulator was the coldest component, and was $-22^{\circ} \mathrm{F}$ at injection.

\section{B. Constant Sun-Constant Shade Orbit}

Graphs 23 and 24 give the temperature distribution of the upper $\mathrm{R} / \mathrm{C}$ and subcooler nodes, respectively. The coldest $\mathrm{R} / \mathrm{C}$ node at injection was $-96^{\circ} \mathrm{F}$.

\section{Case 6 - Removal of Coating on NaK Cold Leg and Half of Preheat Ramp Rate}

With the exception of the slope of the NaK ramp, this case was identical to the previous case. The primary system temperature ramp was half of the normal slope.

\section{A. Transient Orbit}

The mean R/C temperature as a function of orbital position is given by Graph 25. The temperature of this parameter at injection was $26^{\circ} \mathrm{F}$.

\section{B. Constant Sun-Constant Shade Orbit}

The coldest $\mathrm{R} / \mathrm{C}$ node temperature was $-77^{\circ} \mathrm{F}$. The temperature distribution around the upper R/C nodes at injection is given by Graph 26 and the distribution around the subcooler by Graph 27.

\section{Case 2 - Removal of Coating From R/C and NaK Cold Leg}

This and the preceding case represent the extremes as far as the amount of gold-coating which was removed. Gold-coating was removed from the two upper R/C subcooler, and gold NaK leg nodes. A normal stepping rate was used in this analysis. 


\section{ATOMICS INTERNATIONAL}

A Division of North American Aviation, Inc.

DATE September 18,1963

PAGE 11 OF 114

\section{A. Transient Orbit}

A mean $\mathrm{R} / \mathrm{C}$ temperature of $19^{\circ} \mathrm{F}$ was experienced at injection as shown by Graph 28.

B. Constant Sun-Constant Shade

Only one of the $\mathrm{R} / \mathrm{C}$ nodes was below $0^{\circ} \mathrm{F}$ for this case $\left(-9^{\circ}\right)$. The distribution around the $\mathrm{R} / \mathrm{C}$ nodes is summarized by Graphs 29 and 30

Case 8 - Rerroval of Coating from $R / C$ and NaK Cold Leg; Also, half Freheat Kamp Rate

This was a repeat of the previous case, except that the slope of the primary system temperature ramp was half of the normal ramp.

\section{A. Transient Orbit}

The mean $\mathrm{R} / \mathrm{C}$ temperature at injection was $36^{\circ} \mathrm{F}$ (Graph 31). The coldest secondary system temperature was $-20^{\circ} \mathrm{F}$ and was the mercury regulator tank.

\section{B. Constant Suŕ-Constant Shade Orbit}

The upper $\mathrm{R} / \mathrm{C}$ and subcooler temperature distribution at mercury injection are given by Graphs 32 and 33 , respectively. The coldest $\mathrm{R} / \mathrm{C}$ node temperature was $11^{\circ} \mathrm{F}$.

Case 9 - Reference Case with Temperature Soak at End of NaK Ramp

This case was identical to the reference case (1), except the system was allowed to "soak" for three hours at the end of the primary system temperature ranp.

\section{A. Transient Orbit}

Graph 34 gives the mean R/C temperature for a three hour "soak". From this $\mathrm{raph}$, the $\mathrm{R} / \mathrm{C}$ approached its equilibrium temperature during the first hour of the soak and very little chane occurred during the remaining two hours.

\section{B. Constant Sun-Constant Shade}

The coldest individual $\mathrm{R} / \mathrm{C}$ node temperatures were again experienced in this orbit. The coldest temperature was $-83^{\circ} \mathrm{F}$. The temperature distribution around the $\mathrm{R} / \mathrm{C}$ is summarized by Graphs 35 and 36 . 


\section{ATOMICS INTERNATIONAL}

A Division of North American Aviation, Inc.

NAA-SR-TDR 9004

Case 10 - Removal of Coating from NaK Cold Leg with Temperature Soak

For this case, the gold coating was removed from the cold NaK leg while the $R / C$ was coated in the manner described by Case 1 . The system was again allowed to soak for three hours at the end of the NaK ramp.

\section{A. Transient Orbit}

The mean $\mathrm{R} / \mathrm{C}$ temperature at the end of the three hour "soak" was $63^{\circ} \mathrm{F}$ as shown by Graph 37 . The mercury regulator was the coldest component at the end of the temperature soak and was at $4^{\circ} \mathrm{F}$.

\section{B. Constant Sun-Constant shade}

The coldest individual $\mathrm{R} / \mathrm{C}$ node temperature at the end of the ramp was $-54^{\circ} \mathrm{F}$. The mean $\mathrm{R} / \mathrm{C}$ temperature again had nearly reached its equilibrium temperature at the end of the first hour of the soak and, therefore, no advantage would be gained by extending the length of the soak.

The temperature distributions for both sets of $R / C$ nodes are summarized by Graphs 38 and 39.

\section{B. Recommendations}

The results which are included in this report are based on an emissivity for gold of .05 . However, this value is only valid if the coating is applied in an impeccable manner so that there is contact between the coating and surface being coated at all points. The minimum value this parameter can assume was determined by assuming there was no contact between surfaces. For this case, the emissivity of the gold-coating would approach half of the former value. This would represent a significant difference in the results contained herein. Therefore, as soon as this value is obtained experimentally, all of the candidate cases contained herein should be re-evaluated.

A weight study of all candidate cases should be made in order to determine the optimum case for mercury weight savings versus added copper weight resulting from gold removal.

Since the mercury regulator is the only marginal PCS component from mercury freezing considerations at injection, a higher emissivity coating or no coating at all should be considered for this component.

IV DISCUSSION OF THERMAL MODEL AND ANALYSIS

\section{A. Division of $\mathrm{R} / \mathrm{C}$ and PCS Components into Nodes}

1. Radiator-Condenser In order to arrive at a realistic temperature distribution around the $\mathrm{R} / \mathrm{C}$ while in orbit, the $\mathrm{R} / \mathrm{C}$ 


\section{ATOMICS INTERNATIONAL}

A Division of North American Aviation, Inc.

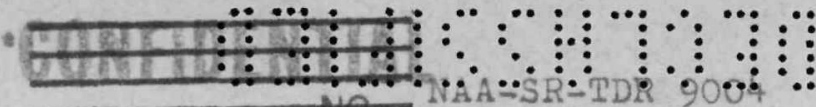

DATE September 18, 1963

PAGE 13 OF 114

\section{FIGURE I \\ DIVISION OF RC INTO NOOES}

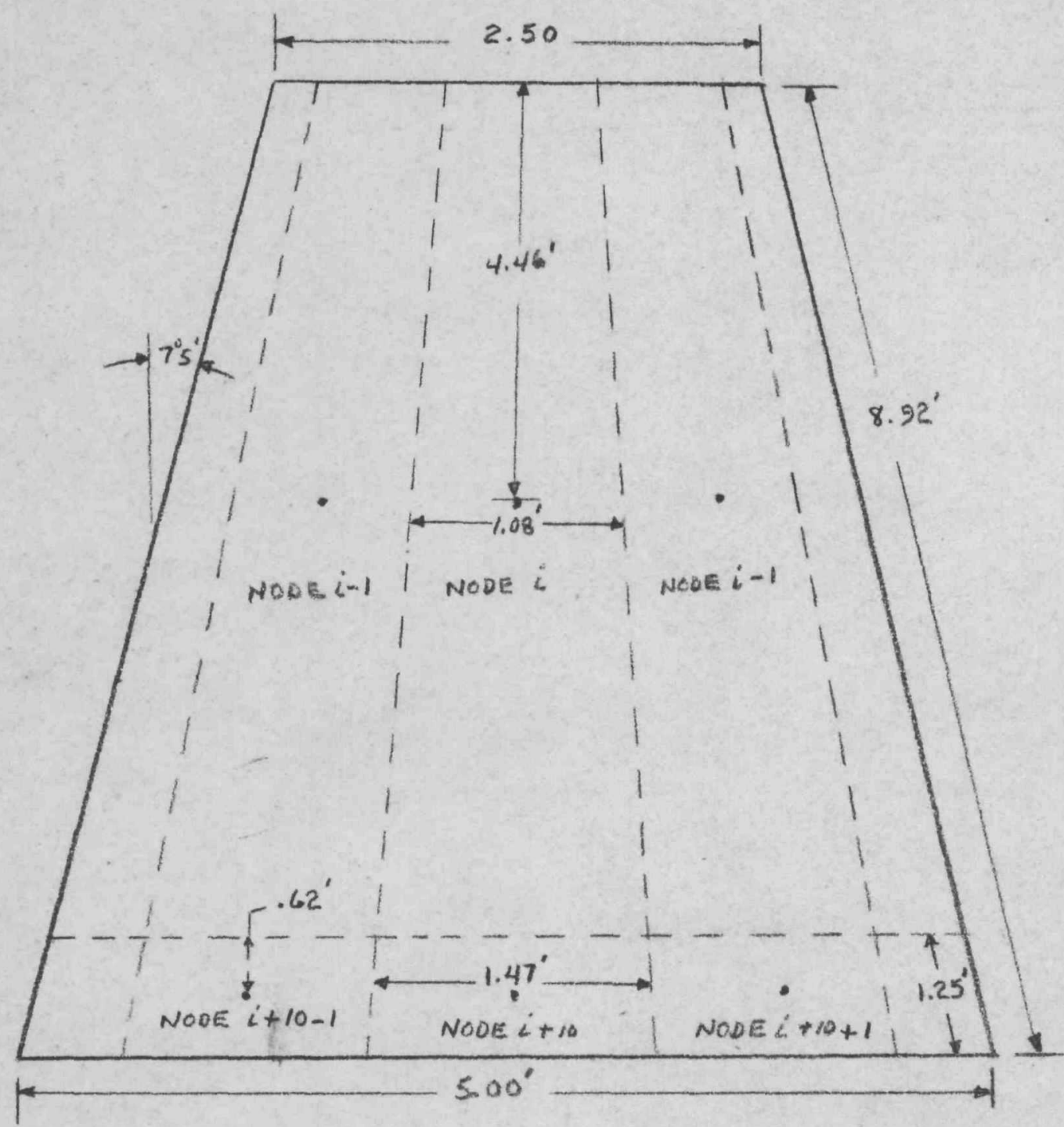




\section{ATOMICS INTERNATIONAL}

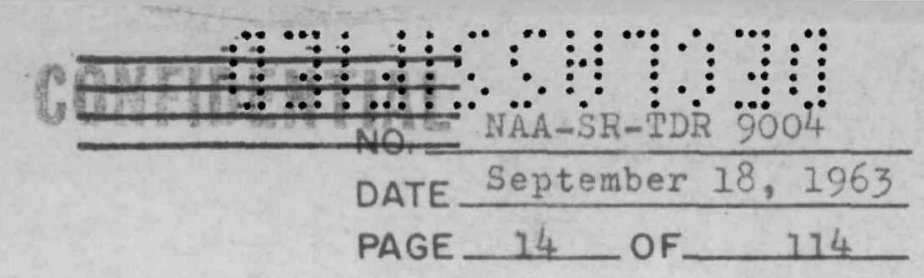

FIGURE 2

PROJECTED AREAS
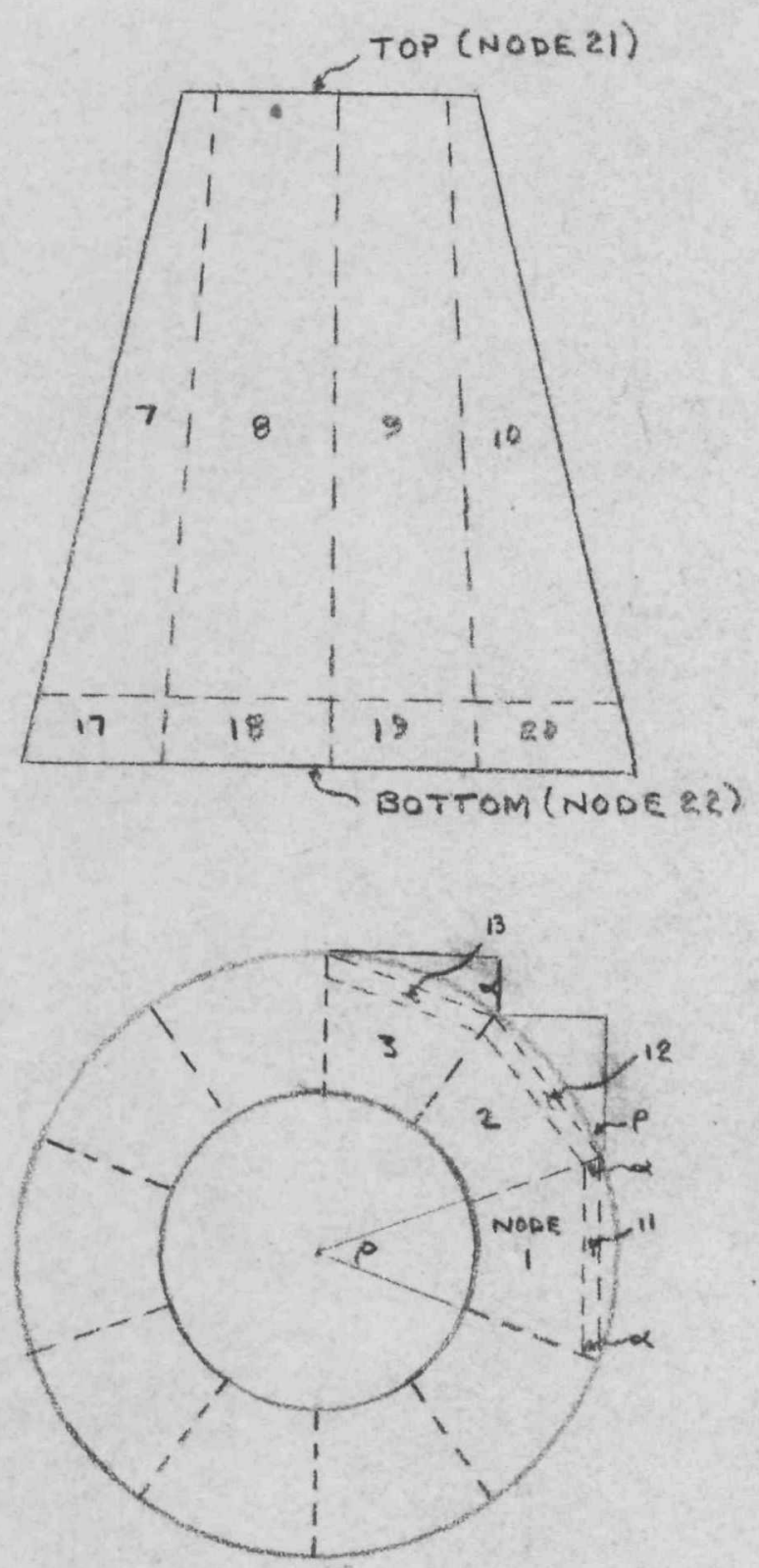

SUN 


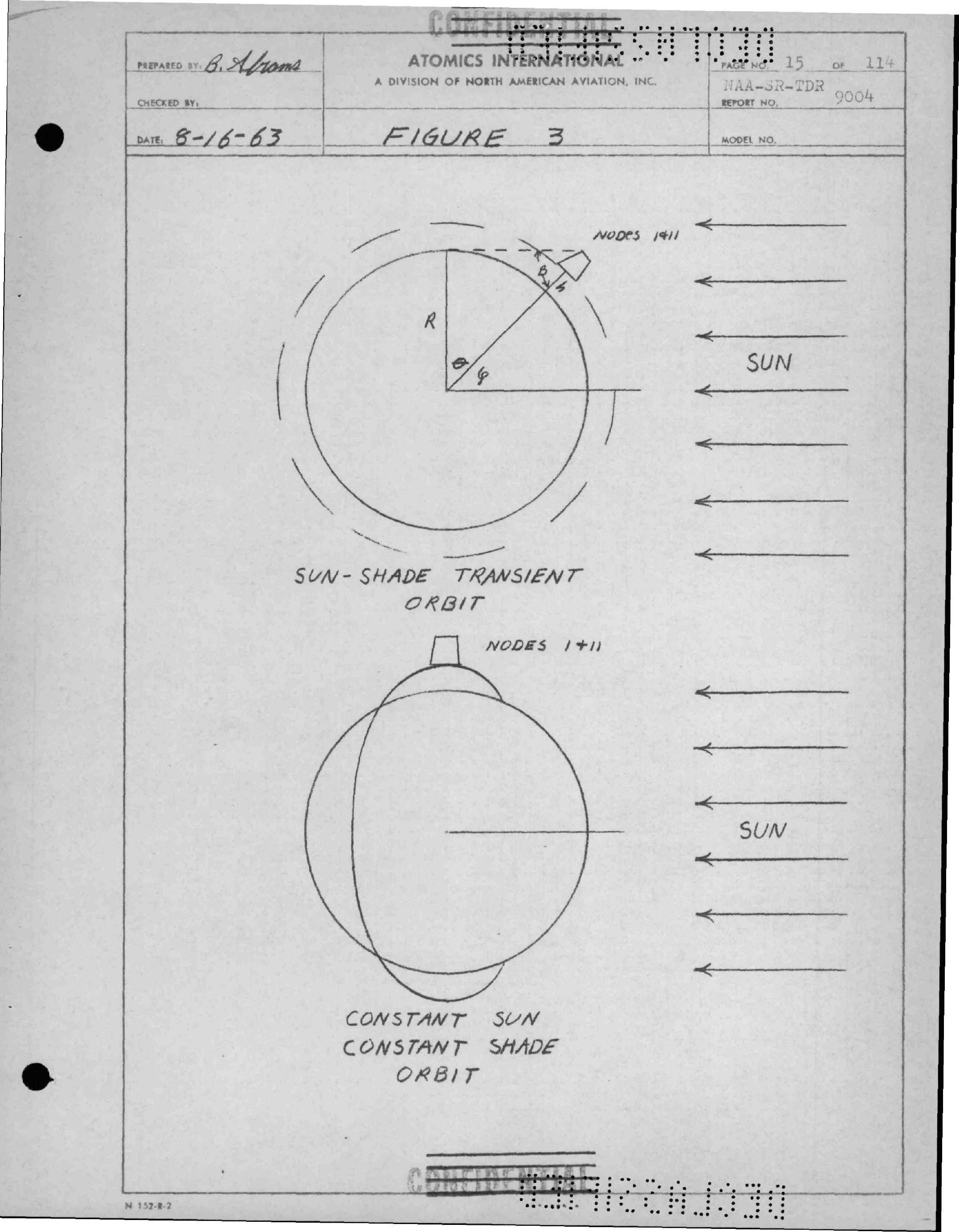




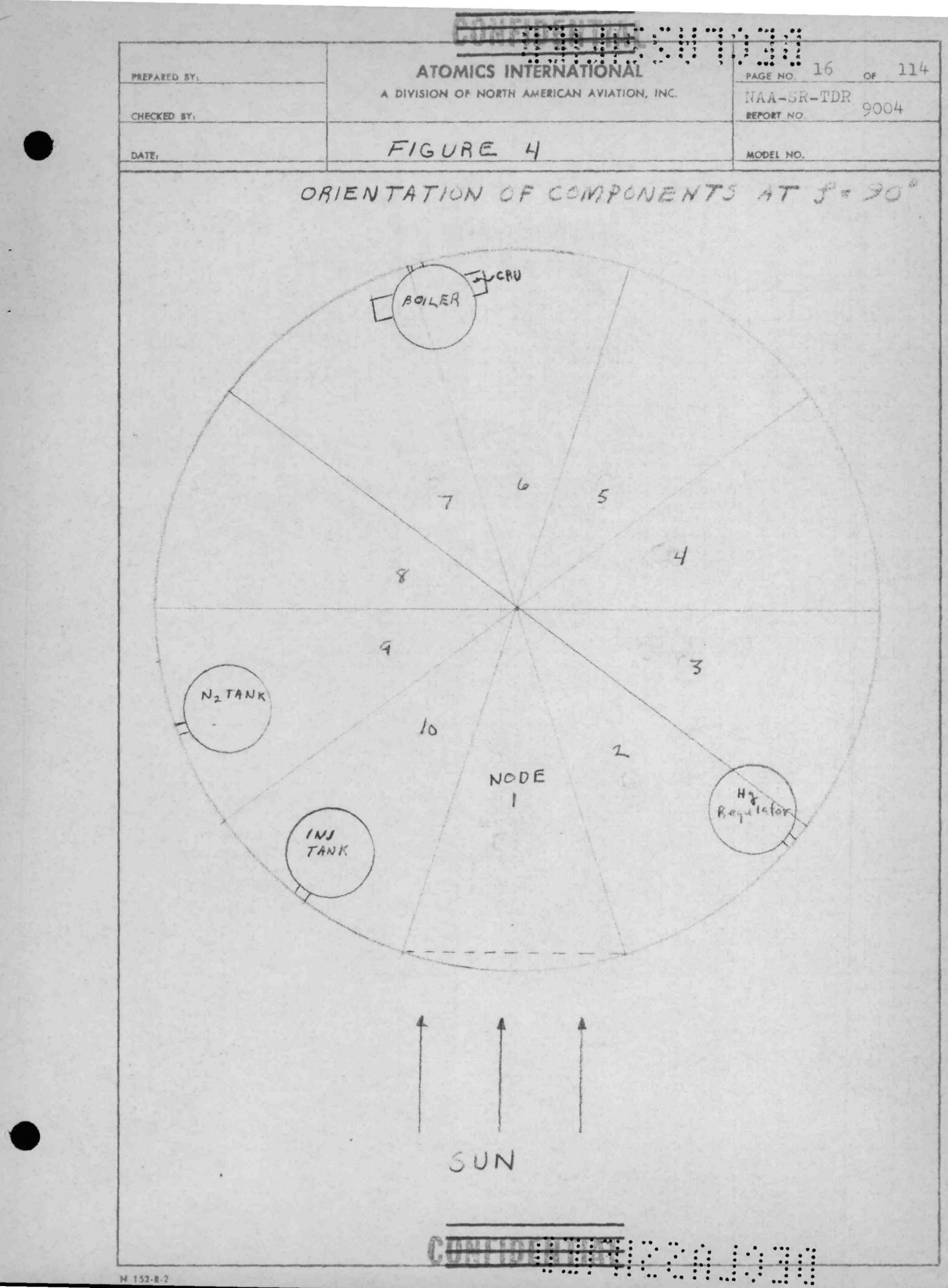




NO. WAA-SR-TDR 9004
DATE Sentember 18,1963
PAGE 17 OF_ 114

was divided into 20 nodes as shown in Figure 1. This division was made by first dividing the $\mathrm{R} / \mathrm{C}$ vertically into 10 equal nodes. A further subdivision at a distance of 15 inches from the bottom of the $R / C$ was necessary since the current design of the $R / C$ designates that the inside surface of the lower 15 inches shall be goldcoated. These lower $\mathrm{R} / \mathrm{C}$ nodes are called subcooler nodes and the upper nodes are referred to as upper R/C nodes throughout the remainder of this report.

In addition to the gold-coating on the interior of the subcooler nodes, eight of the forty $R / C$ tubes which are located directly behind the boiler and NaK lines are presently specified to be gold-coated along their entire lensth. Therefore, the choice of 10 vertically equal nodes adheres to the actual geometry by assuming two of the upper $\mathrm{R} / \mathrm{C}$ nodes are gold-coated. The radiation shield and the thermal barrier constitute two additional nodes at the top and bottom of the $R / C$ respectively.

2. Internal Nodes A total of 15 internal nodes, each of which represents some com onent in the system, were included in this analysis. The criteria which dictated what components should be included were based on:
a) A possible problem area at irjection because of mercury freezing.
b) The addition of heat that this component contributes
to the systen.
c) The simularity of the component (with respect to location) to others in the system.
d) Components which require a more detailed study of the effects of internal radiation and conduction to the $\mathrm{R} / \mathrm{C}$

This analysis utilized the current $\mathrm{R} / \mathrm{C}-12$ and component designs. The corresponding node number for each component and the properties of each are listed in Table I.

\section{B. External Heat Inputs}

Two different orbits were considered in this study. Each of these represents the extremes of any orbit into which the actual flight system might be placed. These two orbits are shown in Figure 3 and are:
a) Sun-Shade transient oribt - the sun's rays and the plane of the orbit are parallel.
b) Constant Sun-Constant Shade Orbit - the plane of the orbit is perpendicular, to the sun's rays.




DATE $\frac{\text { September } 18,1963}{18 \text { OF }}$

The orbit was assumed to be circular and at a distance of 700 miles above the earth. Another assumption was that the vehicle axis was normal to the surface of the earth.

The two major sources of external heat input to the vehicle while in orbit are:

\section{Direct Sunlight \\ 2. Thermal Radiation from the Earth.}

From reference (I), the heat input due to reflected sunlight from the earth was found to be negligible in comparison to the two sources listed above; therefore, this input was not included in the analysis.

$$
\begin{aligned}
& \text { 1. Sun Shade Transient Orbit } \\
& \text { The hirect Sun } \\
& \text { given by: } \quad q_{0 S}=q_{s} \alpha_{s} A_{i}(S) \text { STU/HK }
\end{aligned}
$$

where:

$$
\begin{aligned}
& \text { \&s - solar constant }=443 \mathrm{BTU} / \mathrm{hr} \mathrm{ft}^{2} \\
& \alpha_{\text {s }} \text { - absorptivity to solar radiation }=0.30 \\
& \text { M. (f) projected area of node i which is perpendi- } \\
& \text { cular to the sun's rays as a function of } \\
& \text { orbital position. }
\end{aligned}
$$

The projected area $A_{i}(\rho)$ may be related to the orbital position from Figures 2 and 3 . From these figures the projected area is represented by:

for

$$
\begin{aligned}
& \text { Wode } i=1,11 \\
& \text { 2, } 12 \\
& 3,13 \\
& 9,19 \\
& 10,20 \\
& \text { 4,14 } \\
& 5,15 \\
& 6,16 \\
& 7,17 \\
& 8,18 \\
& x \sin (f+\delta) \text { for } 0<f<90^{\circ}+\theta \\
& \begin{array}{c}
x \\
x
\end{array}
\end{aligned}
$$

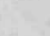


$\mathrm{Ai}(f)=0$ for alI nodes

for $90^{\circ}+\theta<\rho<270^{5}-\theta$

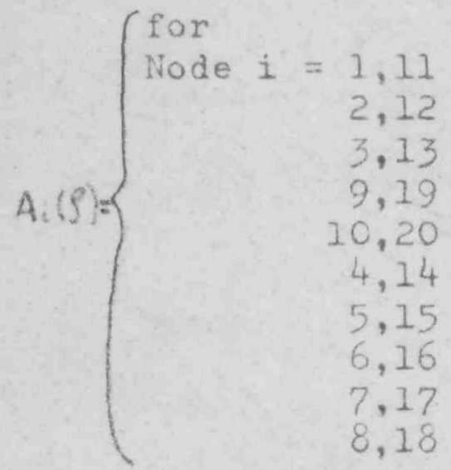

$\left.\begin{array}{ll}\mathrm{Ai} & \\ \mathrm{Ai} & \cos \\ \mathrm{Ai} & \cos \\ \mathrm{Ai} & \cos \\ \mathrm{Ai} & \cos \\ \mathrm{Ai} & \cos \\ \mathrm{Ai} & \cos \\ \mathrm{Ai} & \\ \mathrm{Ai} & \cos \\ \mathrm{A} i & \cos \end{array}\right\}$

$x \sin (\xi-\rho)$ for $360^{\circ}-\$<\rho<360^{\circ}$

$x \quad 0$ for $270^{\circ}-0<5<36025$

where Ai - maximum projected area of any nodei

$\begin{array}{rlrl}\text { for } I \leq i \leq 10 & \mathrm{~A} i=9.90 \mathrm{ft}^{2} \\ 11 \leq i \leq .20 & \mathrm{~A} i=1.81 \mathrm{ft}^{2}\end{array}$

$S$ - nalf apex angle of $\mathrm{R} / \mathrm{C}=7^{\circ} 5$

$\theta-\cos ^{-1}\left(\frac{R}{R+h}\right)=31^{\circ} 47$

$R$ - radius of earth $=3,960$ miles

h - orbital height $=700$ miles

P - see Figure $3=36^{\circ}$

$\propto$ - see Figure $3=72^{\circ}$

$\rho$ - orbital position (Figure 2)

The total heat input due to direct sunlight may be written as

$$
Q_{D S}=q_{s} \alpha_{s} \sum_{i=1}^{20} A_{i}(\rho) \text { BTU/HR }
$$

or per node

$$
q_{0 s}=133.0 \mathrm{~A}:(\xi) \text { BTU/HR }
$$

b) Thermal Earth The total heat input to the $\mathrm{F} / \mathrm{C}$ due to thermal radiation from the earth is given by:

$$
Q_{T \varepsilon}=F_{S \rightarrow \varepsilon} \alpha_{T} \varepsilon_{\varepsilon} q_{i \varepsilon} \sum_{i=1}^{20} A_{i}^{\prime}
$$

or per node

$$
q_{r \varepsilon}=F_{S \rightarrow \varepsilon} \alpha_{T} E_{2} q_{b \varepsilon} A_{i}^{\prime} E T U / \Delta E_{i}
$$

where: $A \dot{A}$ - surface area of each node

$$
\begin{aligned}
& \mathrm{Ai}=10.1 \mathrm{ft}^{2} \text { for } 1 \leq i \leq 10 \\
& \mathrm{Ai}=1.9 \mathrm{ft}^{2} \text { for } 10<i \leq 20
\end{aligned}
$$

$F_{s \rightarrow t}$ - view factor from satelite to earth $=0.118$ (Reference 2)

or - absorptivity to thermal radiation $=0.91$

$E_{E}$ - emissivity of earth $=1$

$q_{t E}$ - black body radiation of the earth $=\sigma T_{\varepsilon}$

$\sigma$ - Stefen-Boltzmann constant $=0.1713 \times 10^{-8}$ 


\section{ATOMICS INTERNATIONAL}

A Division of North American Aviation, Inc.

\begin{tabular}{l} 
NO. NAA-SR-TDR 9004 \\
DATE September 18,1963 \\
PAGE 20 OF $\quad 114$ \\
\hline
\end{tabular}

Using a mean earth temperature $\left(T_{\varepsilon}\right)$ of $440^{\circ} \mathrm{R}$, the total heat input due to thermal radiation is

$$
Q_{\text {re }}=6.9 \sum_{i=1}^{20} A^{\prime} \text { : }
$$

or per node $\quad q_{T \varepsilon}=6.7 A_{i}^{i} \quad 85 u / N R$

The total heat input due to direct sunlight and thermal radiation from the earth is

$$
\theta_{r}=133.0 \sum_{i=1}^{20} A_{i}(s)+6.9 \sum_{i=1}^{20} A_{i}^{\prime}
$$

or per node

$$
q_{T}=133.0 A_{i}(S)+6.9 A_{i}^{\prime} \quad B+U / H R=N O B E_{i}
$$

c) Heat Radiated to space The heat radiated to space by the RC can be represented by

$$
q(r a d) i^{x}-A^{\prime}=\varepsilon_{2}+z_{i}^{4}
$$

where $\varepsilon_{t}$ is the thermal emissivity of the outside surface of the $R / C(.91)$.

\section{Constant Sun-Constant Shade Orbit}

The heat inputs per node for a constant sun-constant shade orbit may be obtained directly from equation (?). "or this case, the vehicle will be at an angle of $90^{\circ}$ with the line $\rho=0$ in Figure 3 . Therefore, for a constant sun constant shade orbit, the heat input into each node from direct sunlight becomes a constant.

C. Internal Heat Inputs

1. Transfer of Heat Between R/C Nodes by Conduction Each of the R/C nodes conduct heat to or from the adjoining nodes. By using the same configuration for the $\mathrm{R} / \mathrm{C}$ nodes as those used in the heat input analysis (Figure 1 ), the net interchange of heat by conduction can be determined.

\section{A. Upper R/C Nodes}

The net gain or loss in heat of any upper $\mathrm{R} / \mathrm{C}$ node due to conduction is

$$
\left(q_{m}-q_{\text {out }}\right)_{i}=\left(\frac{K A}{\Delta x}\right)_{i}\left[t_{i+1}-2 t_{i}+t_{i+i}\right]+\left(\frac{K A}{A X}\right)_{2}\left[t_{10+i}-t_{i}\right] \text { BTU/HR }
$$


where: $(K 4)$ - thermal conductance between upper $\mathrm{R} / \mathrm{C}$ nodes $=$ hX) $1.045 \frac{\mathrm{BTU}}{\mathrm{hr}^{\circ} \mathrm{F}}$

$\left.\frac{K A}{\Delta x}\right|_{2}$ - thermal conductance between any upper $R / C$ node and the corresponding subcooler node $i+10=$ $.0476 \frac{\mathrm{BTU}}{\mathrm{hr}^{\circ} \mathrm{F}}$

\section{b) Subcooler Nodes}

The net gain or loss in heat due to conduction for the subcooler is

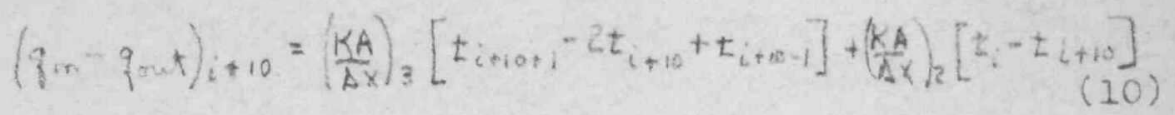

where: $\left(\frac{\mathrm{A}}{\mathrm{A} \gamma}\right) \mathrm{g}$ is the thermal conductance between the lower $\mathrm{R} / \mathrm{C}$ nodes and equals $0.117 \frac{\mathrm{BrU}}{\mathrm{hr} \mathrm{r}^{\circ} \mathrm{R}}$

The manner in which the thermal conductance between $\mathrm{R} / \mathrm{C}$ nodes was determined is included in the calculations.

\section{Transfer of Heat Between Nodes by Radiation}

The interchange of heat due to the internally reflected and radiated heat from the $\mathrm{R} / \mathrm{C}$ nodes and internal components is expressed as:

$$
q_{i}(\operatorname{rod})=A_{i}^{\prime \prime} \sum_{j} F_{i j}\left(E_{j}{ }^{4}-Z_{i}{ }^{4}\right) B+U / H R
$$

where: $F_{j}$ - interchange factor which is used in determining the amount of heat interchanged between some node $i$ and node $j$ by reflection, emission, and reradiation. (A more detailed explanation is included in the Appendix)

$A_{i}^{*}$ - total surface area of the node or component $i$, $\mathrm{ft}^{2}$

$z_{j}$ - instantaneous temperature of any node $j$.

D. Resulting Heat Balance

The change in temperature as a function of time of any node can be determined from

$$
(m c)_{i} \frac{d z}{d t}=g_{i n} g a t
$$

where: $(m c)_{i}$ - mass tine specific heat of any node or comporient $i$, $\frac{3 T U}{\mathrm{R}}$

$\gamma$ - unit of time, hr 


\section{1. $\mathrm{R} / \mathrm{C}$ Nodes}

Substituting the change in heat $\left(g_{m}-z_{m}+\right)$ due to:
a) direct sunlight
b) thermal earth radiation
c) conduction
d) radiation to space
e) internal radiation

into equation (12), the time rate of change, in temperature for the $\mathrm{R} / \mathrm{C}$ nodes car be obtained, or for the

a) Upper R/C Nodes

$$
\begin{aligned}
& \text { (mc)i } \frac{d t_{i}}{d r}=\left(\frac{K A}{\Delta x}\right)_{1}\left[t_{i+1}-2 t_{i}+t_{i+1}\right]+\left(\frac{K A}{\Delta x}\right)_{2}\left[t_{i+10}-t_{i}\right]+g_{5} \cos A_{i}(\rho)+
\end{aligned}
$$

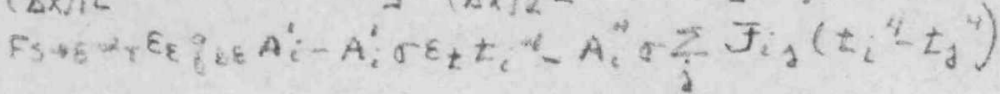

$$
\begin{aligned}
& \text { for } 1 \leq i \leq 10
\end{aligned}
$$

b) Subcooler Nodes

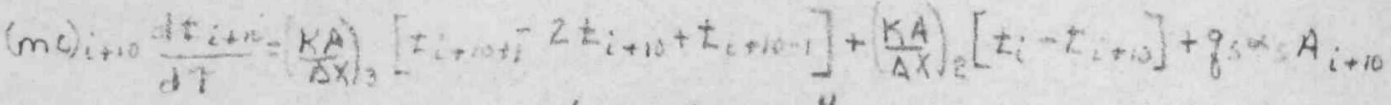

$$
\begin{aligned}
& +F_{5-8} \alpha_{+} \varepsilon_{2} q_{B \varepsilon} A_{i+10}^{\prime}-A_{i}^{\prime} \sigma \varepsilon_{t} t_{i+10}^{4}-A_{i+10}^{\prime \prime} \sigma \sum_{j}\left(t_{i+10}^{4}-t_{j}{ }^{4}\right) \mathcal{F}_{i-j} \\
& \text { for } 1 \leqslant i \leqslant 10
\end{aligned}
$$

In order to correlate the heat input with real time, it was necessary to express the orbital position angle $f$ in terms of the angular velocity, or $\rho=\omega 7$

An approximate relationship for obtaining angular velocity of an object $h$ miles above the earth is:

$$
\omega=\frac{R_{0}}{R_{0}+h}\left[\frac{g}{\mu_{0}+h}\right]^{\text {है }} \text { (Reference I) }
$$

where: $\mathrm{g}$ - gravity constant $=32.2 \mathrm{ft} / \mathrm{sec}^{2}$

$R_{0}$ - radius of earth $=3960 \mathrm{miles}$

h - 700 mile orbit

$\omega-.00097 \mathrm{rad} / \mathrm{sec}$ or 200 degrees per hour 


\section{ATOMICS INTERNATIONAL}

\section{Internal Components}

Initially, all of the internal components were assumed to have no conduction losses through the brackets, pipes, etc. From this assumption, the time rate of change in temperature was simply written as

$$
\text { (mc) } i \frac{d t_{i}}{d r}=A_{i}^{i} r \sum_{j} f_{i j}\left[t_{i}^{4}-t_{i}^{4}\right] \text { for } 22 \leqslant i \leqslant 37
$$

The capability to simulate a heater on all of the internal components was included in this analysis by the addition of a constant to equation (15). This term represents a constant number of BTU/hr which can be added to the component in order to maintain a higher component temperature or

$$
(m c)_{i} \frac{d t_{i}}{d t}-A_{i}^{11}+\frac{5}{2} F_{i j}\left[t_{j}^{4}-t_{i}^{4}\right]+C_{3}
$$

Some of the internal components which are included in this analysis and their time rate of change in temperature are not adequately described by Equation (15). These components fall into at least one of the following three catagories:

a) A one node model for the entire component is not sufficient.

b) Conduction through the brackets which support the component is significant.

c) Due to the NaK circulating through the component or gamma heating from the reactor, the components temperature change is not described by equation (15). The modifications which were made on these components are as follows:

1) Multi-liode Component

CRU At mercury injection, one of suspected mercury freezing problem areas was the CRU. In order to obtain a nore realistic temperature distribution of the CRU, this component was divided into three subnodes according to Figure 5 .

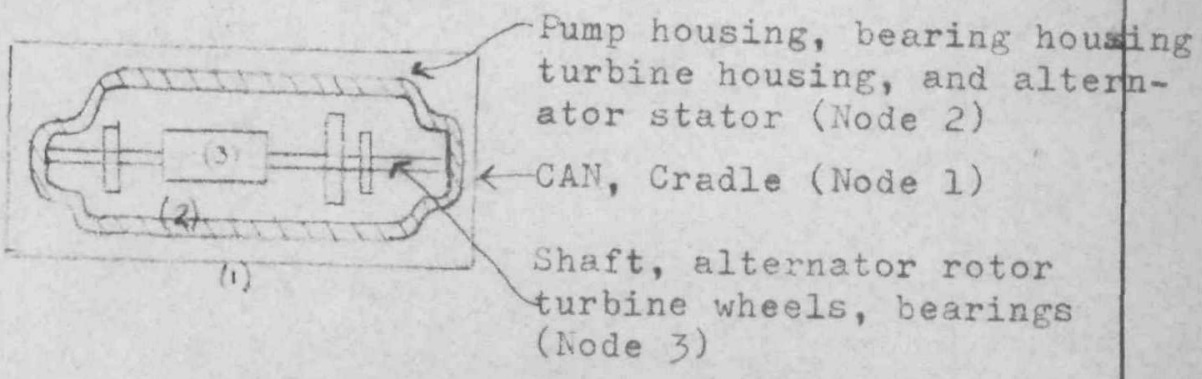




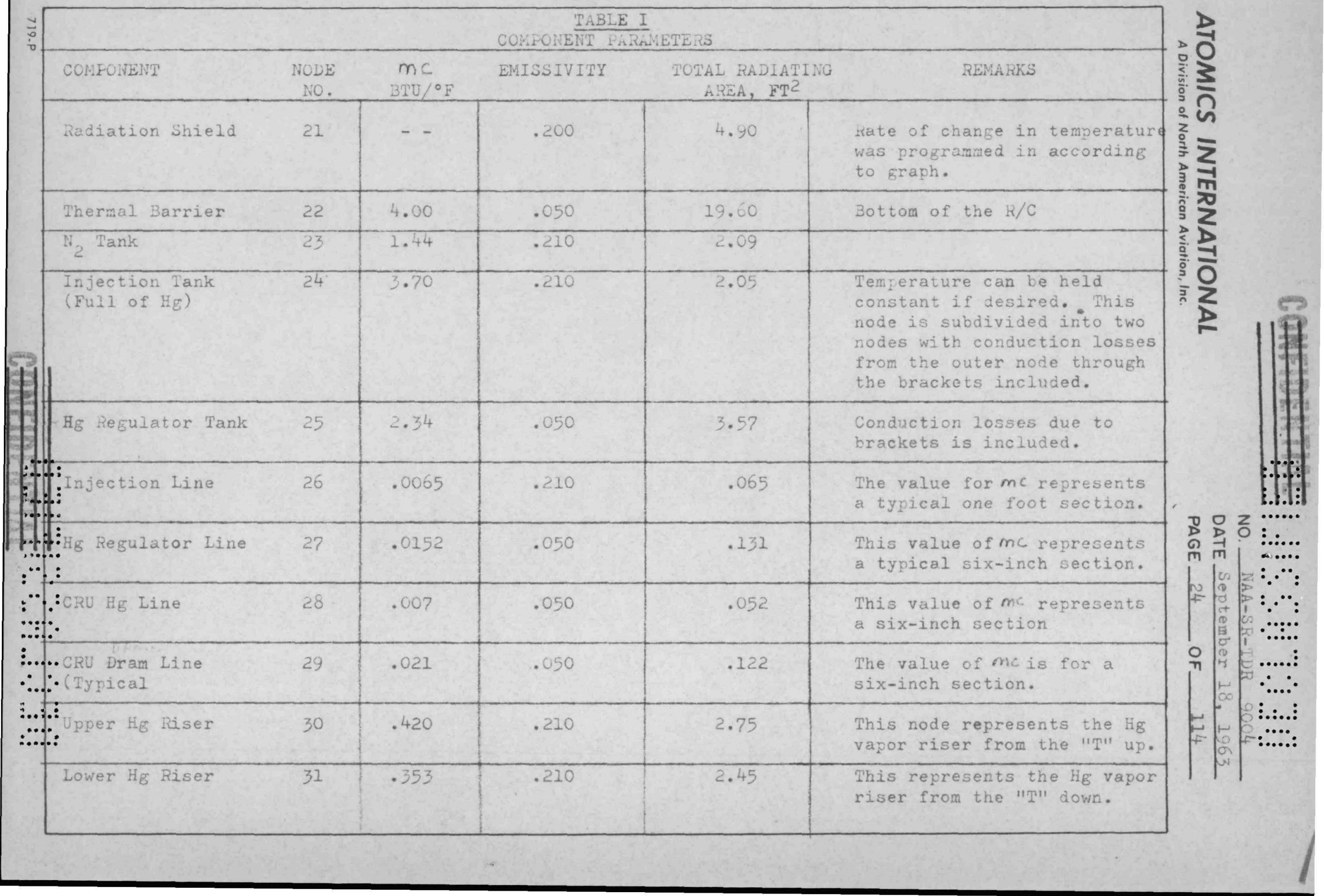




\section{ATOMICS INTERNATIONAL}

Because of the complexity of adequately determining the thermal conductance between nodes, the only source of heat transfer considered was by radiation. A detailed thermal analysis of the CRU is currently being made, thus, the results in this report should be considered only as a first order approximation. Nriting the equation of heat exchange for node 1 ,

$$
\left(m c_{1} \frac{d t_{1}}{d r}=\sigma A_{1} \sum_{j} F_{1}\left(t_{j}-t_{1}^{4}\right)+\sigma A_{1} F_{i-2}\left(t_{2}^{4}-t_{1}^{4}\right)\right.
$$

The first term on the right hand side of this equation is the same as equation (15) and represents the net interchange of heat between node 1 and all the other external nodes which are included in the analysis however, the product (), now pertains to the outer can of the CRU and not the entire component.

Since conduction between nodes was not considered with this model, the interchange of heat due to radiation between nodes was assumed to be a maximum be setting the view factors between nodes equal to one and neglecting reflection and reradiation.

$$
(m c)_{1} \frac{d^{t} t_{1}}{d T}=\sigma A_{1} \sum_{j} J_{1-j}\left(t_{j}^{4}-t_{1}^{4}\right)+\sigma\left(\varepsilon A_{1}\right),-\left(t_{2}^{4}-t_{1}^{4}\right)
$$

The equations of heat transfer nodes 2 and 3 may be written as

$$
\begin{aligned}
& \text { (mc) } 2 \frac{d t_{2}}{d t}=\sigma(\varepsilon A)_{1-2}\left[t_{1}^{4}-t_{2}^{4}\right]+\sigma(\varepsilon A)_{2-3}\left[t_{3}^{4}-t_{2}^{4}\right] \\
& \text { (mc) } \frac{d t_{3}}{d t}=\sigma\left(\varepsilon A_{t}\right)_{2-3}\left(t_{2}^{4}-t_{3}^{4}\right)
\end{aligned}
$$

Table II lists the values of the parameter used in the solution of these equations.

Injection Tank From the results of this study, it may be required that the injection tank(s) be continuously heated from the time of launch until mercury injection. Therefore, this progr:m was given added flexibility for future studies by building a more detailed two node model of the injection tank as shown by Figure 6. 


\section{ATOMICS INTERNATIONAL}

A Division of North American Aviation, Inc.
NO.

DATE Sentember 18, 1963

PAGE OF 114

Node 1 (storage tank) was given the capability of heing maintained at a constant temperature if so desired.

(o) outer shell (Node 0)

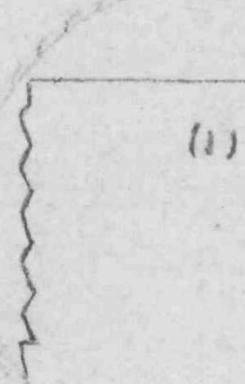
storage tank (Node (bellows and $\mathrm{Hg}$ )

\section{FIGURE 6}

By making the same assumptions as were made for the model of the CRU, the equations of heat transfer may be written as:

$$
\begin{aligned}
& (m c)_{0} \frac{d t_{0}}{d \gamma^{2}}=\sigma A_{0} \sum F_{0 j}\left(t_{2}^{4}-t_{4}^{4}\right)+\sigma(\varepsilon A)_{0-i}\left(t_{1}^{4}-t_{0}^{4}\right)(21) \\
& \text { (mc) } \frac{d t_{1}}{d t}=\sigma\left(E A_{0.4}\left(t_{0}^{4}-t_{1}^{4}\right)\right.
\end{aligned}
$$
the solution of these equations. 
ATOMICS INTERNATIONAL

A Division of North American Aviation, Inc.

NO

DATE $\frac{\text { September } 18,1963}{28 \quad \text { OF } 114}$

TABLE II

CRU PARAMETERS USED FOR THREE NODE MODEL

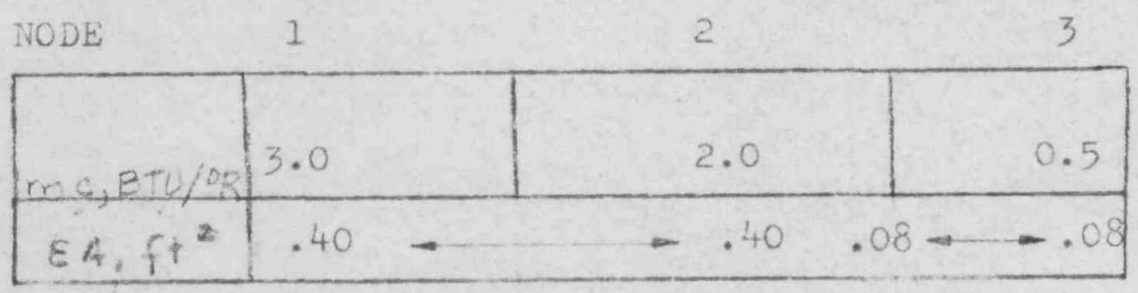

TABLE III

INJECTION TANK TWO NODE MODEL

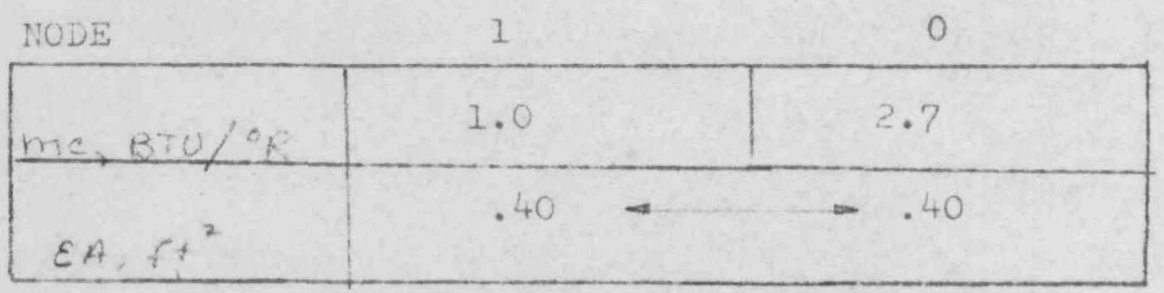

2. Conduction Through the Supporting Brackets

Injection Tank, CRU, and Mercury Regulator Tank Another purpose of this program was to determine the feasibility of eliminating all external heat sources on the components prior to mercury injection. A more stringent model was made of three components to better analyze potential poreheating requirements by including the conduction losses to the $\mathrm{R} / \mathrm{C}$ through the supporting component brackets.

These losses were determined by combining the eight supporting brackets on each component into an equivalent bracket as shown in Figure?.

719.P 


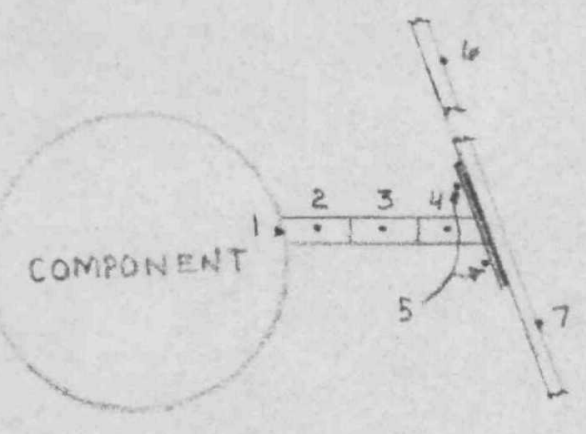

\section{FIGURE?}

Point 1 represents the point of contact between the component and the equivalent bracket. Nodes 2,3 , and 4 were obtained by dividing the bracket into three equal nodes. Node 5 is the total surface area of the brackets which is attached to the supporting ring. The area of the conduction path through the honeycomb to the $\mathrm{R} / \mathrm{C}$ copper fins vas assumed to be the same as the crosssectional area of node 5 . This is probably conservative, however, based on this assumption, this resistance represents only a small percentage of the total resistance from the component to the $\mathrm{R} / \mathrm{C}$ nodes. After passing through the honeycomb, the conduction path divides with part of the heat flow going to the center of the upper $\mathrm{R} / \mathrm{C}$ node $i$ and the remainder to the center of the corresponding subcooler mode $i+10$. The time rate of change in temperature of the component is expressed as:

$$
(m c)_{1} \frac{d t_{1}}{d i}=E_{q} \cdot 15+\left(\frac{K A}{\Delta x}\right)_{1-2}\left[t_{2}-t_{1}\right]
$$

where $\left(\frac{K A}{\Delta K}\right)_{-2}$ is the thermal conductance between nodes 1 and 2 in Figure 6 . The time rate of change for node 2 is

$$
\left(m c_{2} \frac{d t_{2}}{d t}=\frac{\varepsilon_{2} A_{2} \sigma\left(t_{R c}-t_{2}{ }^{4}\right)+(k A}{\left(\frac{K A}{\Delta x}\right)_{2-3}\left(t_{1}-t_{2}\right)}\left(t_{1}-t_{2}\right)+\right.
$$

The first term on the right hand side of this equation represents the interchange of heat between this node and the mean radiating temperature of the $\mathrm{R} / \mathrm{C}$. The determination of this temperature is given in the appendix. 


\section{ATOMICS INTERNATIONAL}

Similarly, the equations of heat transfer for the remaining nodes are written as:

$$
\begin{aligned}
& \left(m c_{3} \frac{d t_{3}}{d \gamma}=\varepsilon_{3} A_{3} r\left(t_{R^{2}}-t_{3}^{4}\right)+\left(\frac{K A}{\partial x}\right)_{2-3}\left(t_{2}-2 t_{3}+t_{4}\right)_{(25)}\right. \\
& \left(m c_{4} \frac{d t_{1}}{=}=\varepsilon_{4} A_{4} \sigma\left(E_{R_{C}}^{-4}-t_{4}^{4}\right)+\left(\frac{K_{A}}{\Delta x}\right)_{2-3}\left(E_{3}^{-} E_{4}\right)\right. \\
& +\left(\frac{R A}{\Delta x}\right)_{4-5}\left(t_{5}-t_{4}\right) \\
& \text { (mc) } 5 \frac{d t_{5}}{d 7}=\varepsilon_{5} A_{5} \sigma\left(t_{2 c}^{-4}-t_{5}^{4}\right)+\left(\frac{K A}{\Delta x}\right)_{5-6}\left(t_{i}-t_{5}\right) \\
& \left.+\frac{K A}{\Delta x}\right)_{5-1}\left(t_{7}-t_{5}\right)+\left(\frac{K A}{A X}\right)_{4-5}\left(t_{4}-t_{5}\right) \\
& \text { mc } \left.)_{6} \frac{d t}{d \gamma}=E q 13+\frac{K A}{\Delta x}\right)_{5-6}\left( \pm s-t_{6}\right) \\
& \text { (inc) } \frac{d t_{7}}{d 7}=E_{9} \cdot 1+t+\left(\frac{\mu_{A}}{\Delta x / 5-7}\right)\left(t_{5}-t_{7}\right)
\end{aligned}
$$

Nodes 6 and 7 correspond to the upper $R / C$ node $i$ and subcooler node $i+10$ respectively.

Table IV lists the values of the heat transfer properties of the brackets which were used in the solution of these equations.

\section{Constant or Programmed Temperature Changes}

WaK Cormonents Dhe to the circulation of heated NaK through the primary system, the NaK components remain at a nearly constant temperature until the initiation of startup. At startup, the primary system and corresponding components heat up in a manner which was determined by Reference 3 .

Nuclear Radiation Shield the shield (node) has a large mass which gives this node a slow response to temperature changes. At startup, this components's 


\section{ATOMICS INTERNATIONAL}

A Division of North American Aviation, Inc.
NO

DATE September 18,1963

PAGE 31 OF

time rate of change is dictated by gamma heating and radiation from the reactor. This rate of change was determined by reference 4 and these results were simulated in the program as shown by Graph 40. Frior to startup, this component was held constant at $25^{\circ} \mathrm{F}$

TABIE IV

PARAMETERS USED IN DETERMINATION OF

HEAT LOSSES IHROUGH BRACKETS

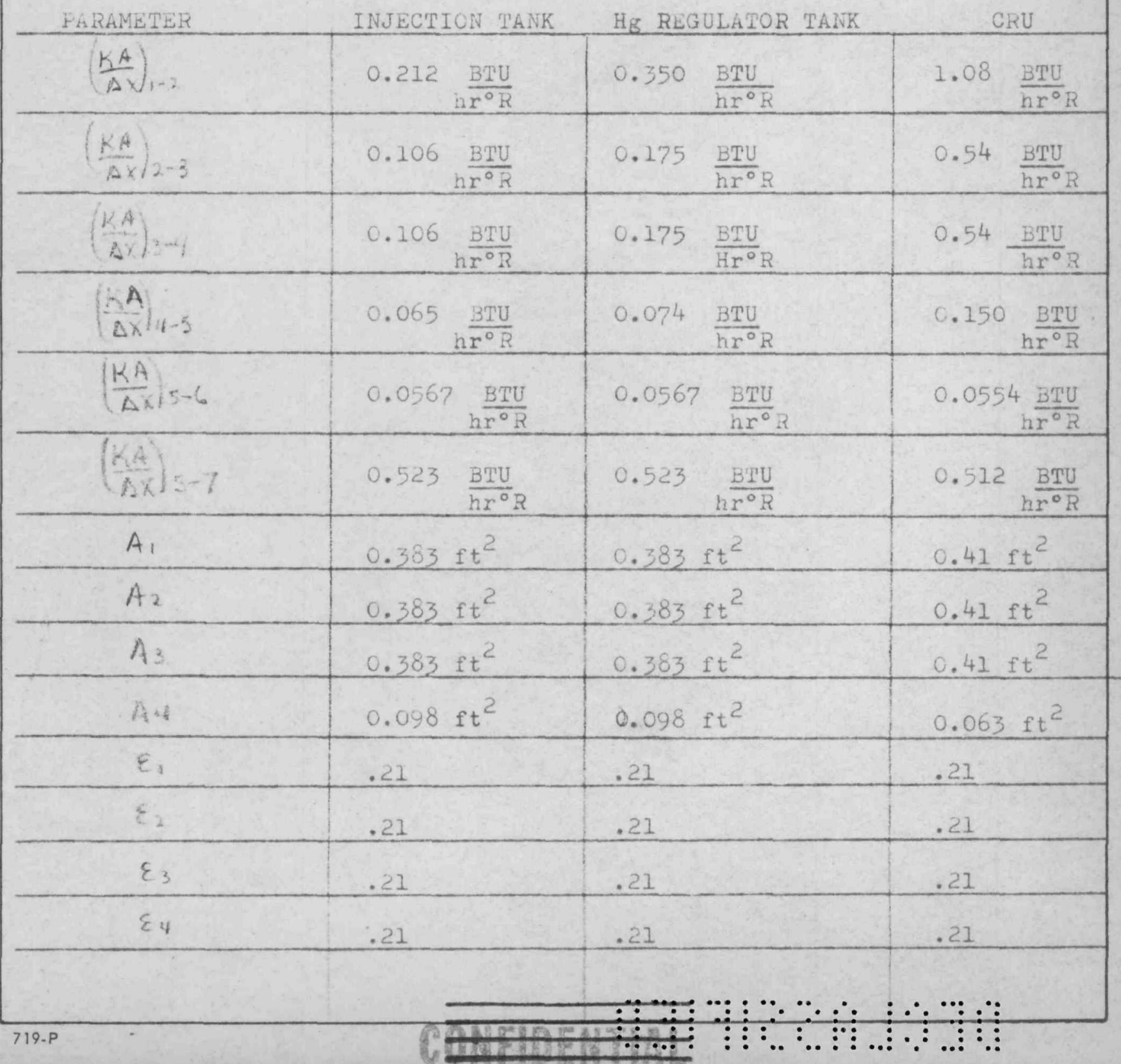




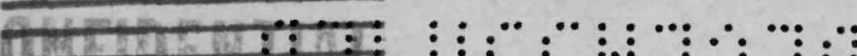

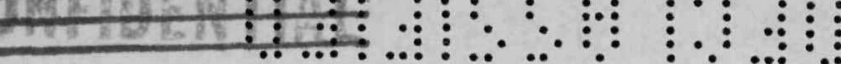

NO. NAA-SR-TDR 9004

ATOMICS INTERNATIONAL

DATE Septémber 18, 1963

A Division of North American Aviation, Inc.

PAGE 32

OF

124

\begin{tabular}{|c|c|c|c|}
\hline PARAMETER & INJECTION TANK & Hg REGULATOR TANK & CRU \\
\hline$(m c)_{1}$ & .021 & .064 & .084 \\
\hline$(m c)_{2}$ & .021 & .064 & .084 \\
\hline$(m c)_{3}$ & .021 & .064 & .084 \\
\hline$(m c)_{4}$ & .0136 & .0136 & .016 \\
\hline
\end{tabular}




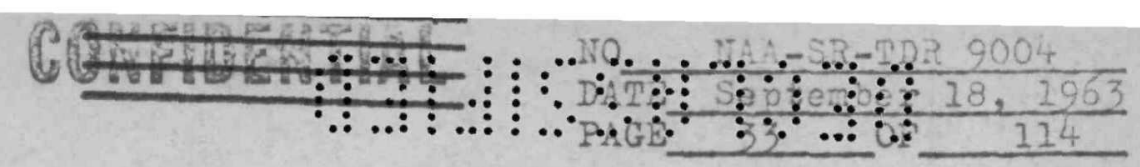

CASE I TRANSIENT ORBIT

PRE-START UP MEAN TEMPERATURE VERSUS REVOLUTION

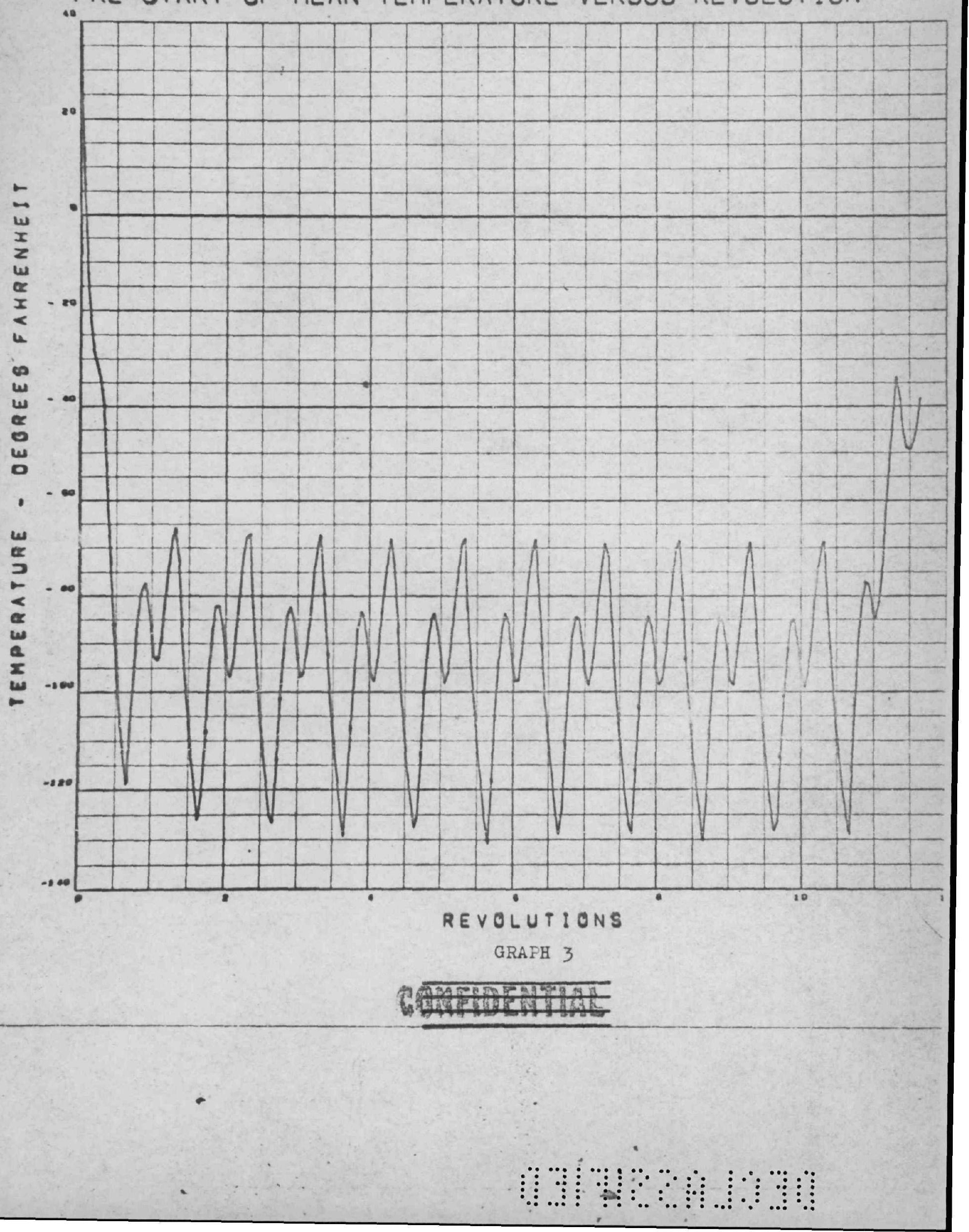




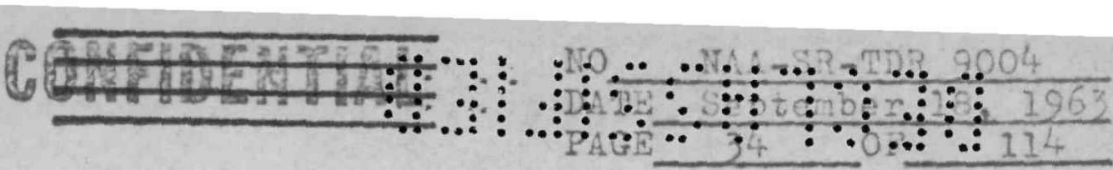

CASE TRANSIENT ORBIT
TEMPERATURE DISTRIBUTION OF R/C NODES

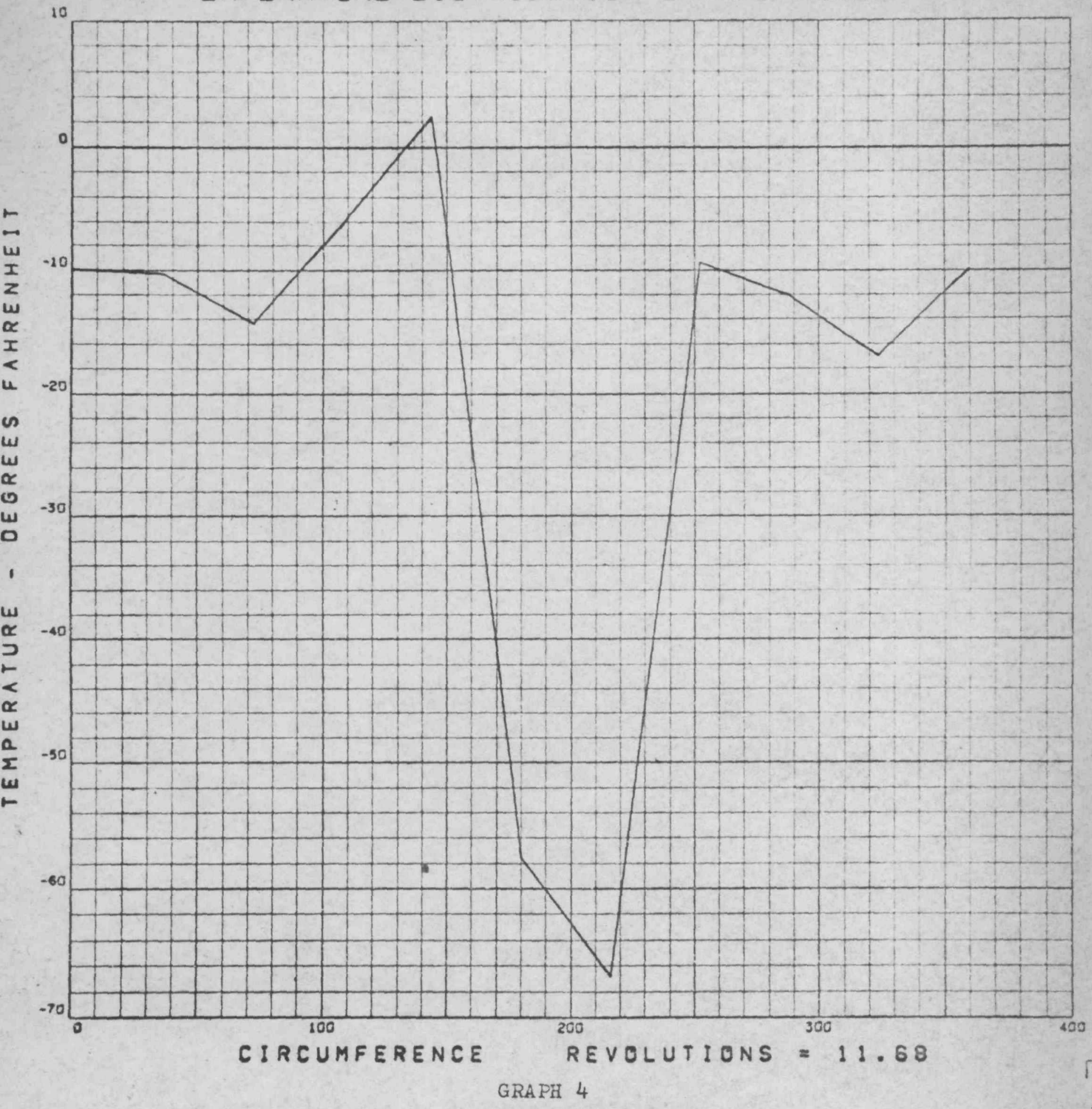

C 


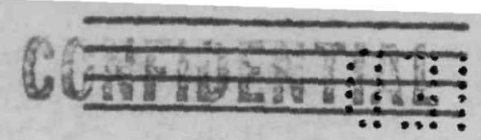

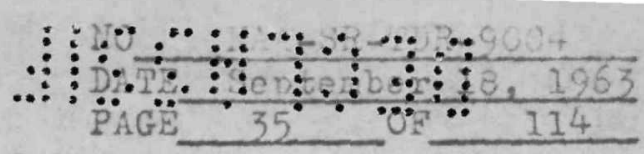

$\checkmark$ TPANSIENT ORBIT

TEMPERATURE DISTRIBUTION OF SUB-COOLER NODES

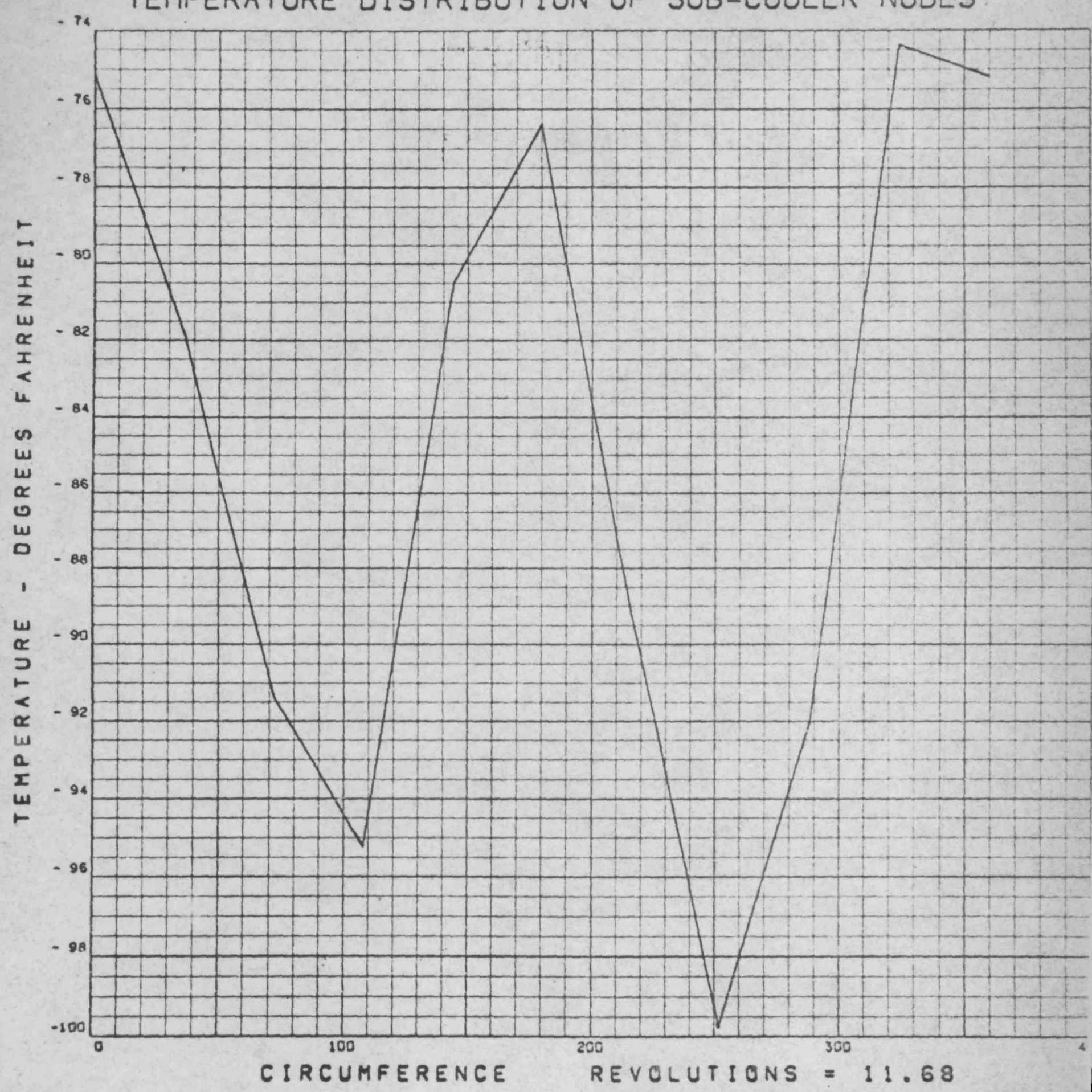

GRAPH 5

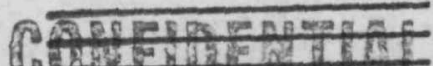

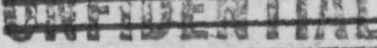




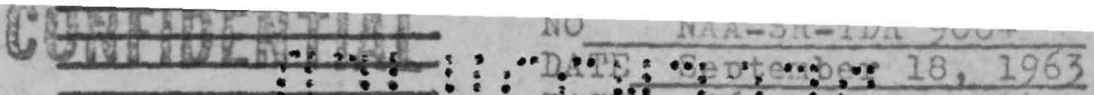

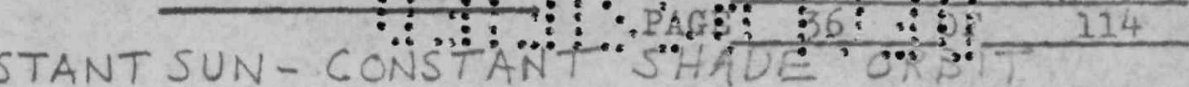
PRE-START UP MEAN TEMPERATURE VERSUS REVOLUTION.
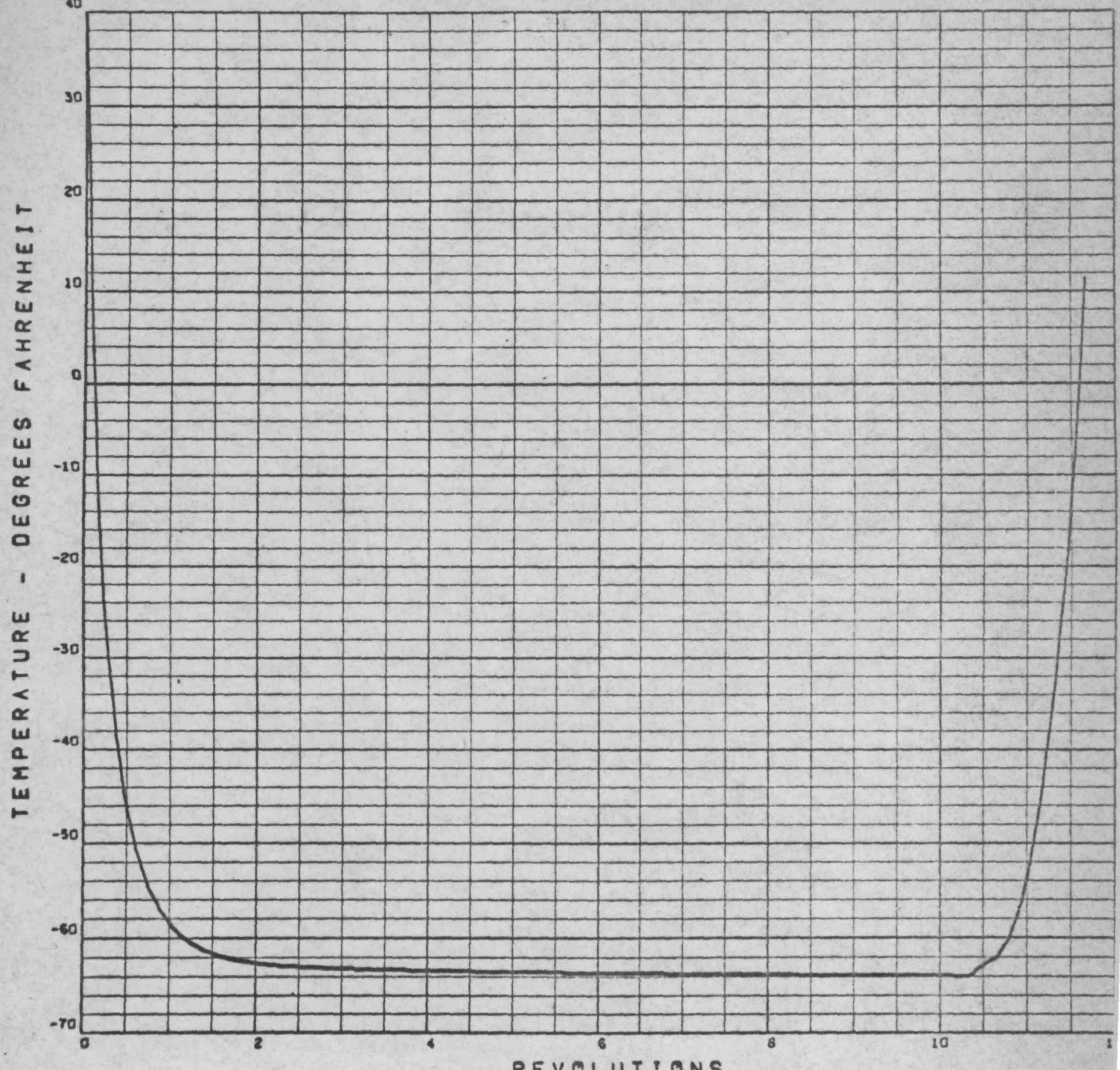
REVOLUTIONS

GRAPH 6 


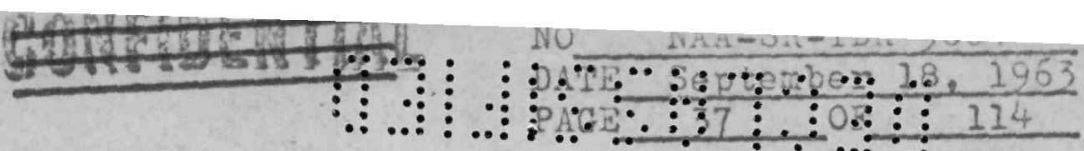
TEMPERATURE DISTRIBUTION OF R/C NODES

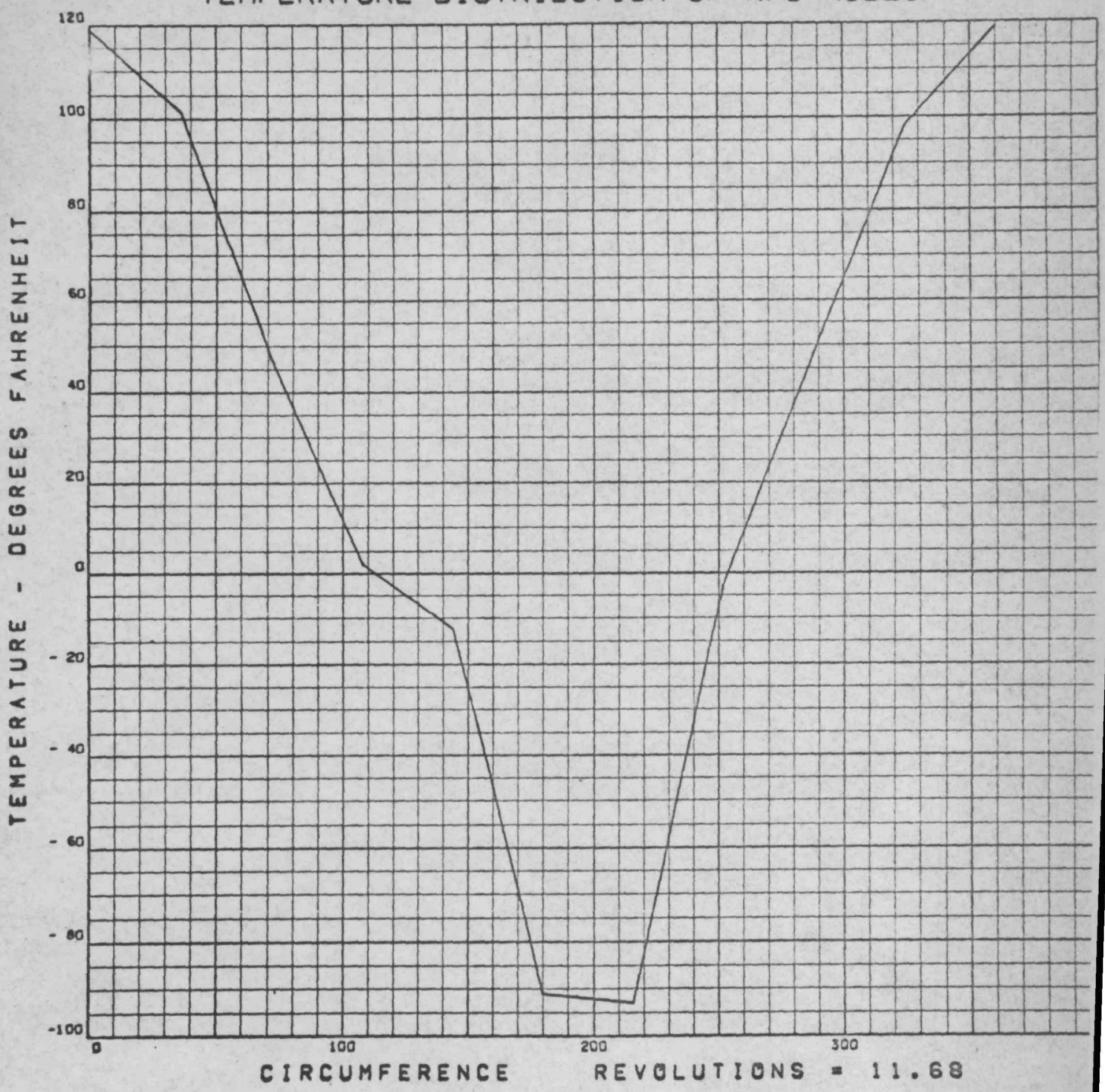



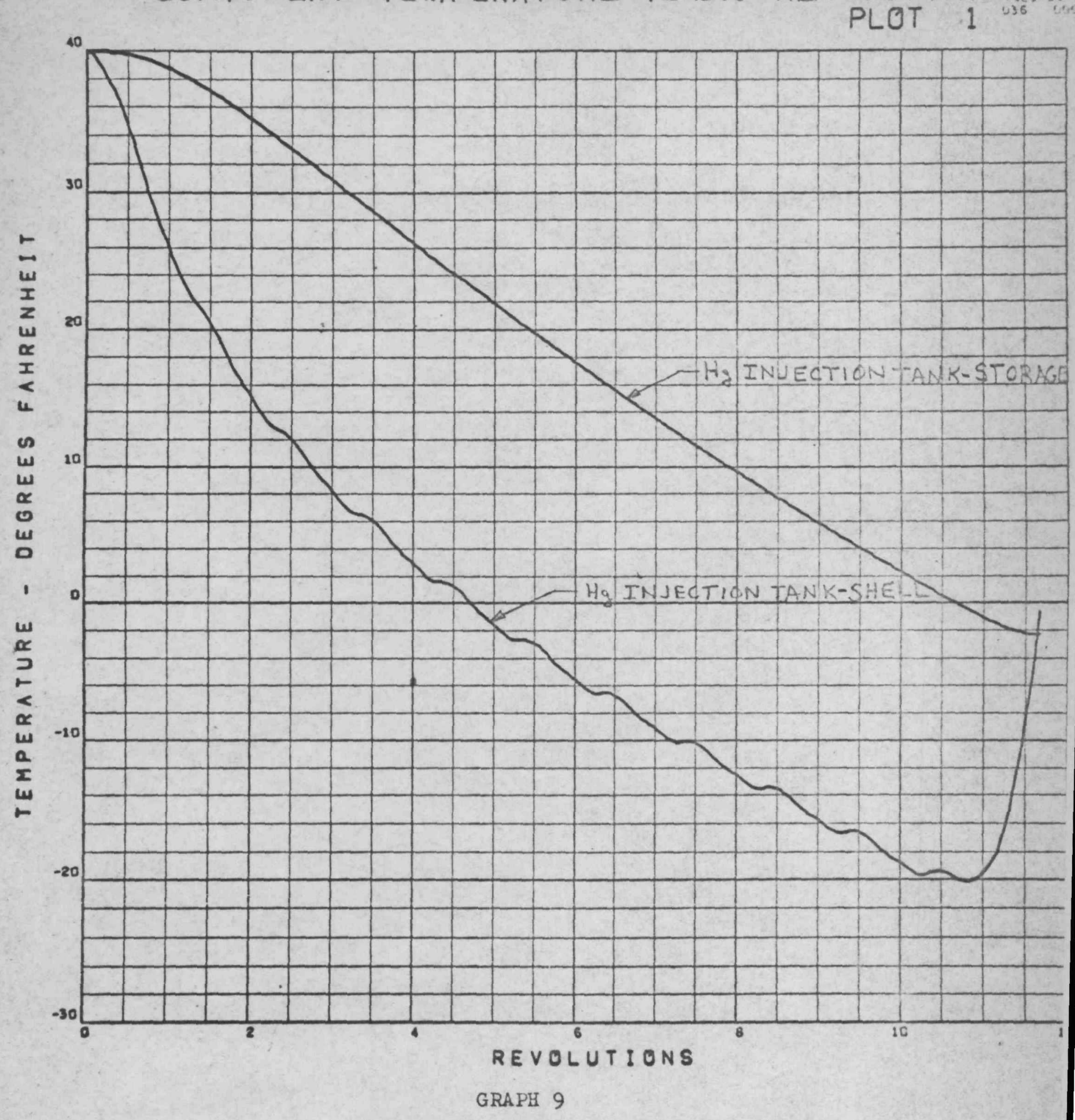
CASE I TRANSIENT ORBIT

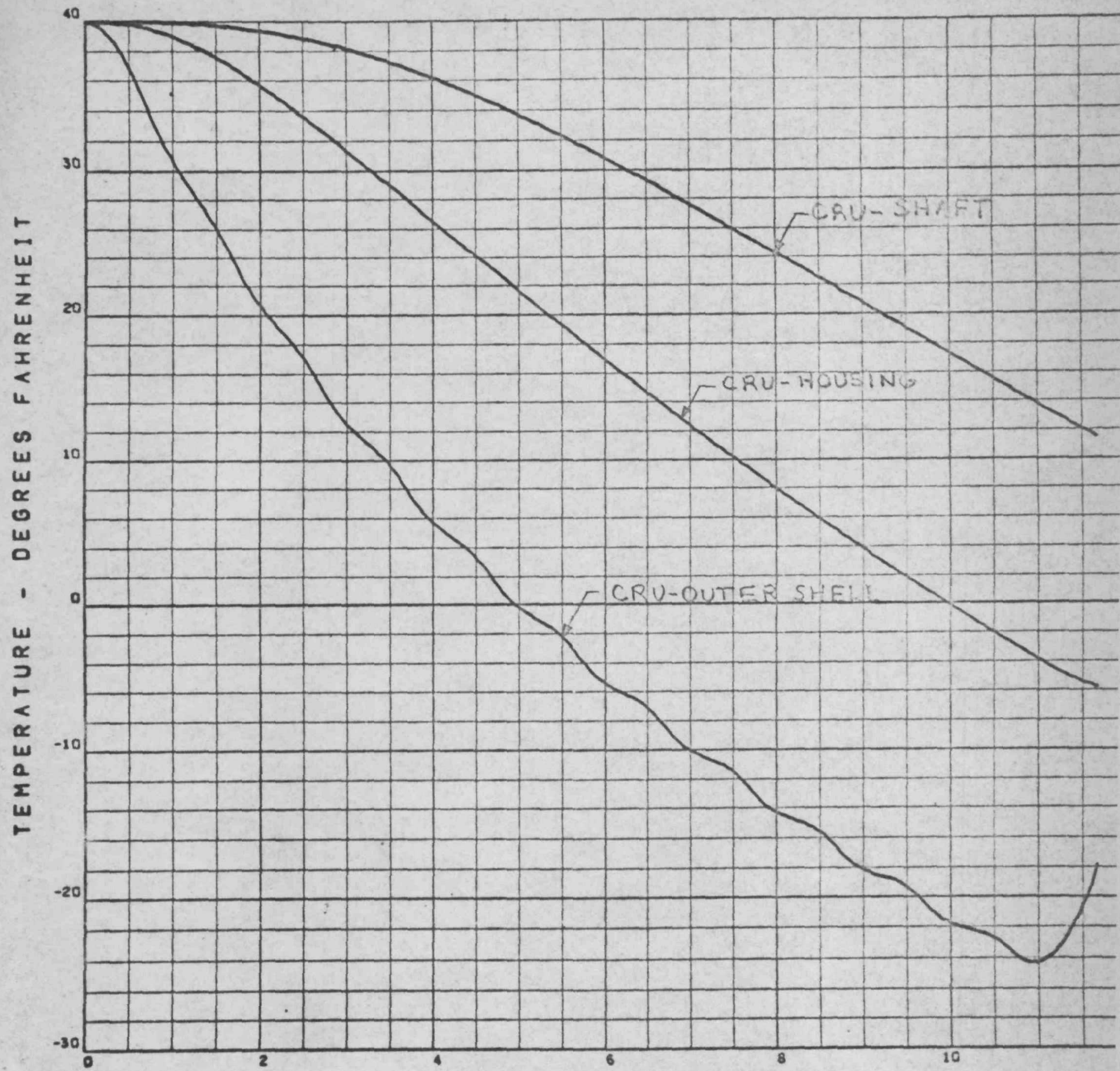

GRAPH 10

C) 


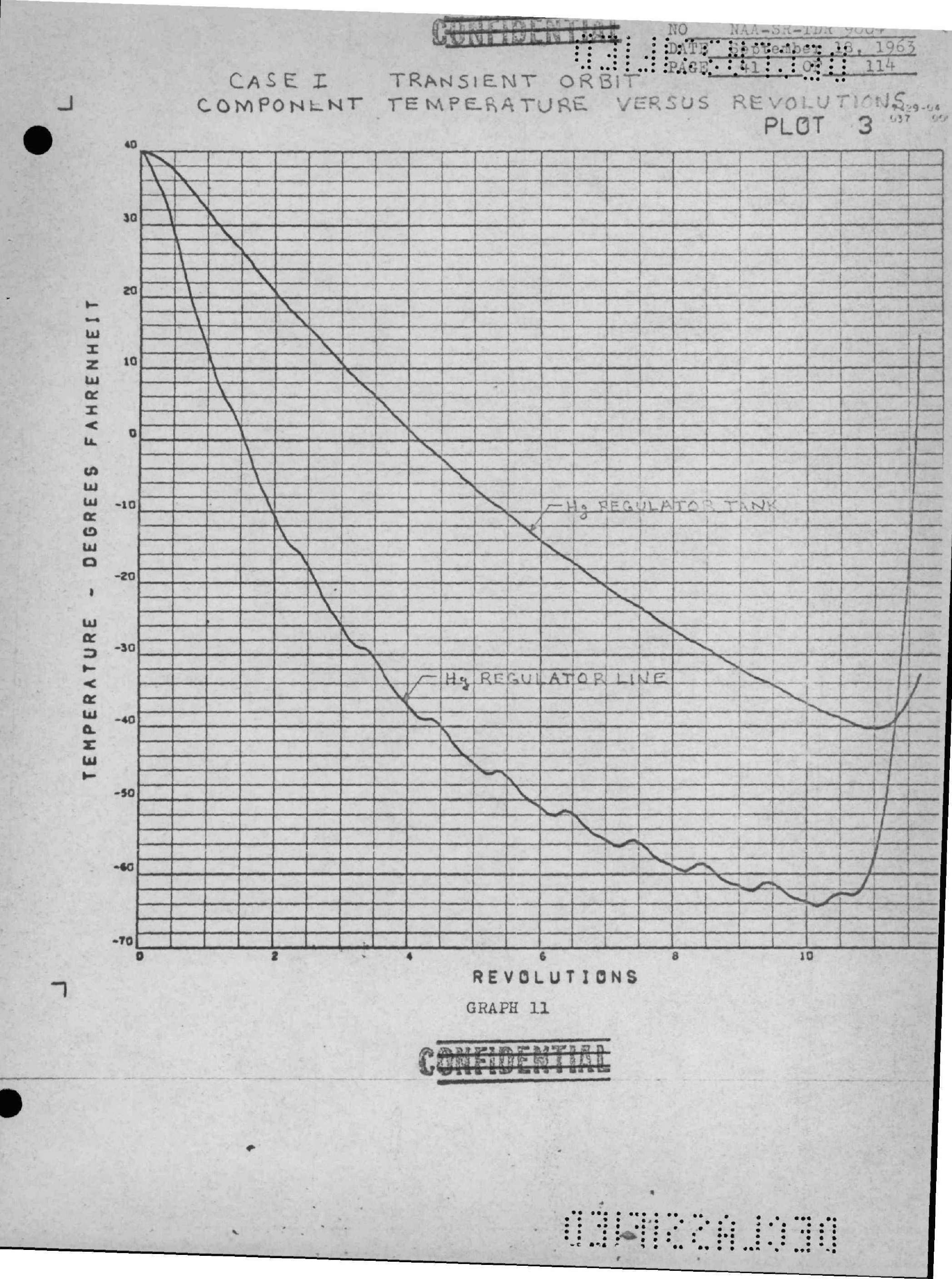




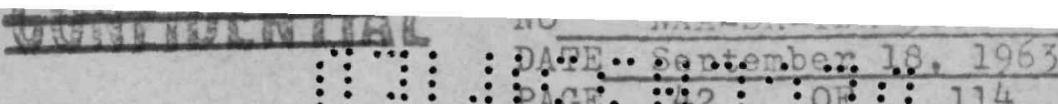

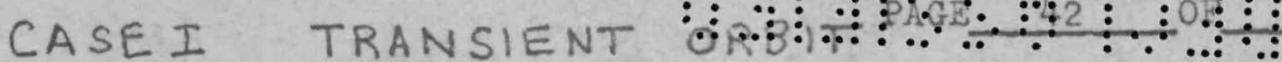

180
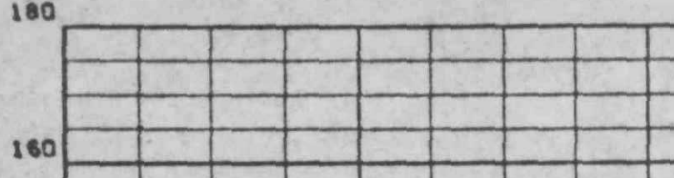

140

$\mapsto$

w 120

I

w

$\underset{\alpha}{a}$

$\stackrel{x}{x}$

$<$

4

$\infty$

$w$

100

80

60

w

1

w

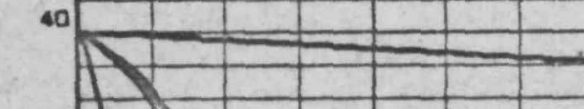

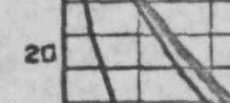

$\stackrel{5}{2}$

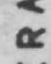

a.

$\sum$

w

$-20-$ CBEARING WINE (EXPOSED TO NAKLOOP

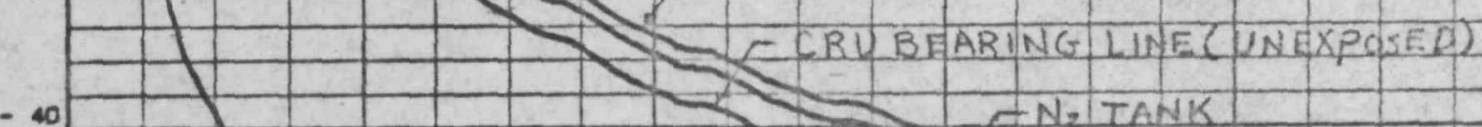

-400 - $10 \mathrm{~N}_{2}$ TANK

$-$
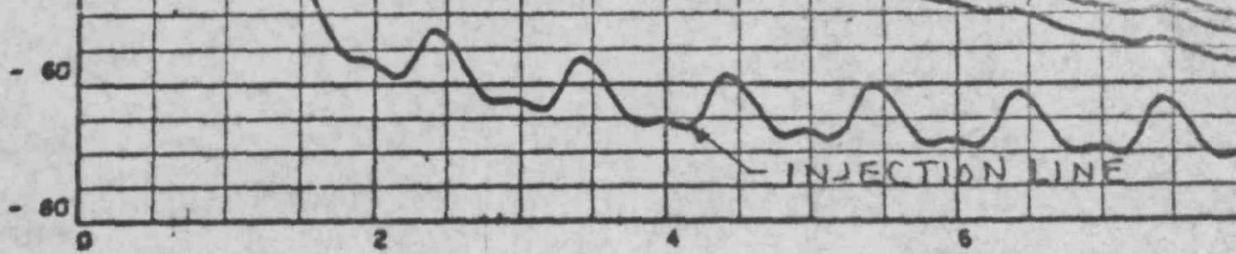

INJECTION WINE

REVOLUTIONS

7

GRA PR 12

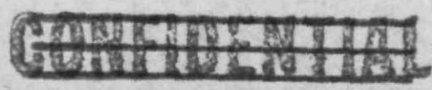


CASE I TRANSIENT ORB OT

$\downarrow$ COMPONENT TEMPERATURE VERSUS REVALWTHONS-S PLOT 5

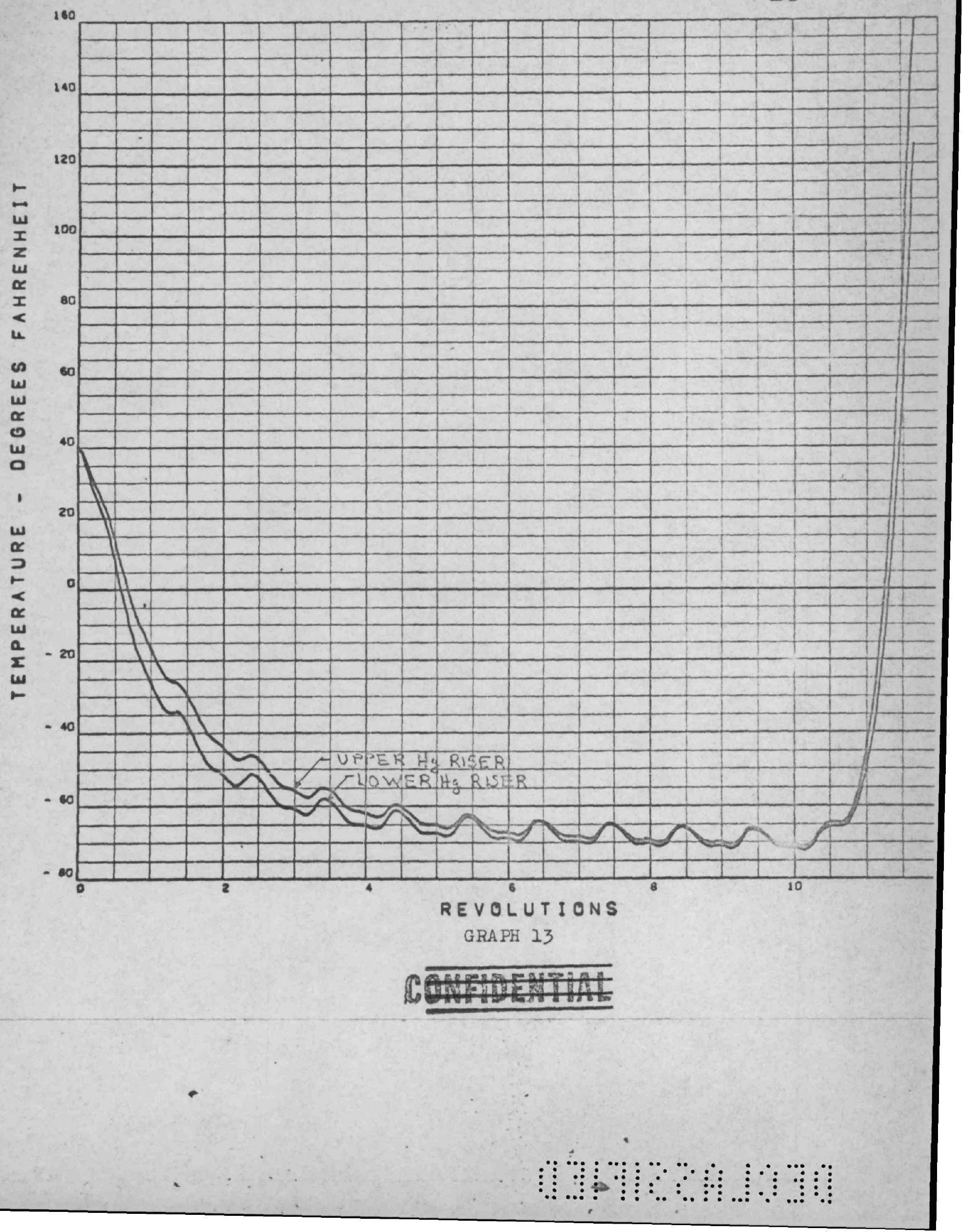




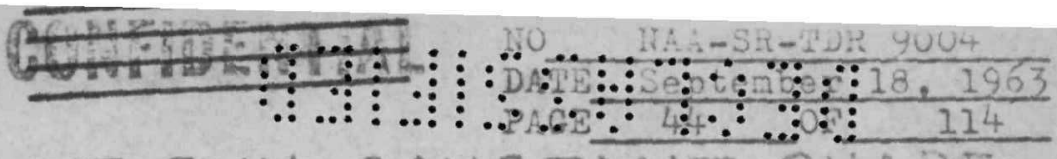

CASE 2 CONSTANT SUN-CONSTANTS SHADE TEMPERATURE DISTRIBUTION OF R/C NODES
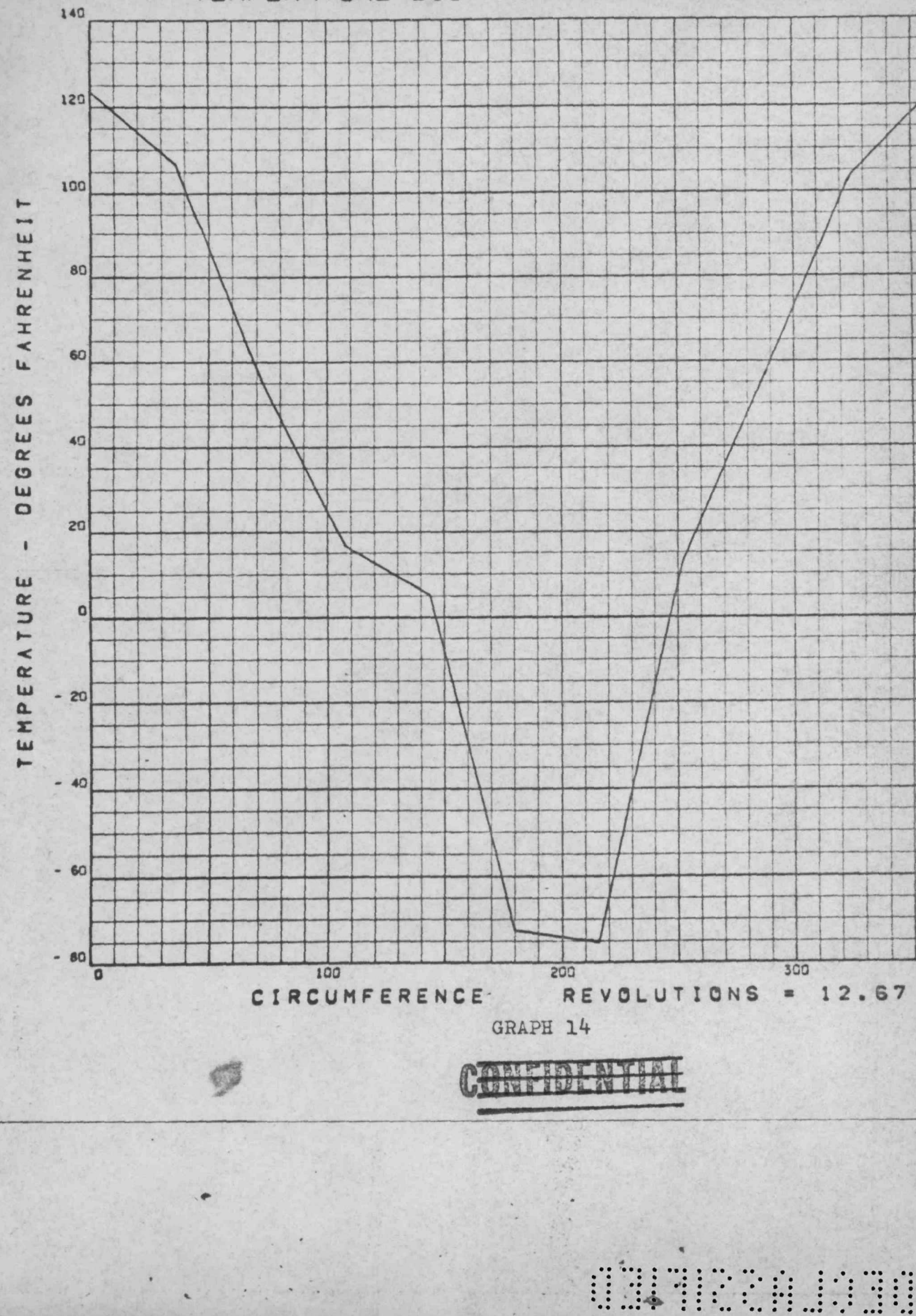


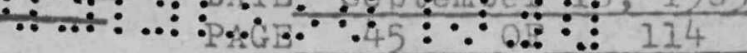

CASE $=$ CONSTANT SUN-CONSTANT SHAUE TEMPERATURE DISTRIBUTION OF SUB-COOLER NODES

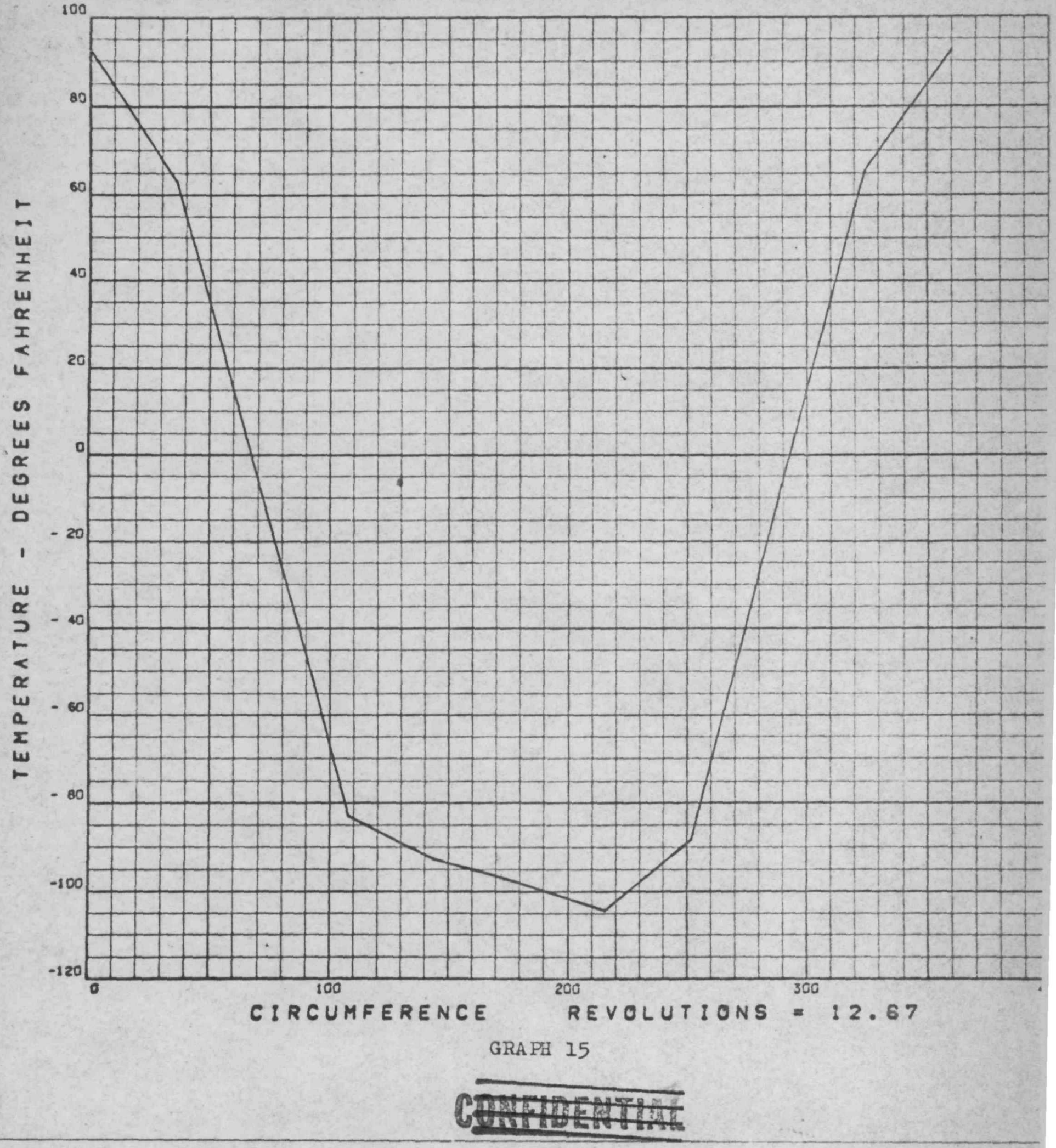




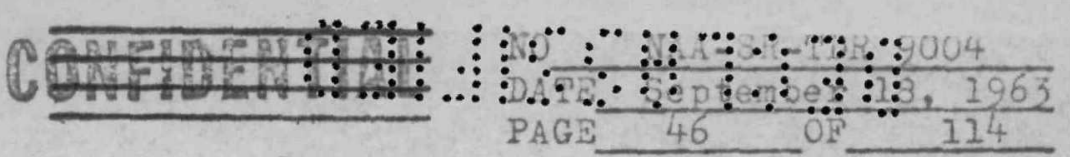

CASE 3 SUN SHADE TRANSIE TI

PRE-START UP MEAN TEMPERATURE VERSUS REVOLUTION

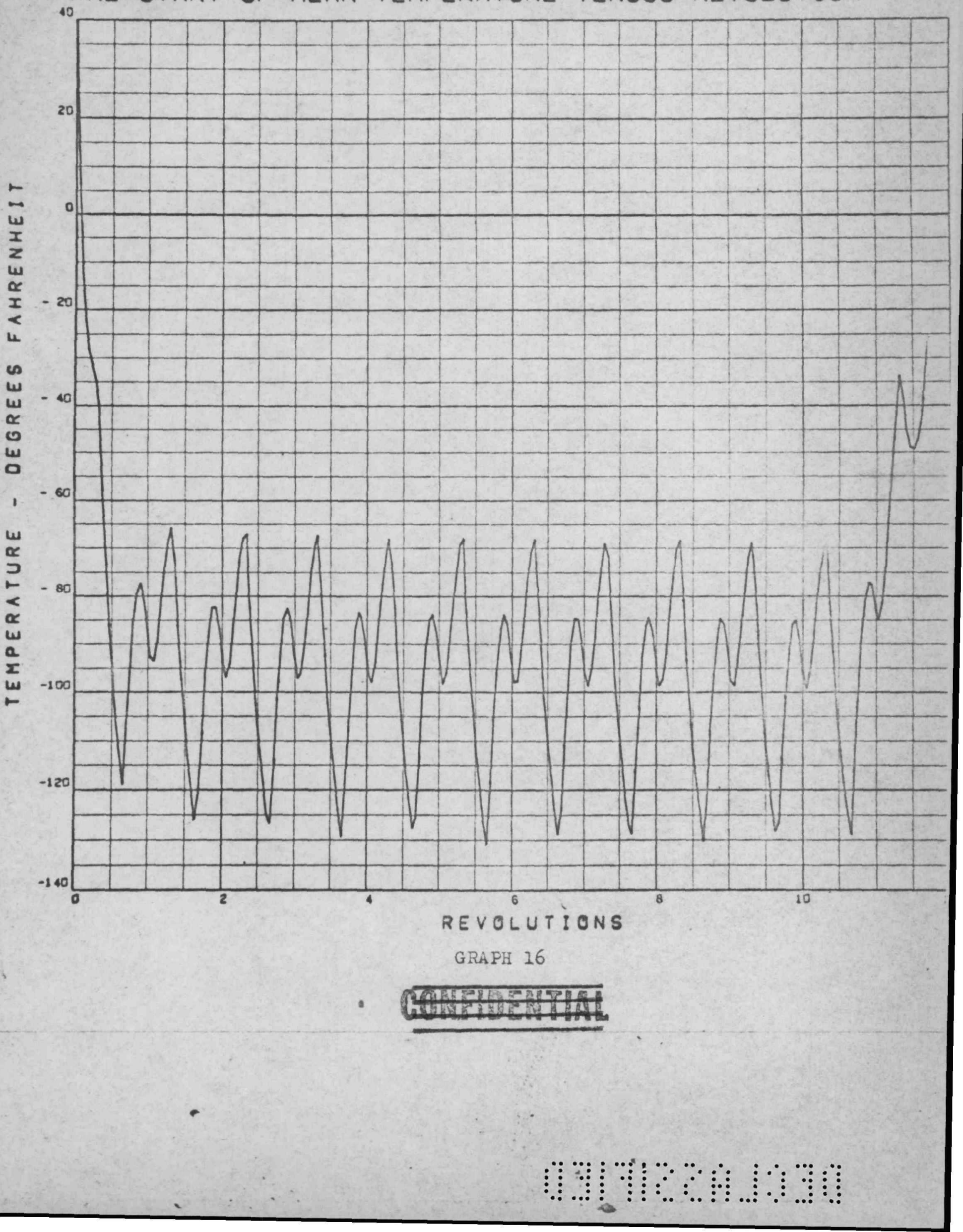


120

\section{TEMPERATURE DISTRIBUTION OF R/C NODES}

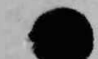
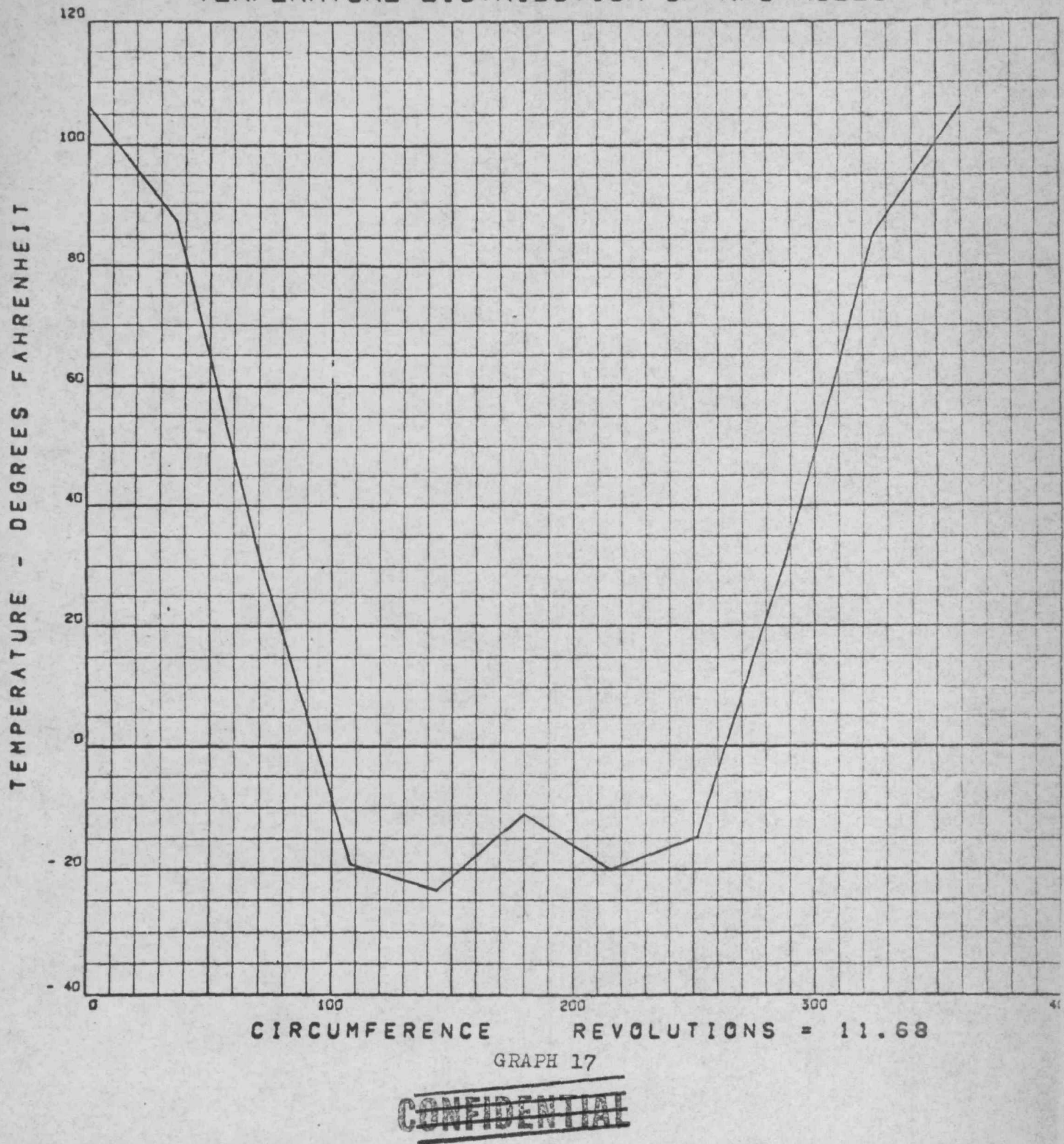


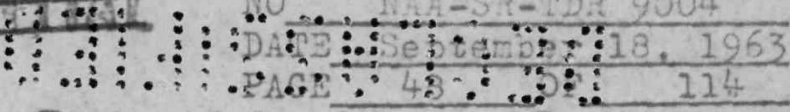
120

TEMPERATURE DISTRIBUTION OF SUB-COOLER NODES

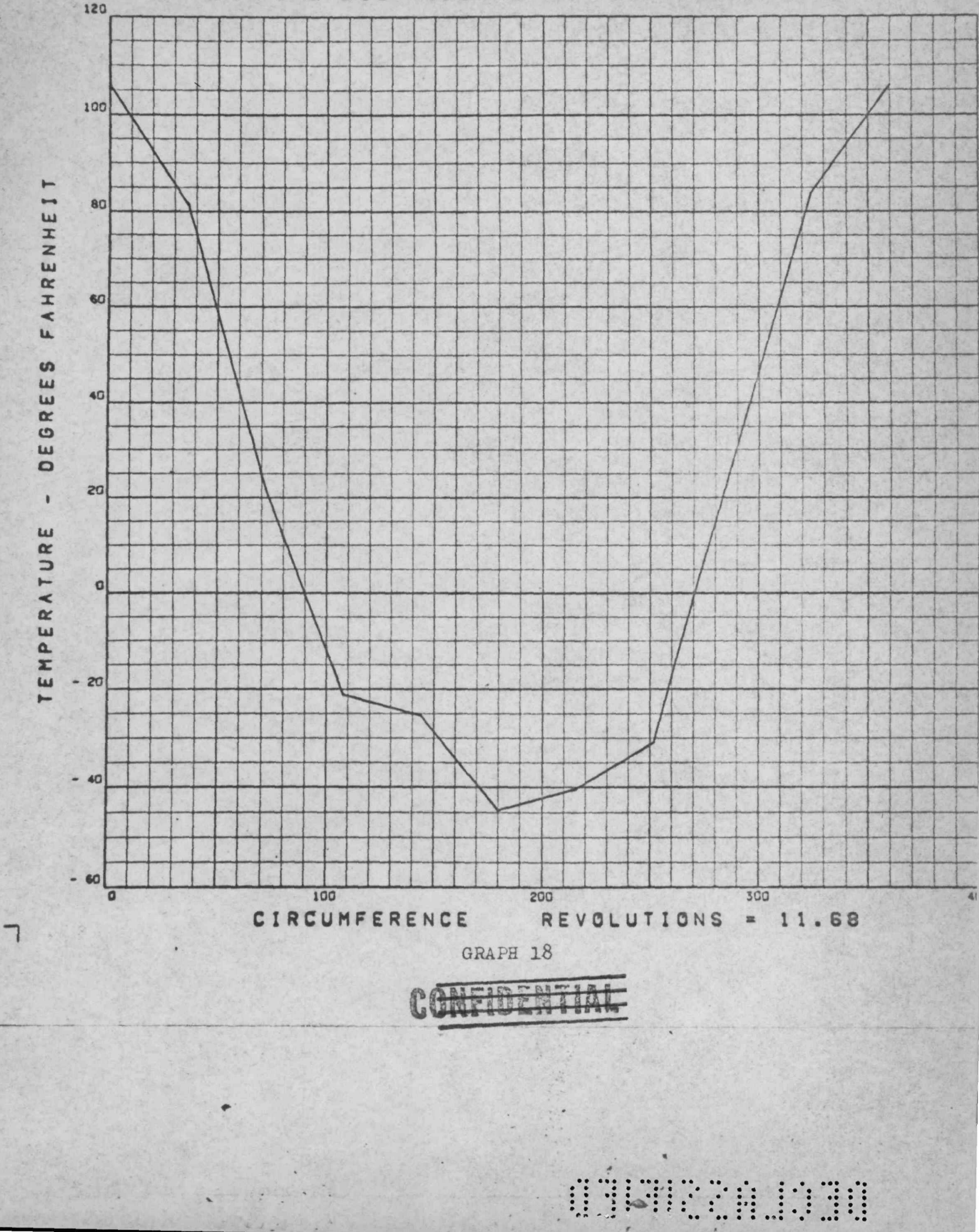




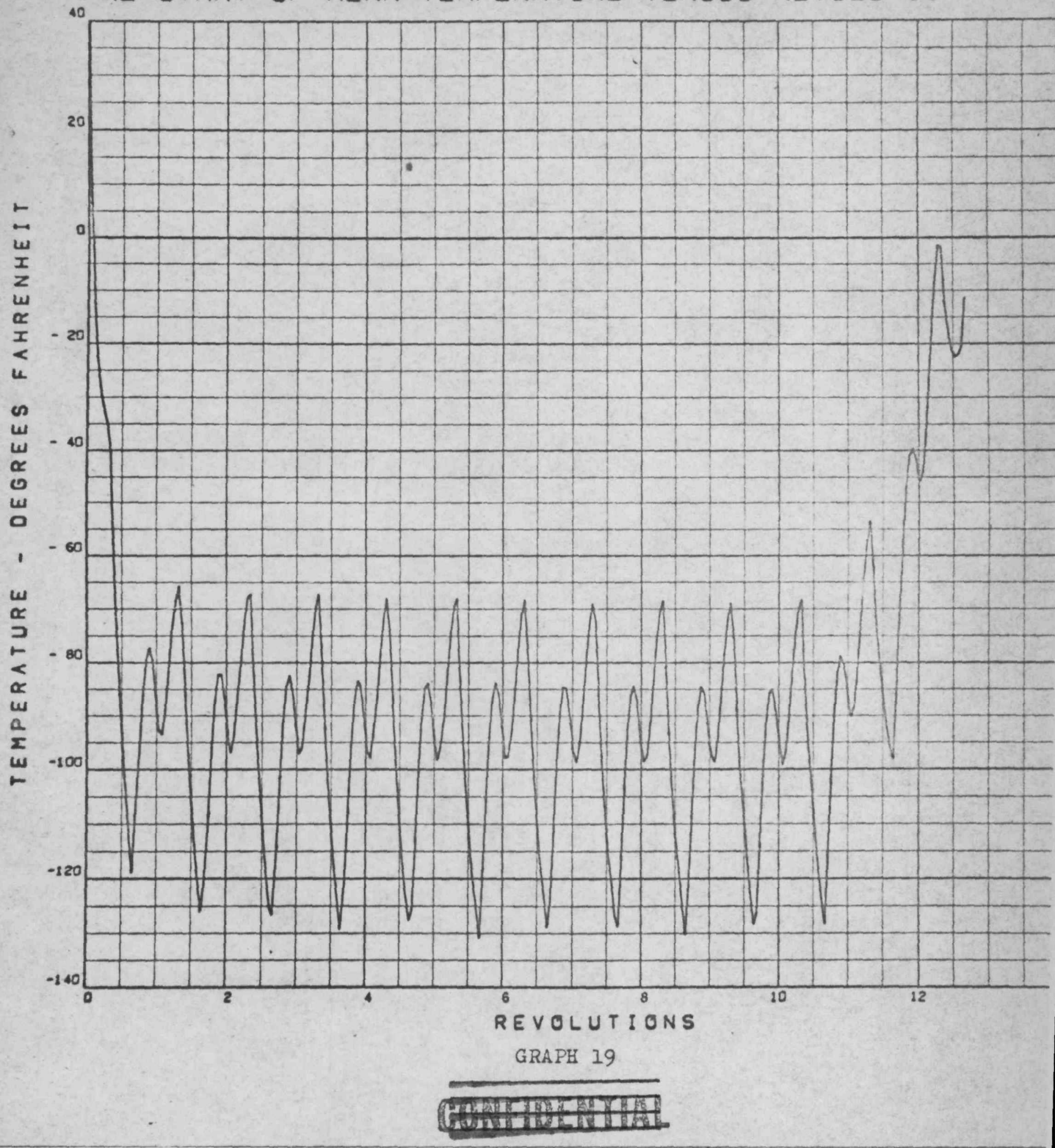



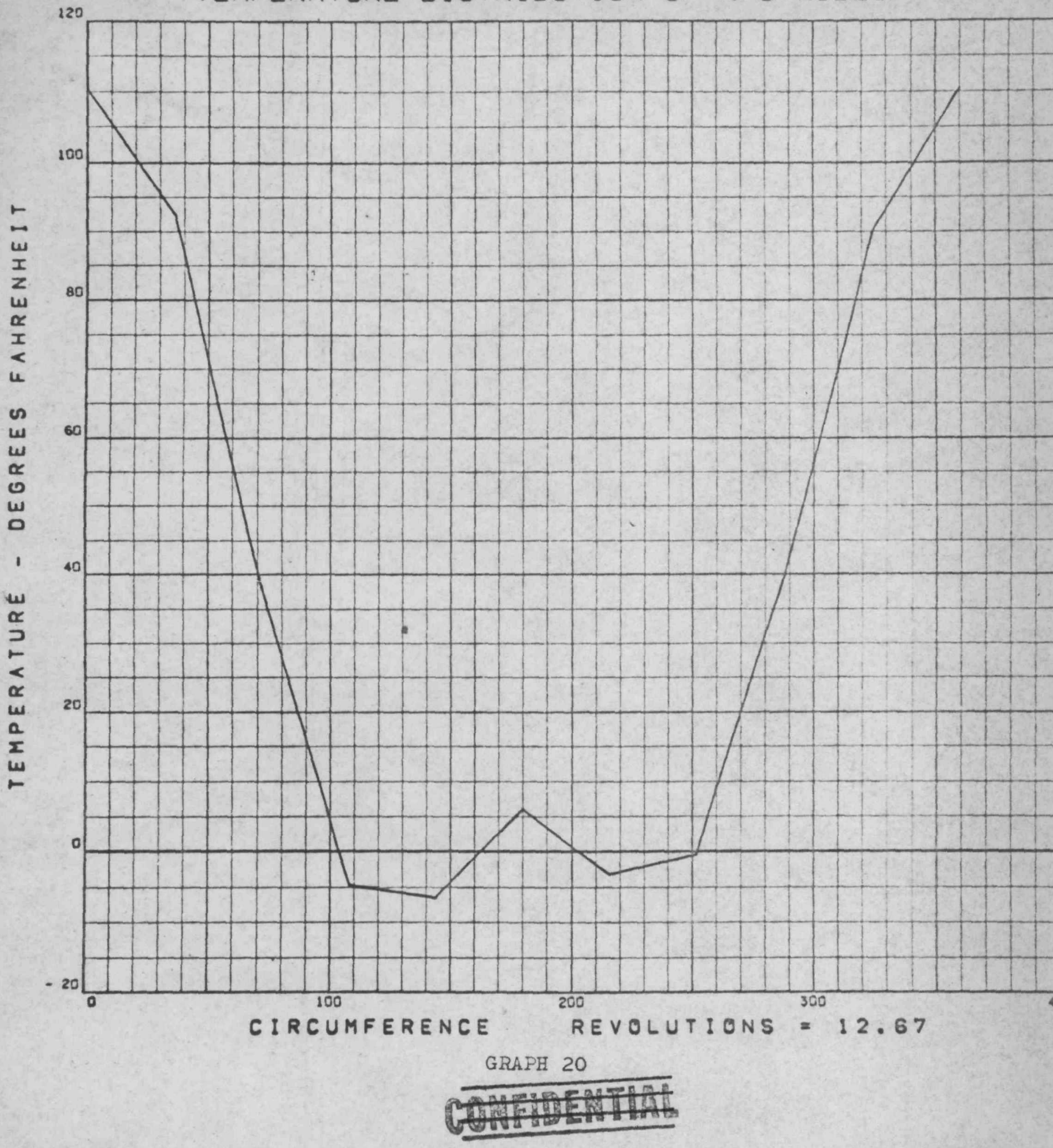
TEMPERATURE DISTRIBUTION OF SUB-COOLER NODES

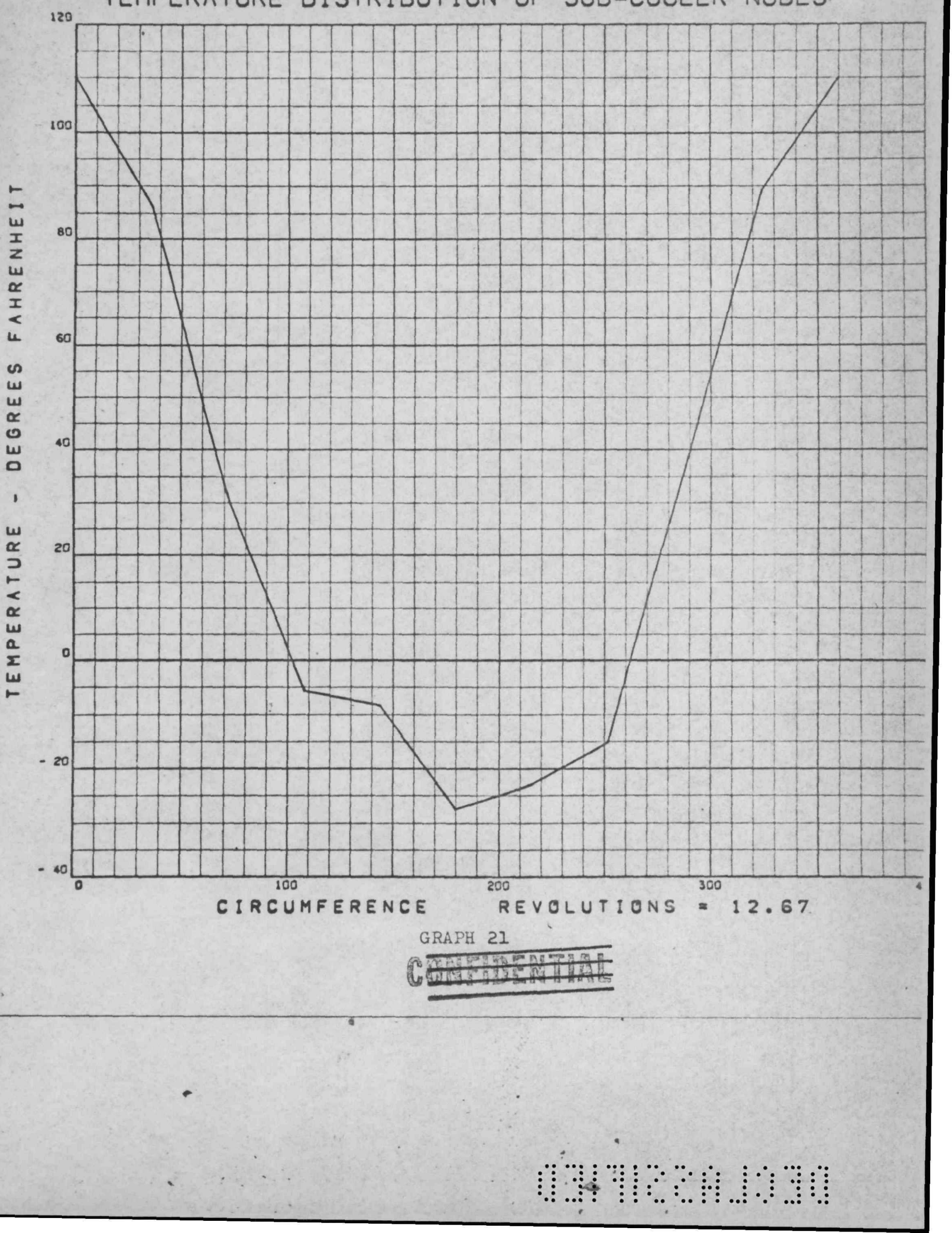




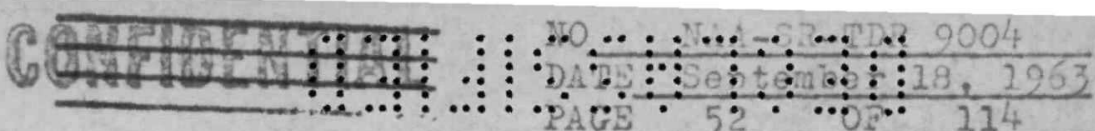
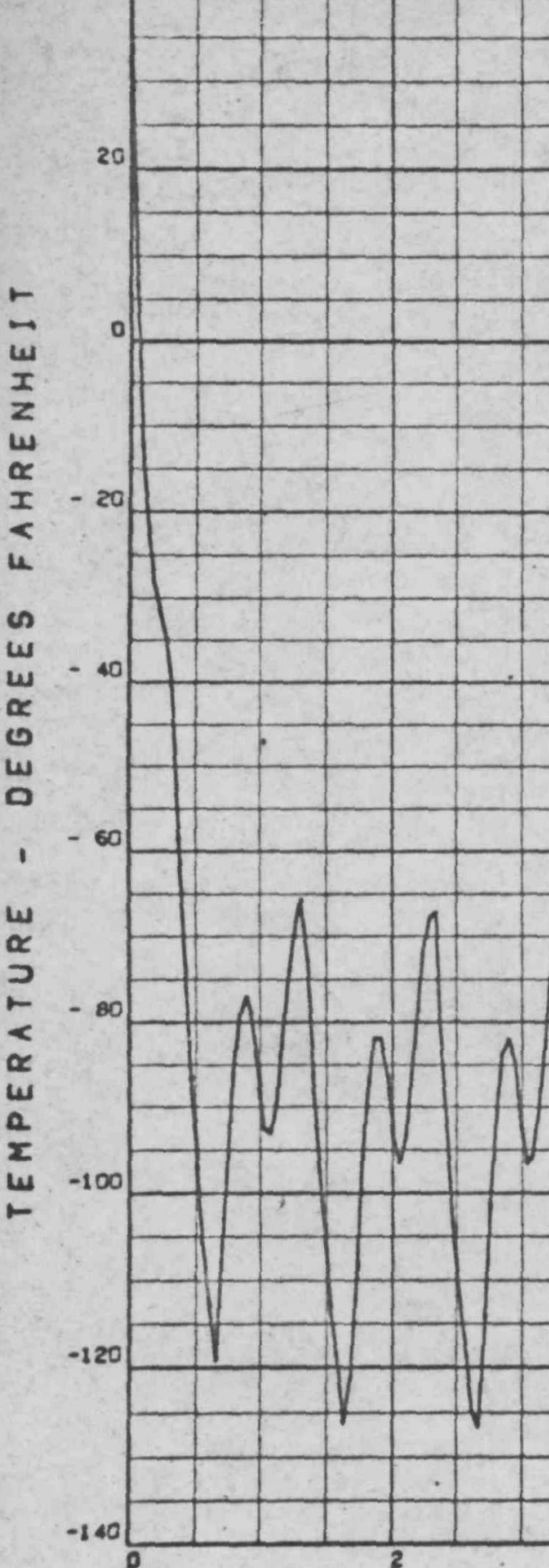

7
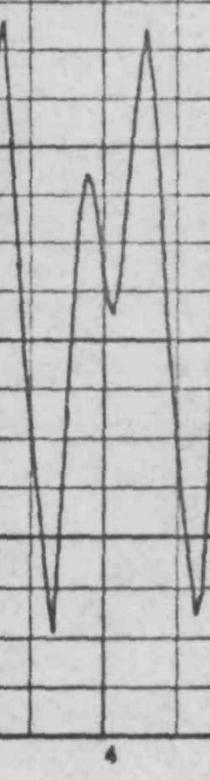

REVOLUTIONS

GRAPH 22

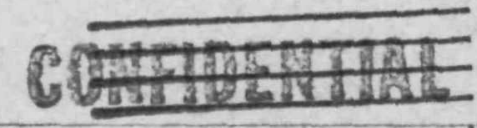




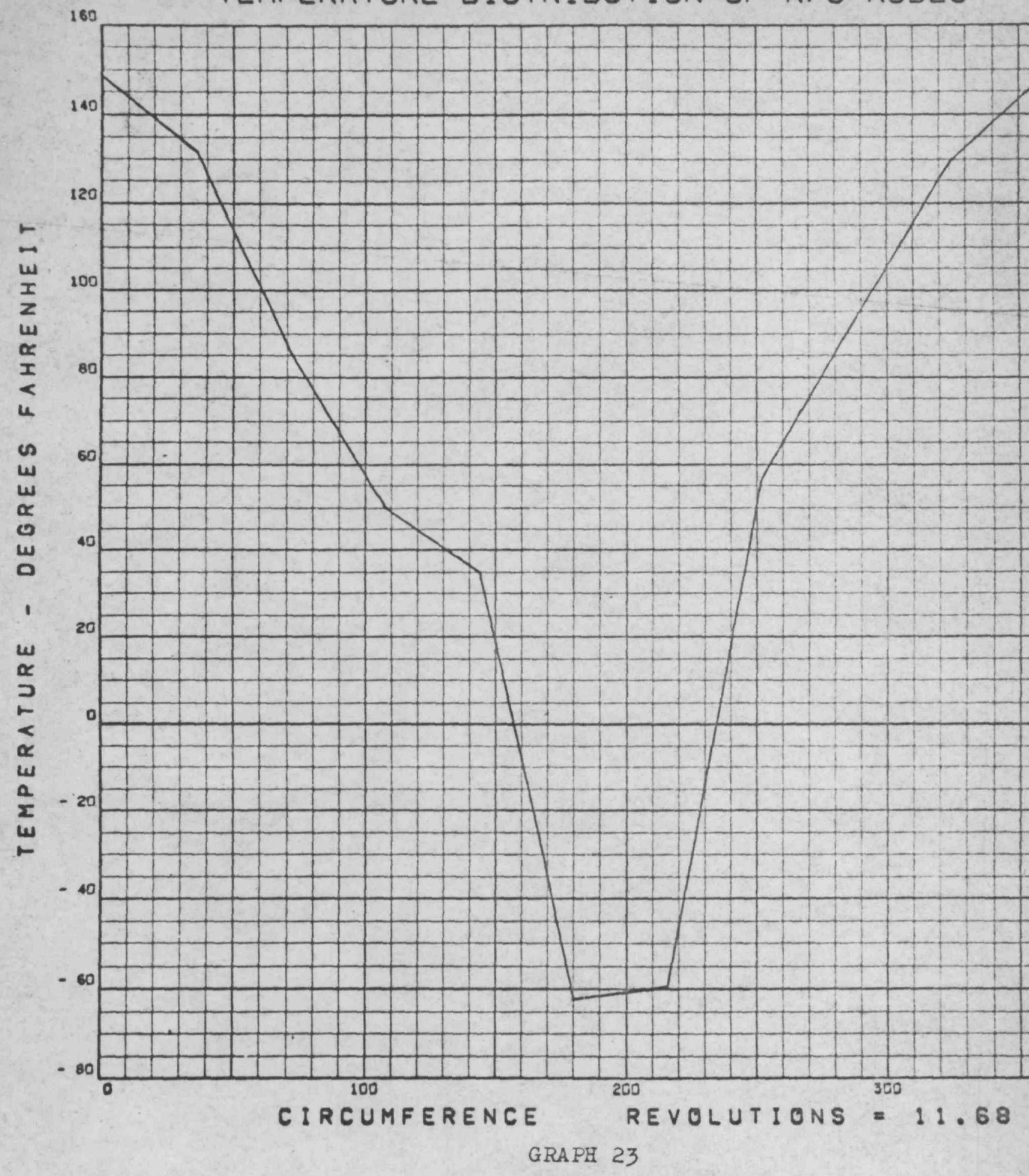

GRAPH 23 


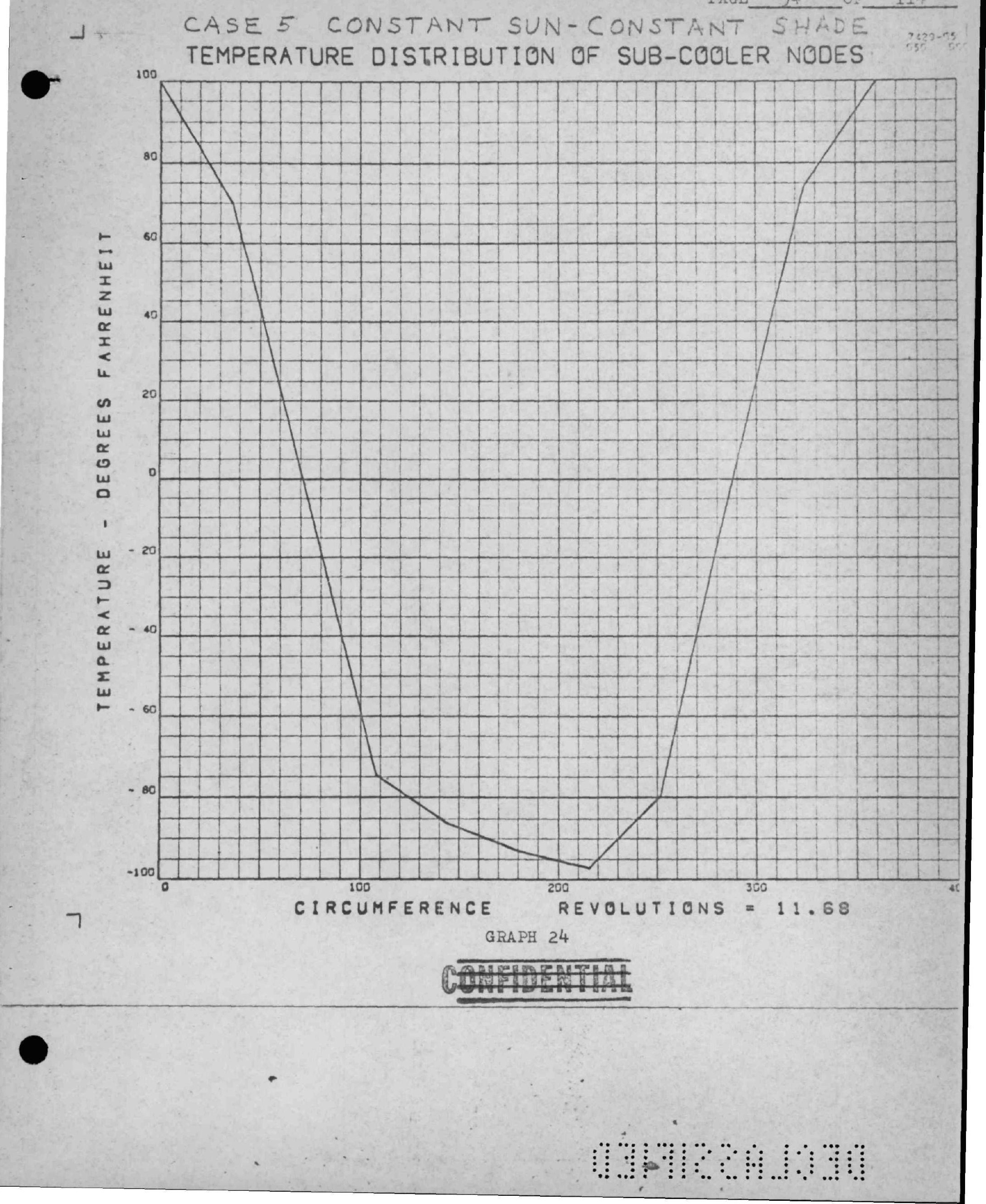



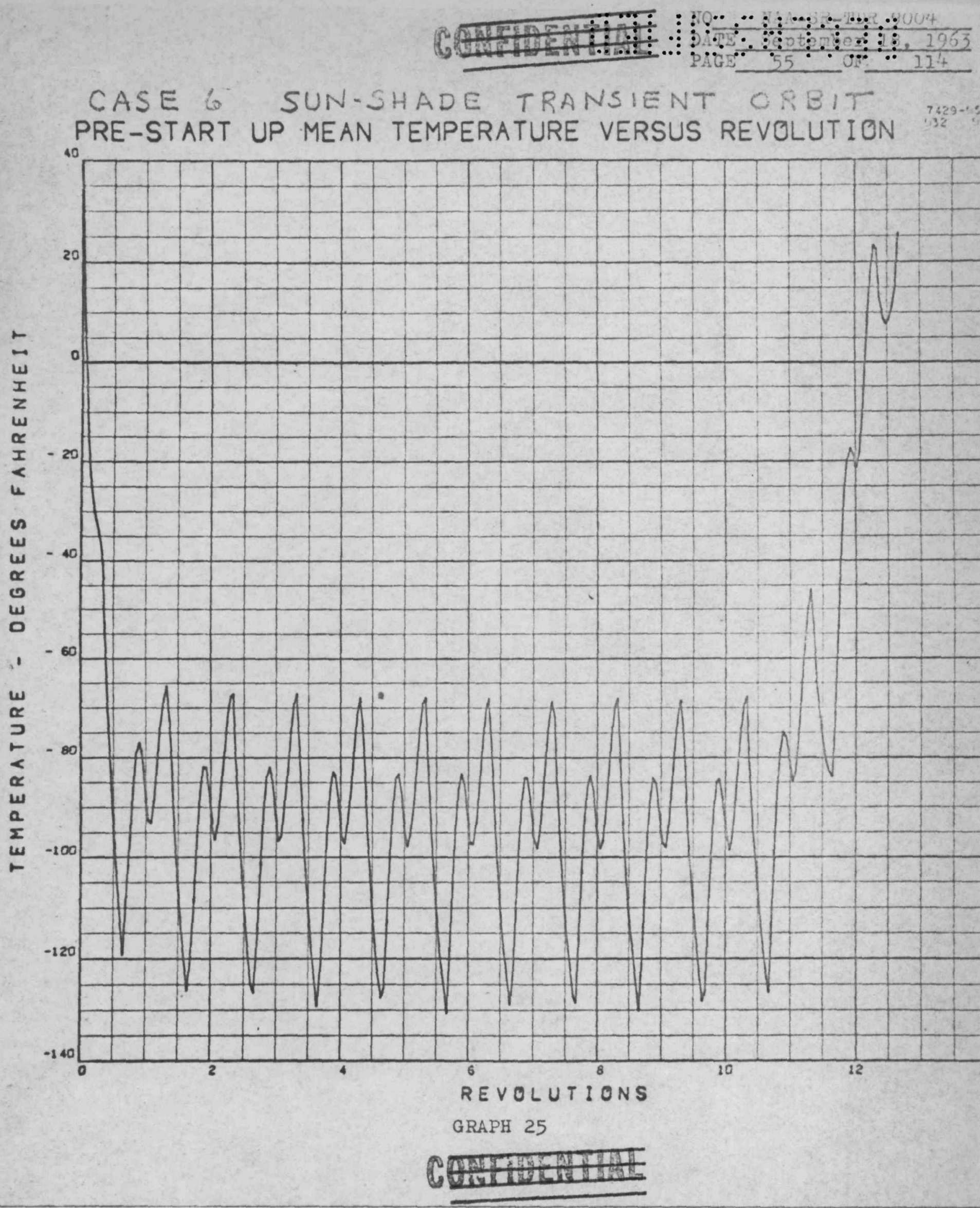


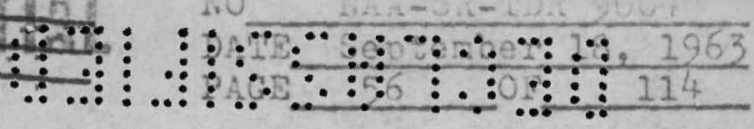

1 CASE CONSTANT SUN-CONSTANT SHADE ORBITran.. TEMPERATURE DISTRIBUTION OF R/C NODES

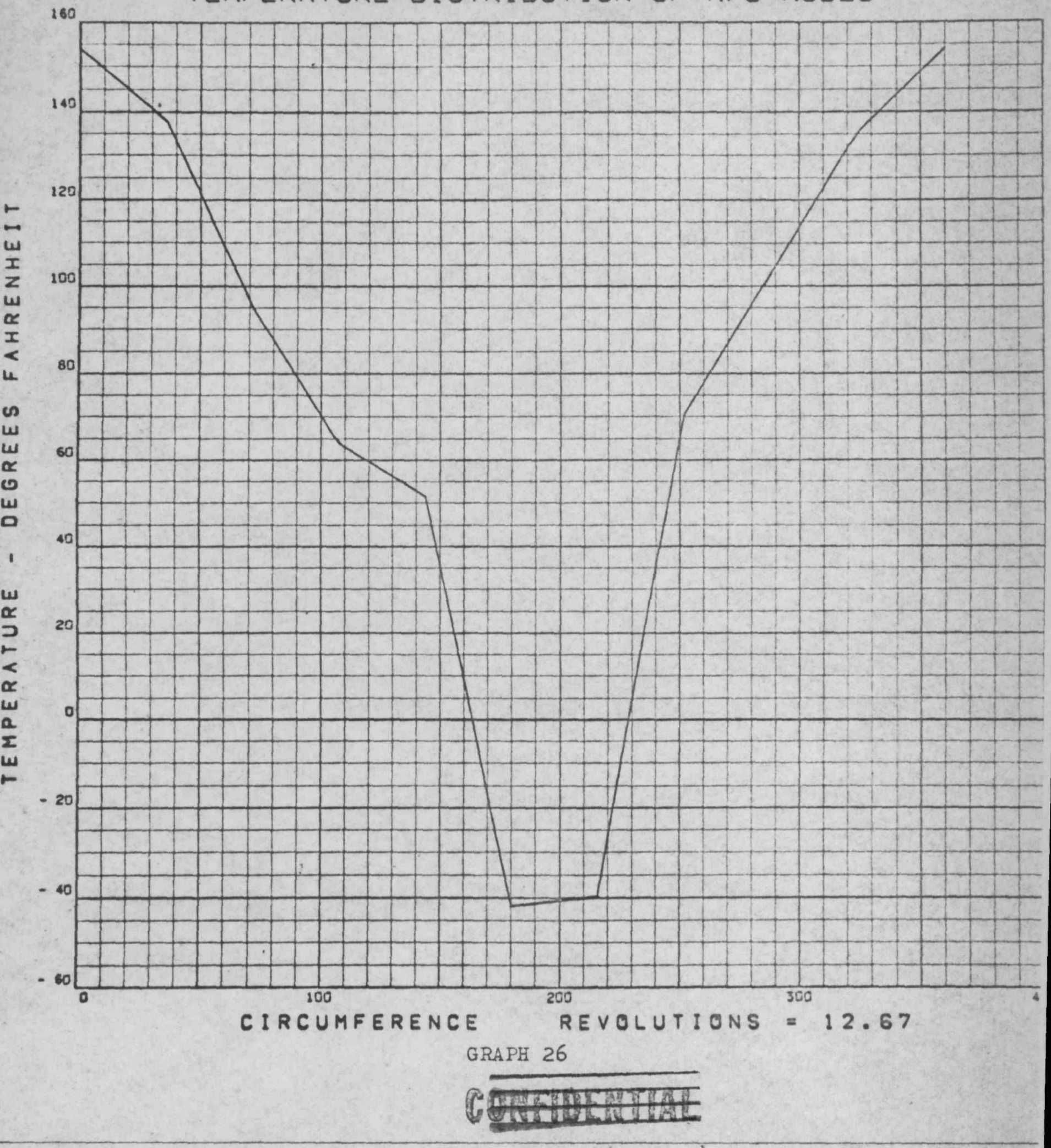



\lrcorner CASE G CONSTANT SUN-CONSTANT SHADE ORBIT TEMPERATURE DISTRIBUTION OF SUB-COOLER NODES

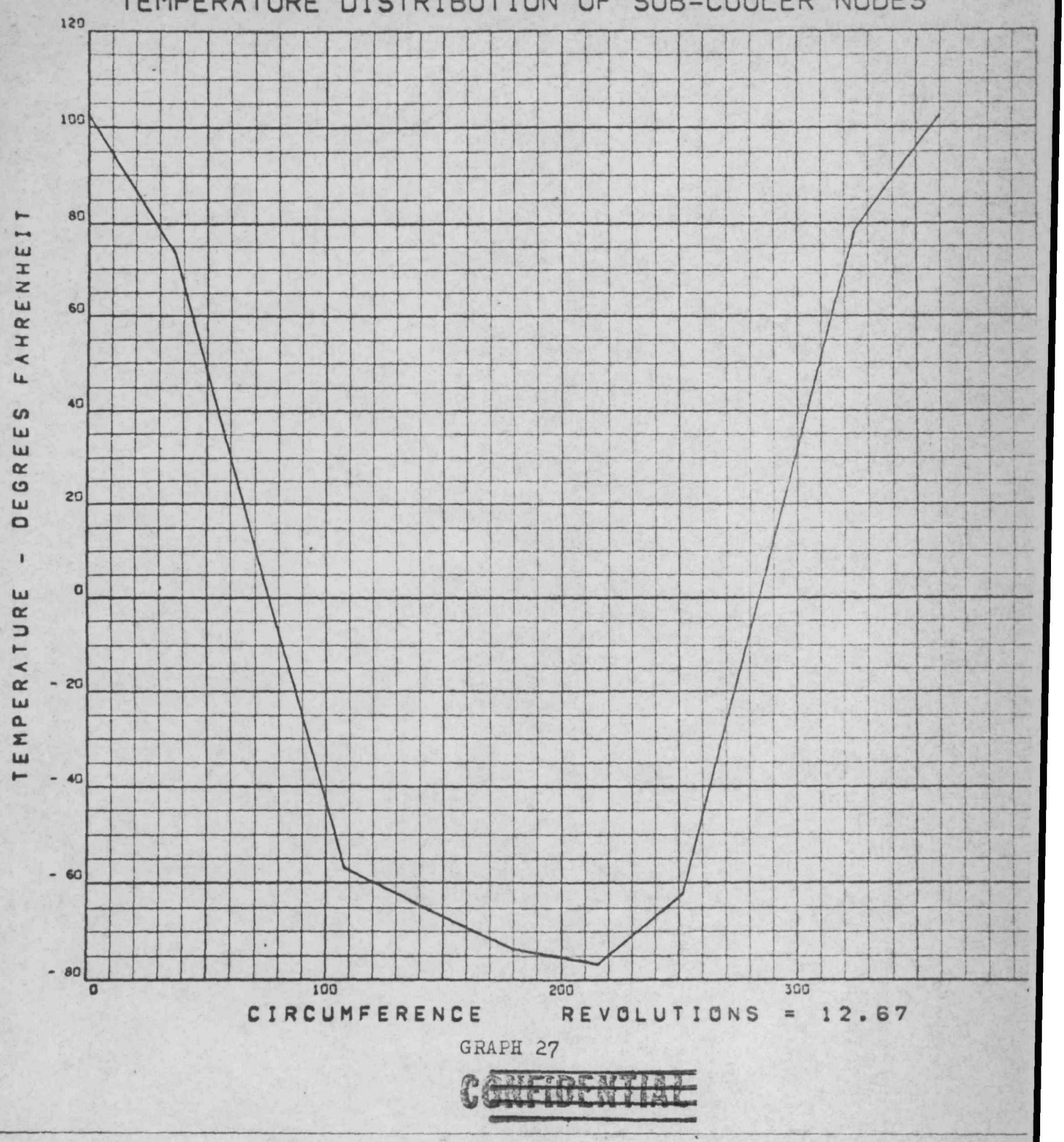




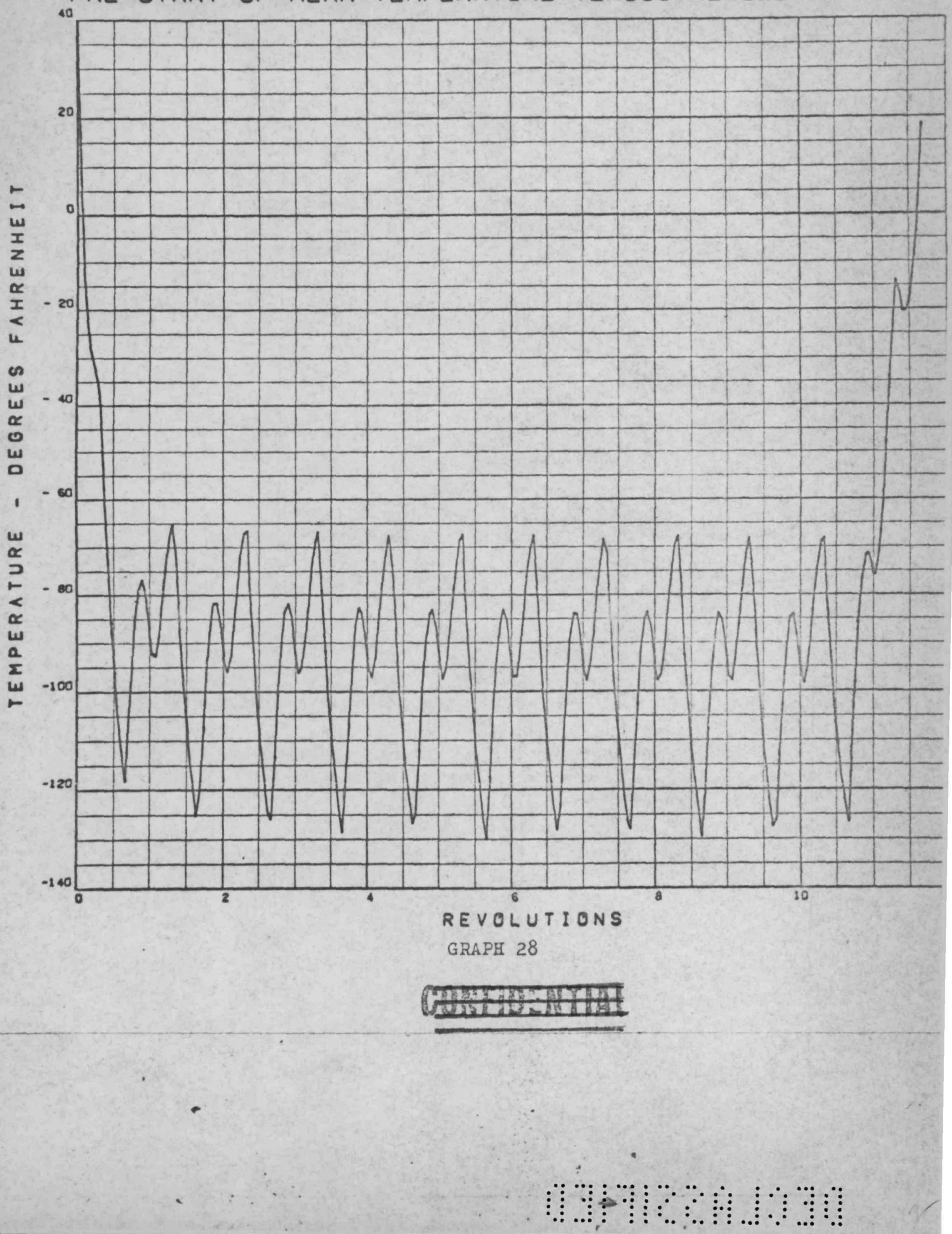




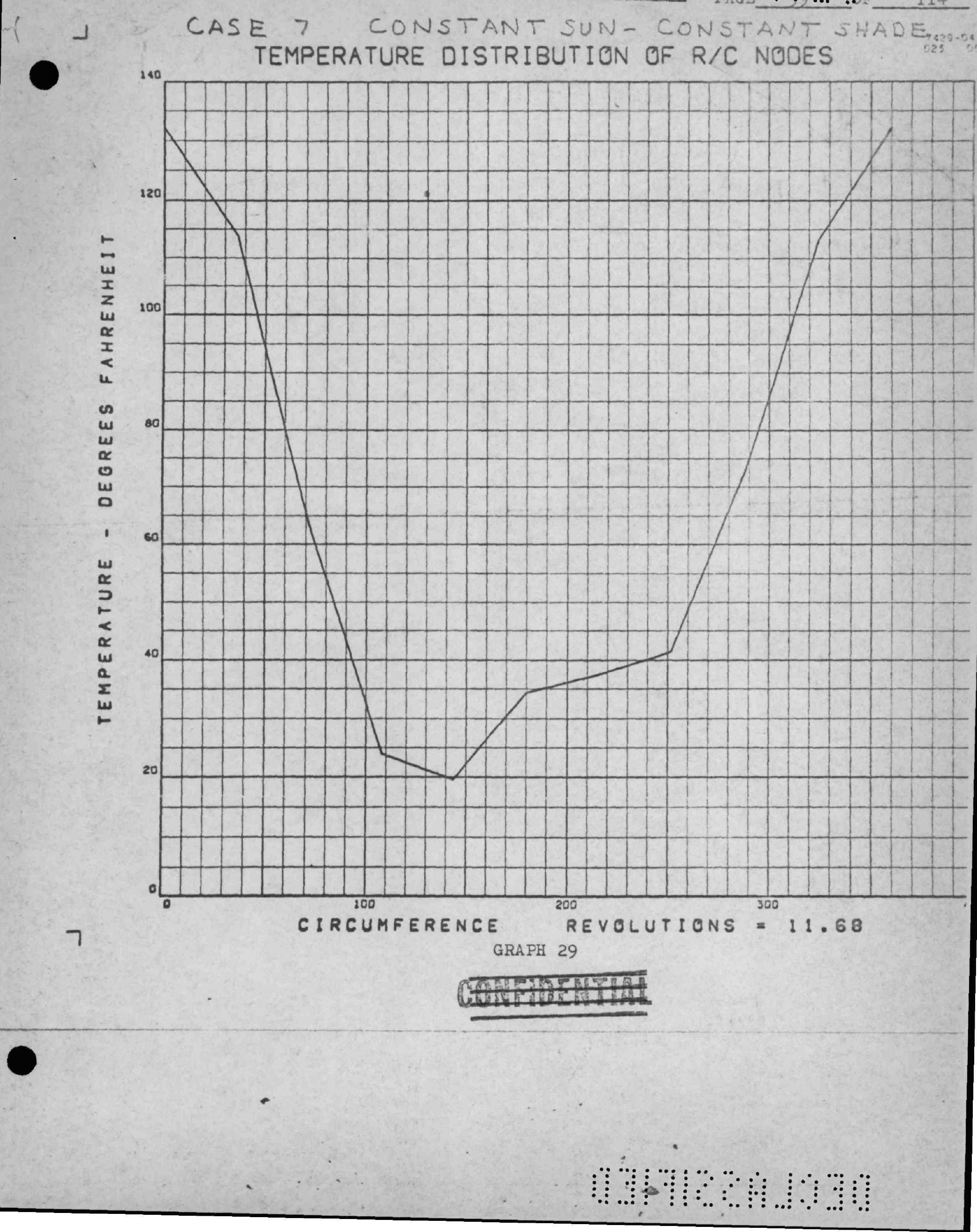


140

TEMPERATURE DISTRIBUT IUN UF SUB-CULE NUDES

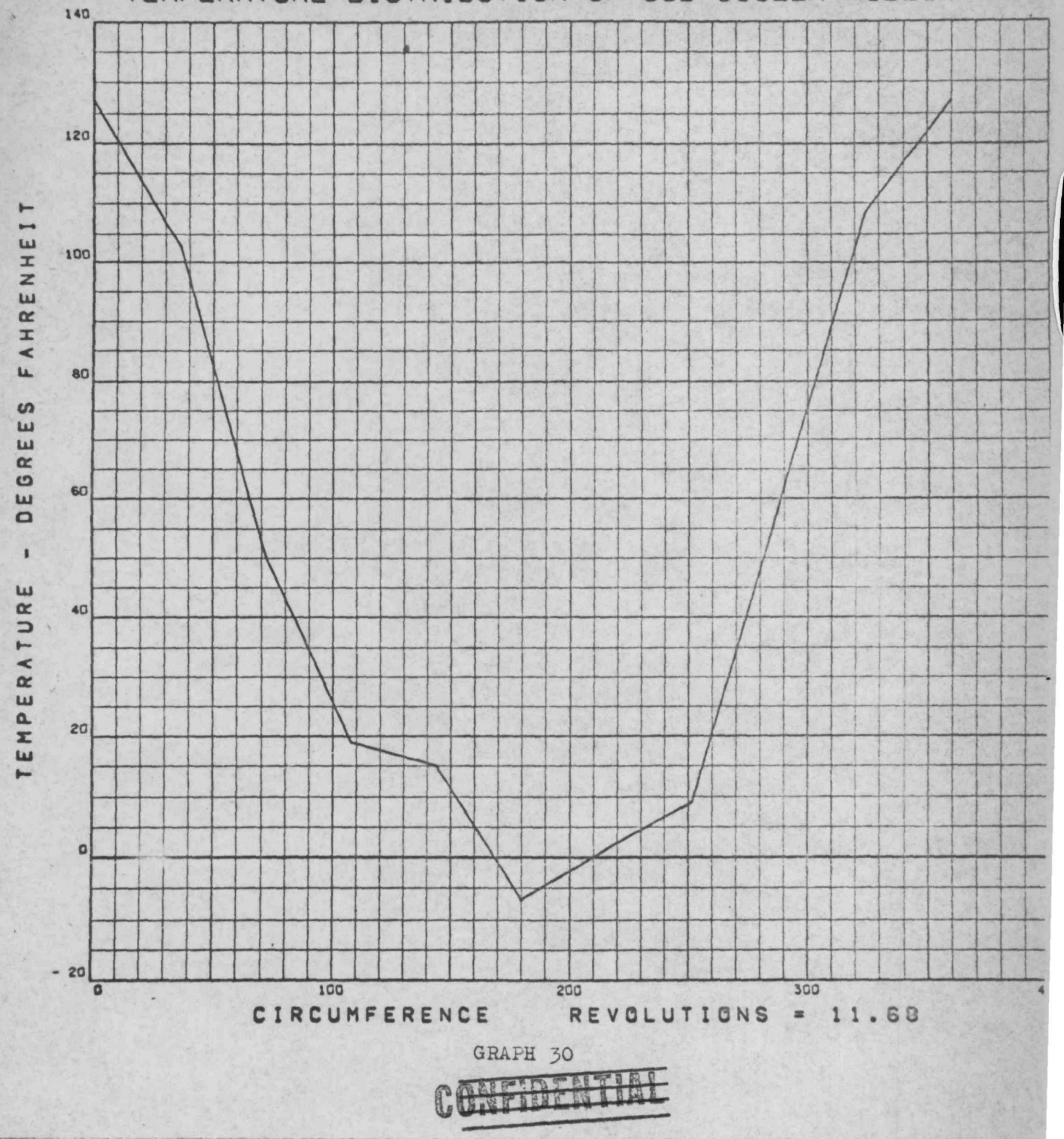


10

PRE-START UP MEAN TEMPERATURE VERSUS REVOLUTION U:G

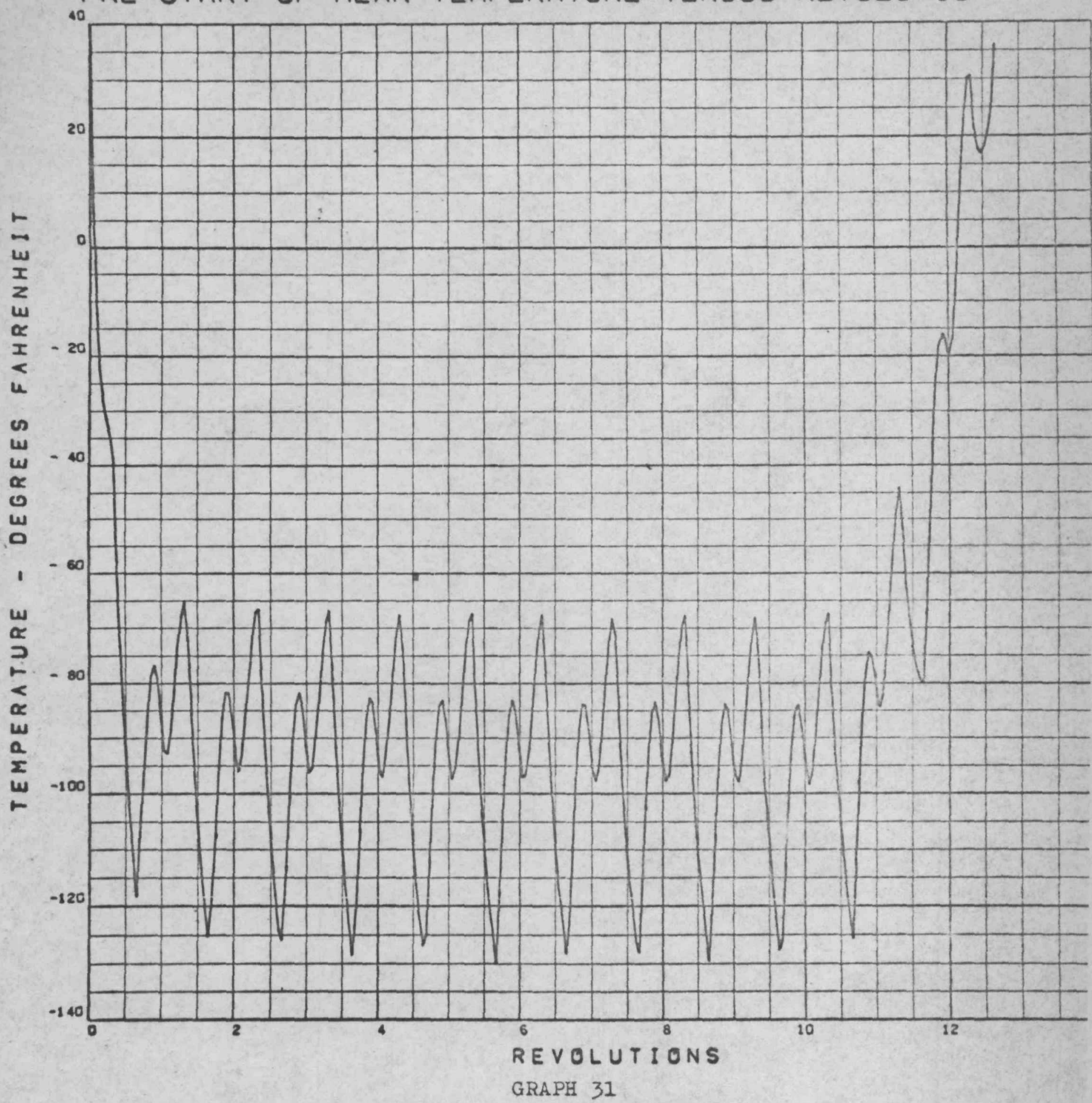
GRAPH 31 
. TEMPERATURE DISTRIBUTION OF R/C NODES

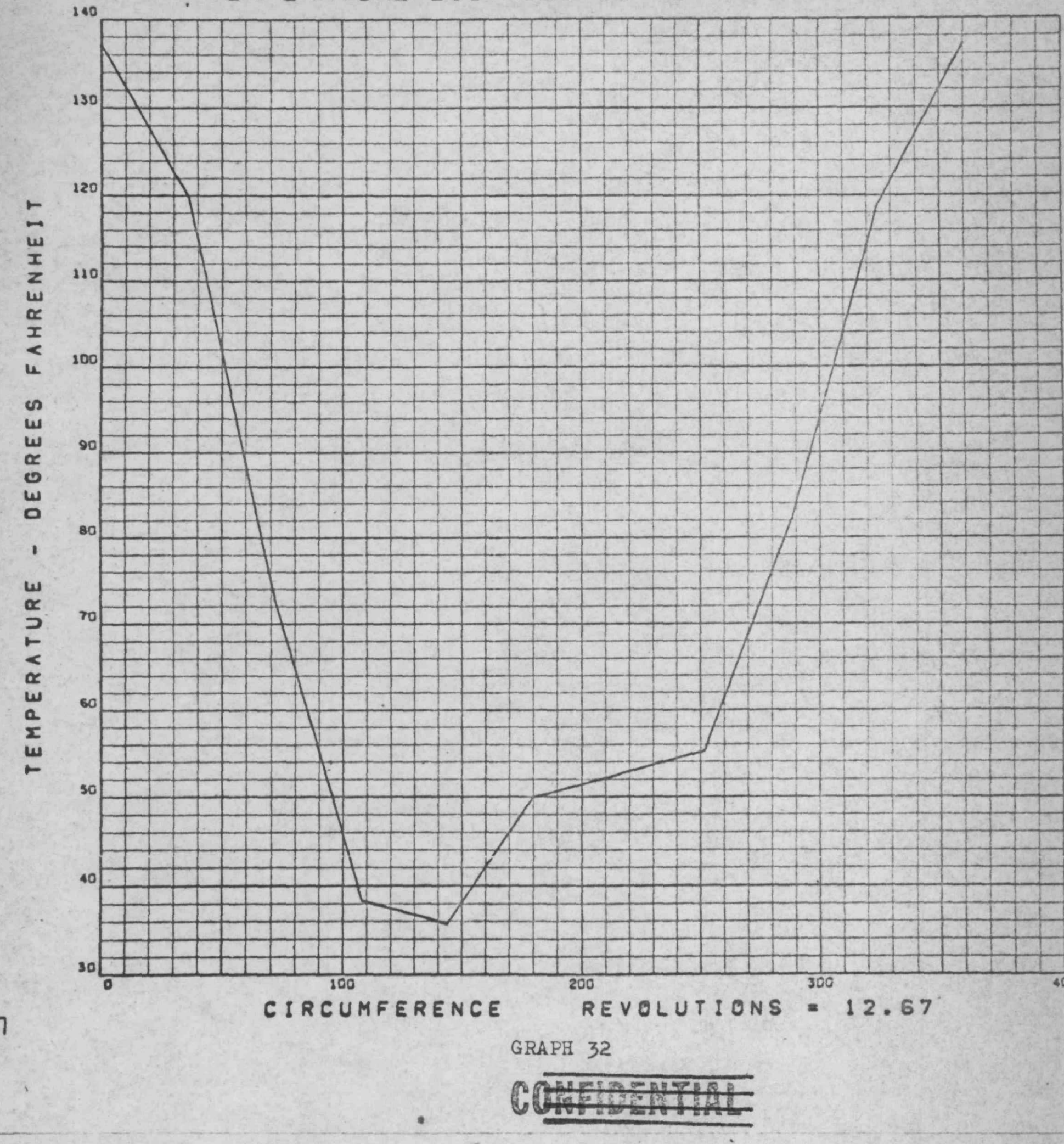




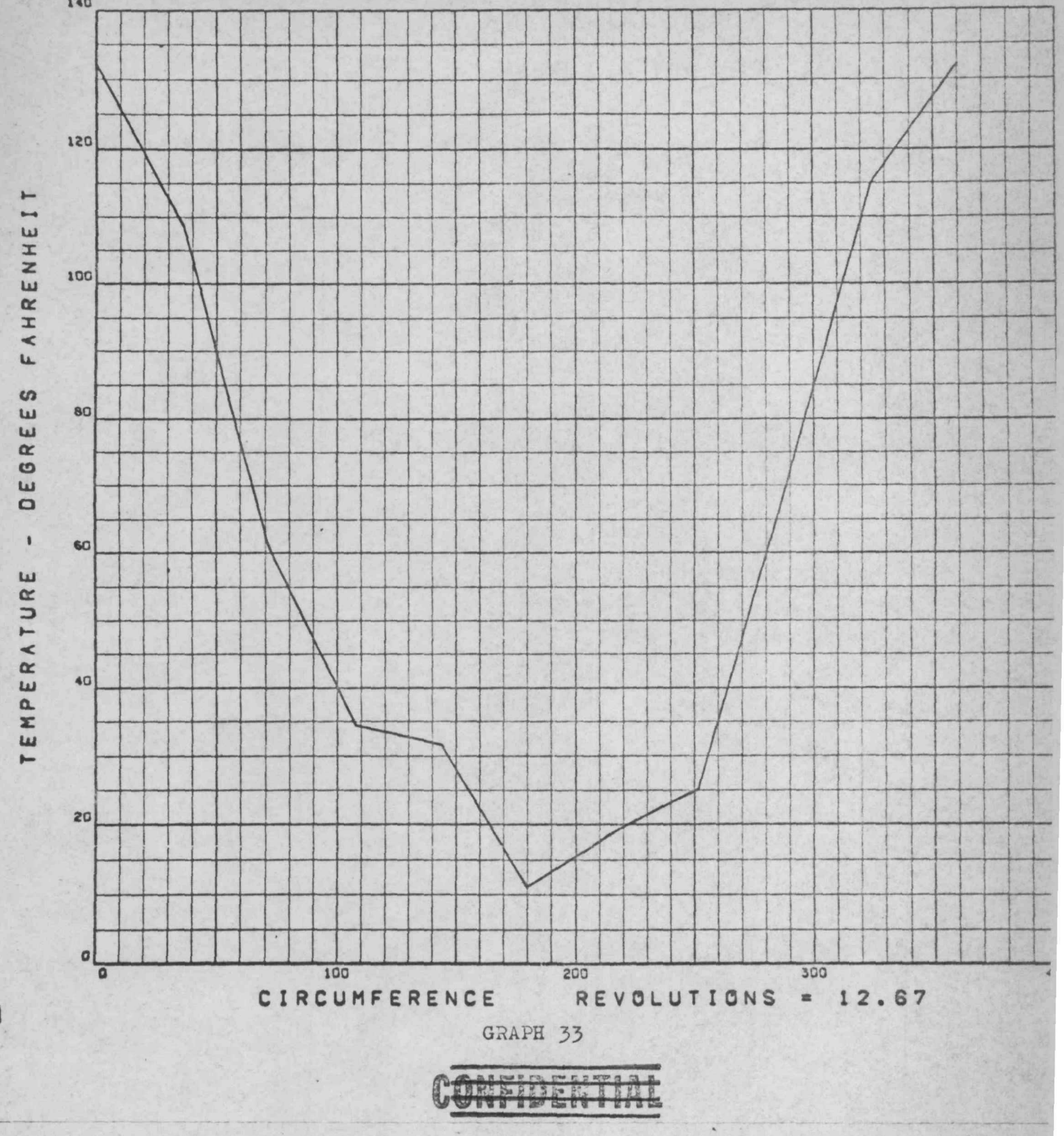




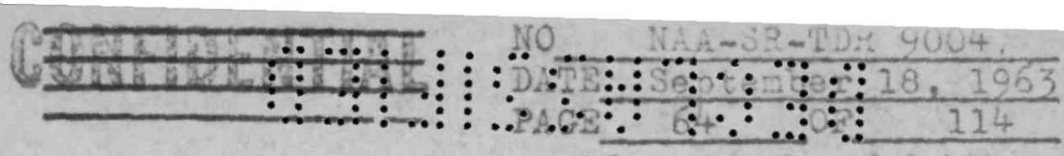

CASE 9

TRANSIENT ORBIT- HOUR SOAK LL PRE-START UP MEAN TEMPERATURE VERSUS REVOLUTION

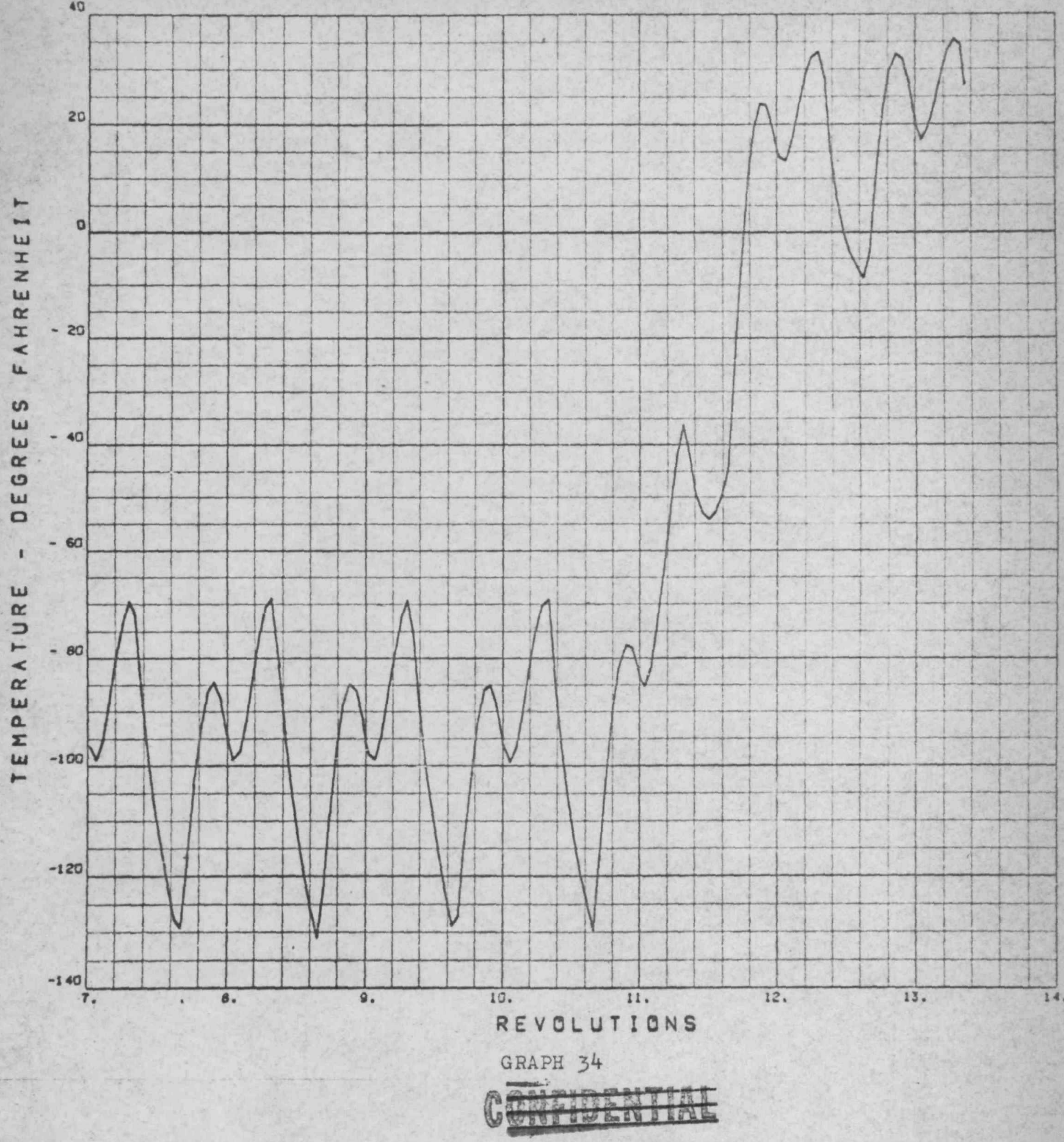




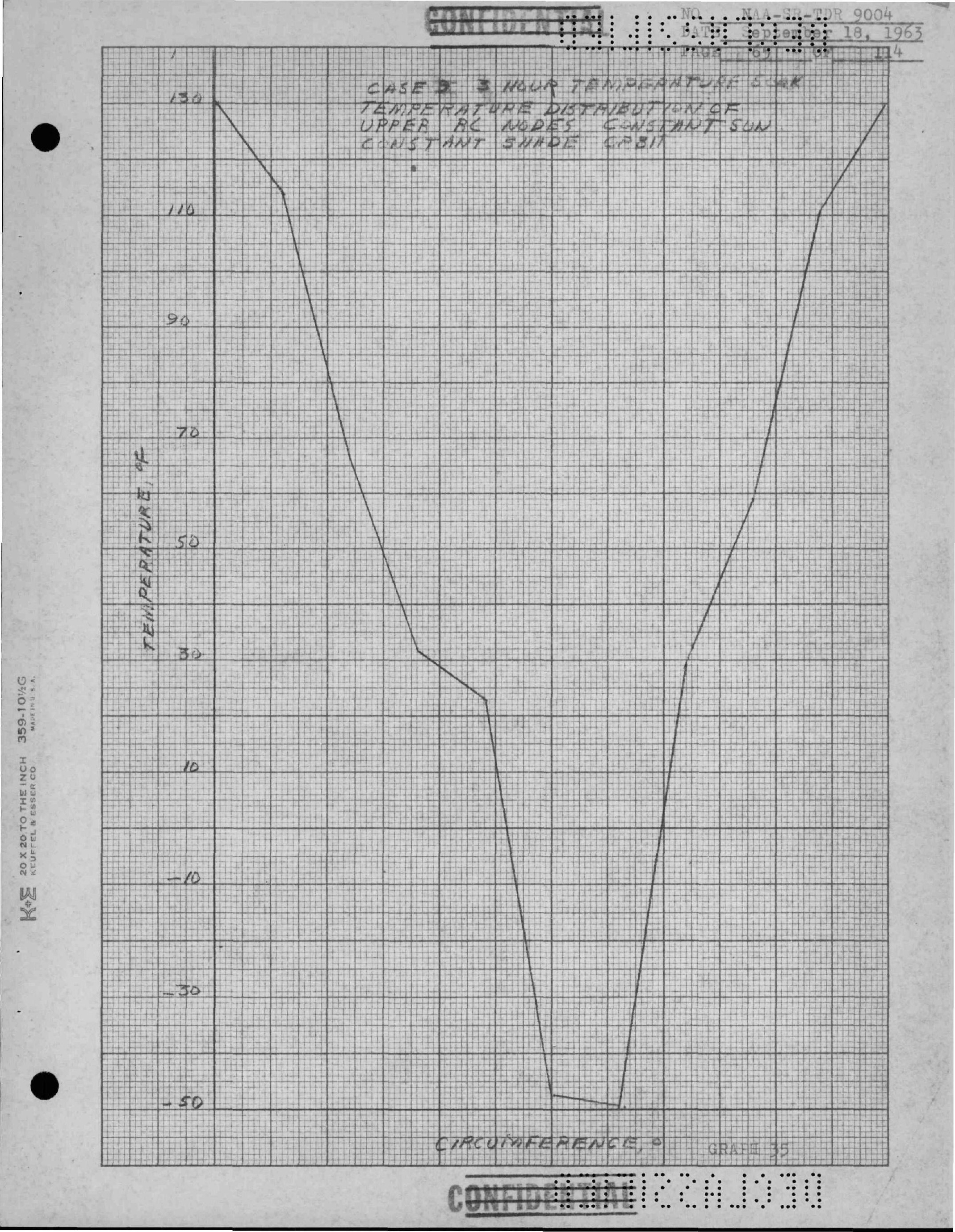




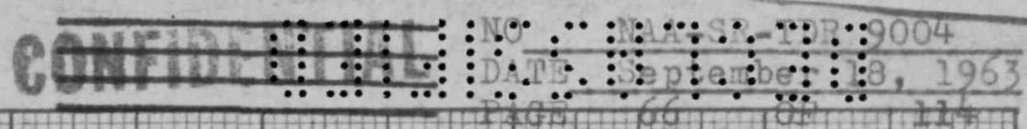

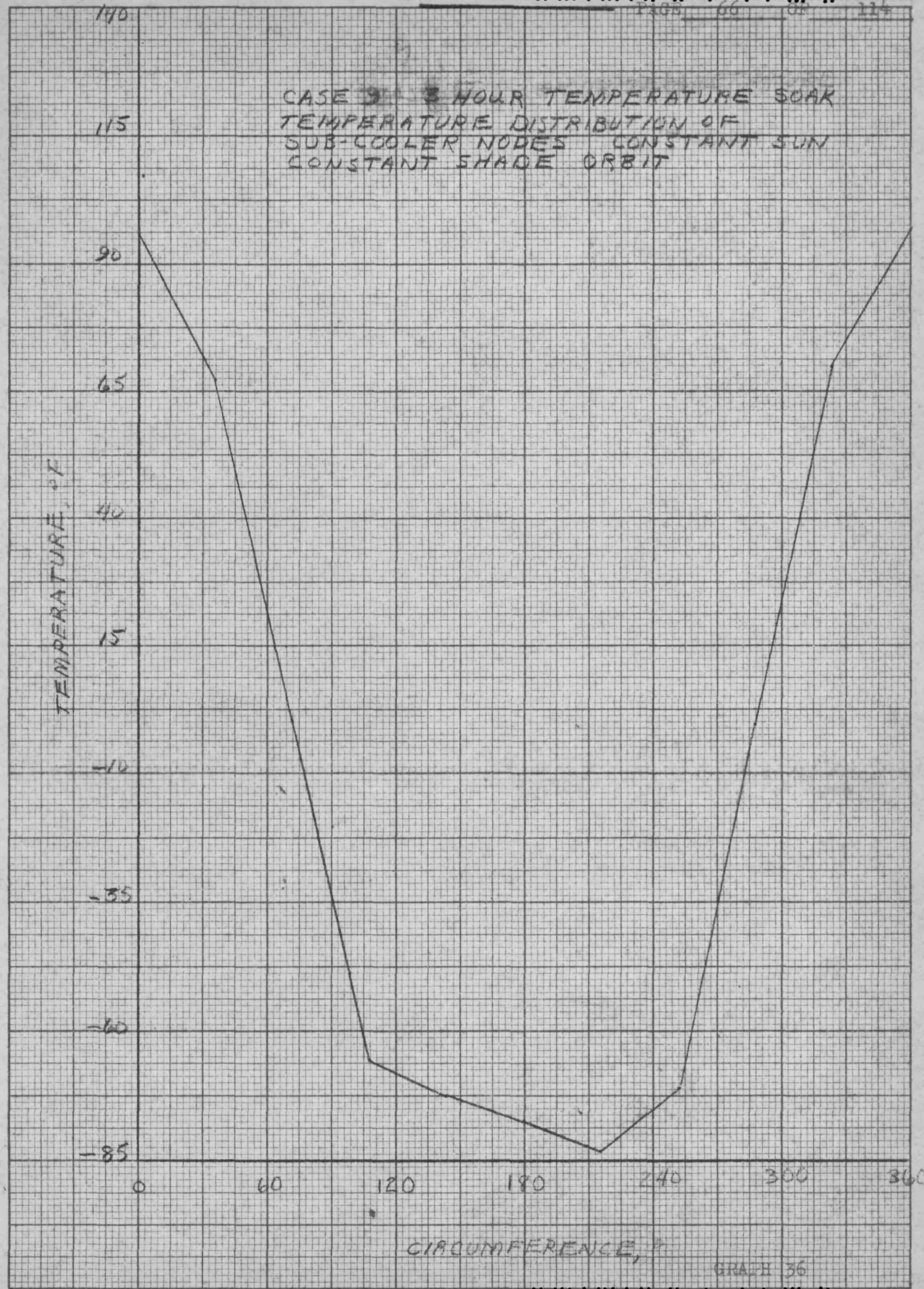




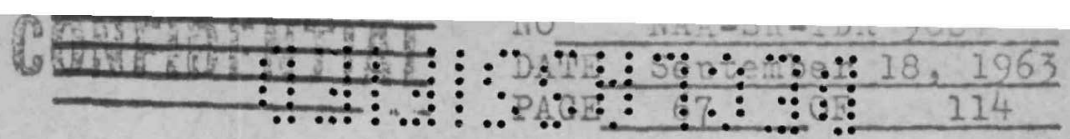

CASE TO TRANSIENT ORBIT- ZHOURTEMPERATURE SUYK PRE-START UP MEAN TEMPERATURE VERSUS REVOLUTION

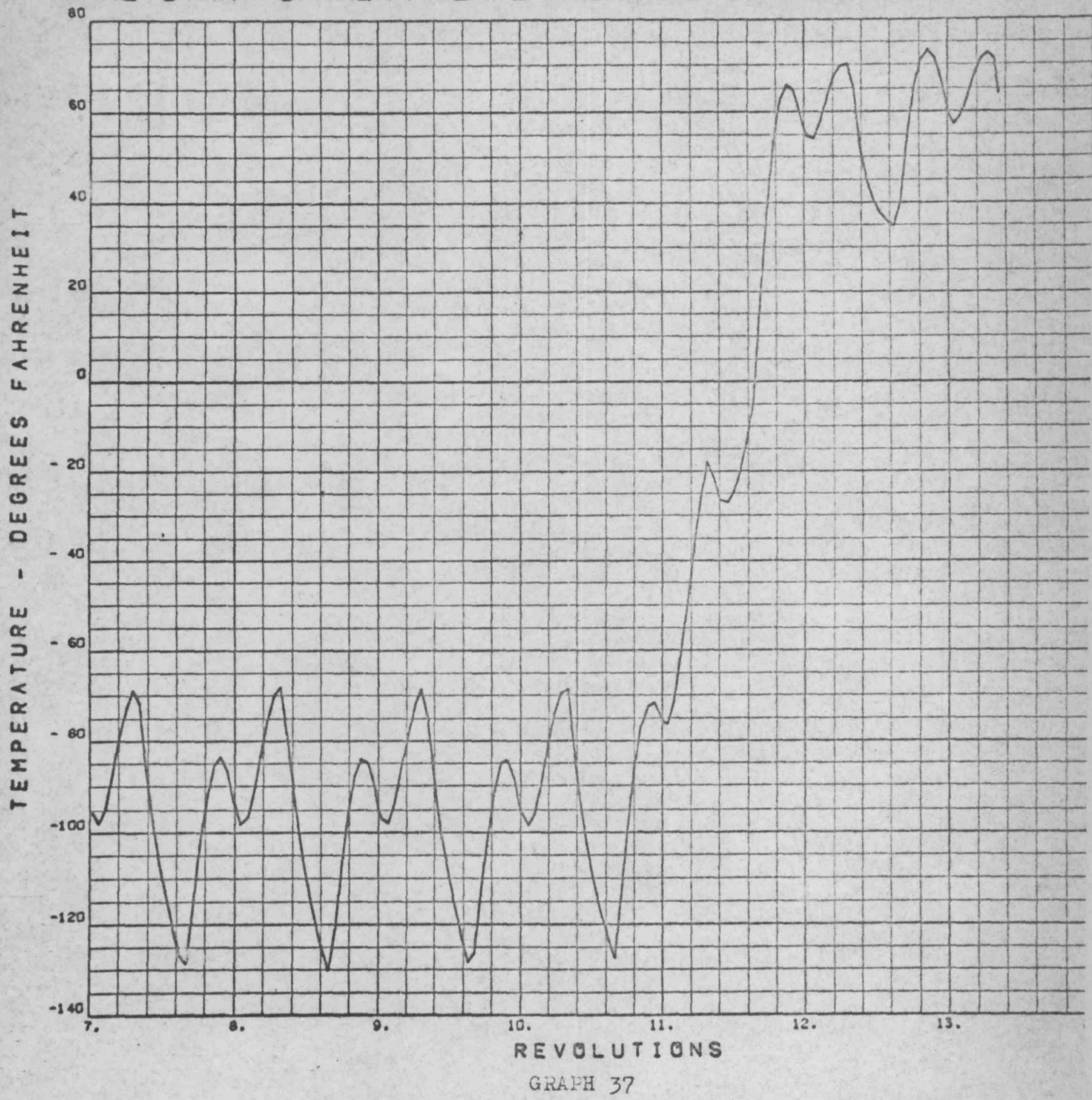


CH

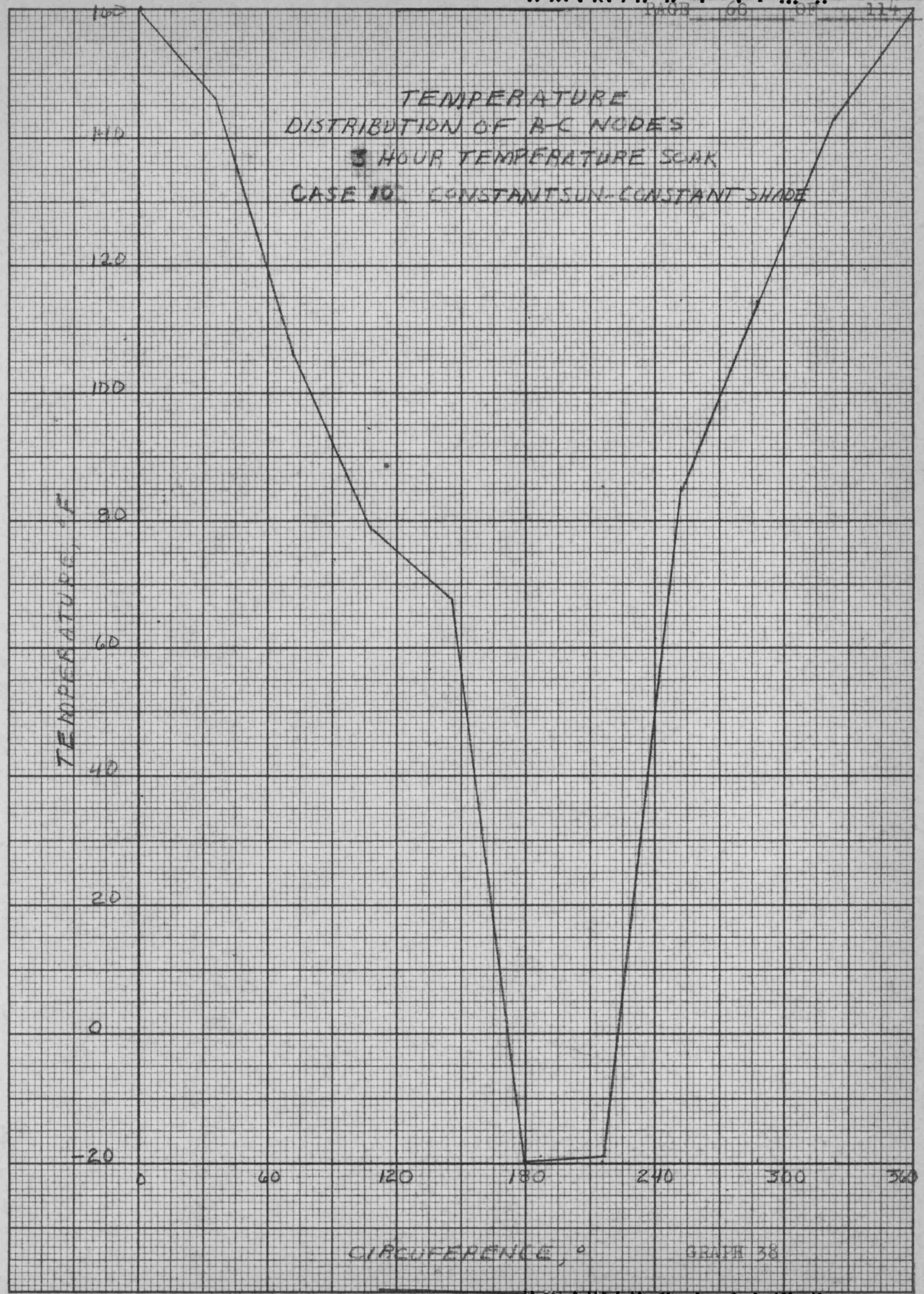


EORTER

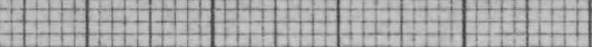

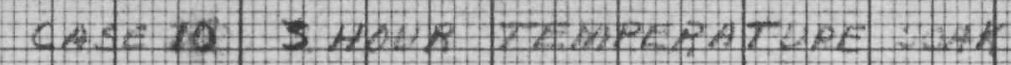
TEMPERATURE DISPRIBUTION DF SUB-D.00LER NODES CONSTANT'SUN-CANSTANT SAADE

60 100

i 90
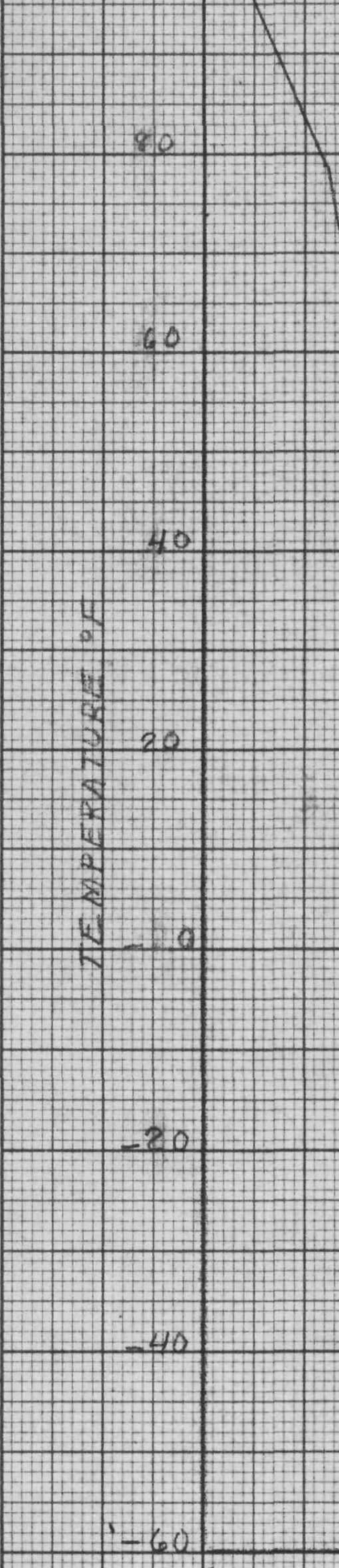

,

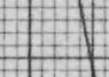

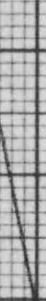
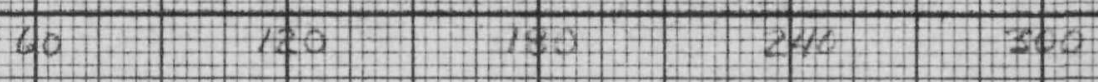

CARCUNDEENENCE:0

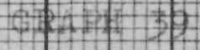


KHEE $20 \times 20$ TO THE INCH $359-10 \frac{1 / 2 G}{K E U F E L ~}$

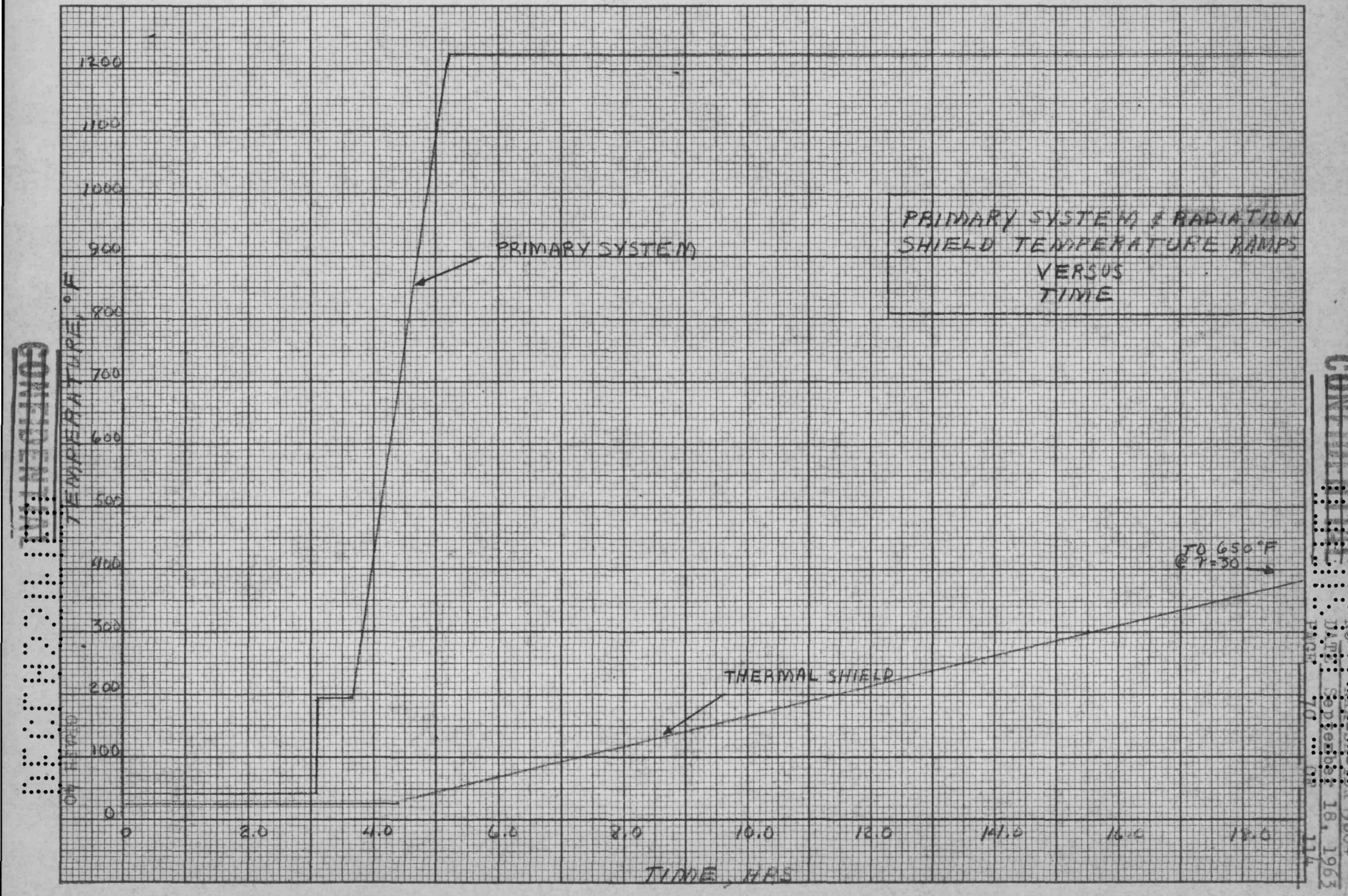


ATOMICS INTERNATIONAL

A Division of North American Aviation, Inc.
NO.

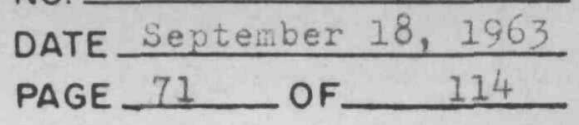

$V$ CALCULATION OF R/C HEAT TRANSFER PROPERTIES

A. Effective Fin Thickness for Conduction Around R/C

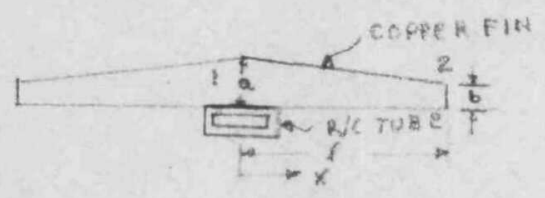

In order to determine the thermal conductance between nodes on the $R / C$, it was necessary to calculate a mean thickness for the $R / C$ fin. Writing the equation for heat conduction (neglecting radialtin) from points 1 to 2 in the Figure above

$$
q=K A(x) \frac{d T}{d x}=K A \text { eff } \frac{\Delta T}{p}
$$

where $A(x)$ represents the conduction area as a function of $x$. Using the linear relationship between area and $X$ this may be rewritten as:

or

$$
q=k(a-b x) \frac{d T}{d x}
$$

(32)

From Equation (30), this may also be expressed as

$$
\begin{aligned}
& T_{1}-T_{2}=\frac{q l}{A-K} \\
& A e_{1}+\frac{l b}{\ln \frac{A_{1}}{A_{2}}}=\frac{A_{1}-A_{2}}{M_{1} / A_{2}}
\end{aligned}
$$

Therefore

or

$$
t=\frac{L_{1}-t_{2}}{\ln t_{1} / t_{2}} \quad \text {. }
$$

B. Thermal Conductance of $\mathrm{R} / \mathrm{C}$ Nodes

1. Between Upper $R / C$ Nodes Thermal conductance between the upper R/C nodes was assumed to be through the copper fins whenever possible once the thermal conductivity of copper is large in comparison to the other materials used for the constraction of the $R / C$. However, because of machine limitations,

719.P 


\section{ATOMICS INTERNATIONAL}

A Division of North American Aviation, Inc.
DATE September 18, 1963

PAGE
72

of

there is a nominal gap of 0.03 inches between 36 of the copper fins. The remaining four gaps are equally spaced 0.25 inches a part at the $R / C$ panel joints. Since the choice of ten nodes does not adhere to a convenient location of these four larger gaps, it was necessary to use a mean value for all 40 gaps for the thermal resistance between fins.

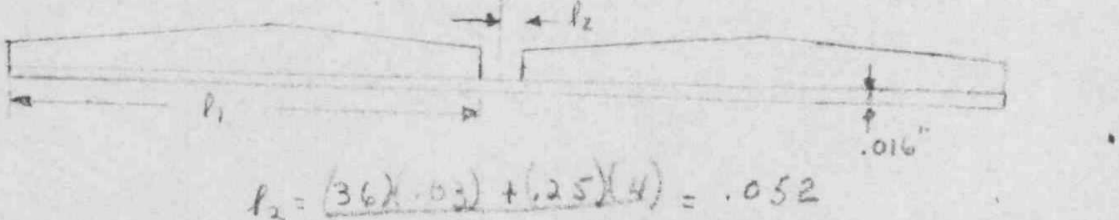

or gap per node $=(0.52)(4)=.21^{\prime \prime}$

Referring to the above figure, the resistivity may be determined from

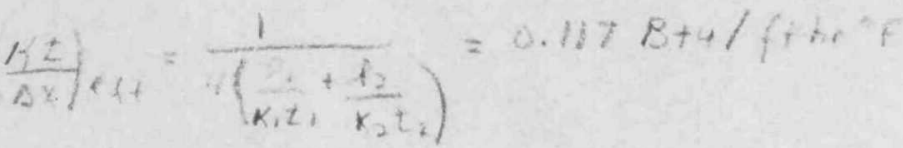

Finally,

$$
\frac{K A}{A D}=\left(\frac{K A}{A x}\right)=\frac{.17(107)}{12}=1.045 \mathrm{Bt} / \mathrm{haF}
$$

where $l$ is the vertical length of the upper $R / C$ nodes.

2. Between Subcooler Nodes Following the same procedure for determining the resistance between the subcooler nodes as was done for the upper $\mathrm{R} / \mathrm{C}$ nodes

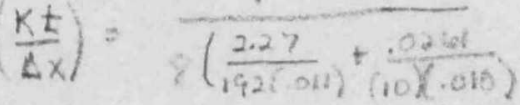

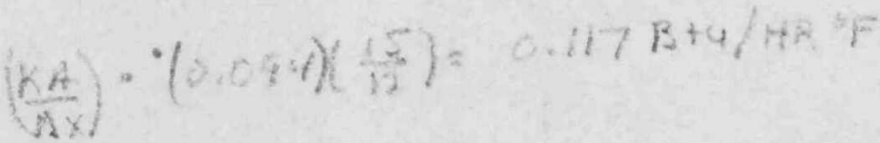




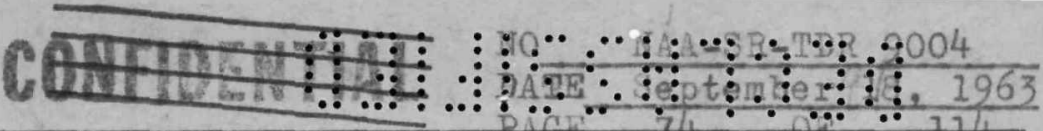

HEAT CAdachty aEA TUBE

5.0

PERUNIT LENGTH RICCIZ

COPAER APMOUP, TPBE

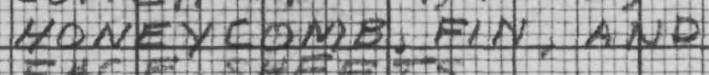

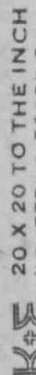

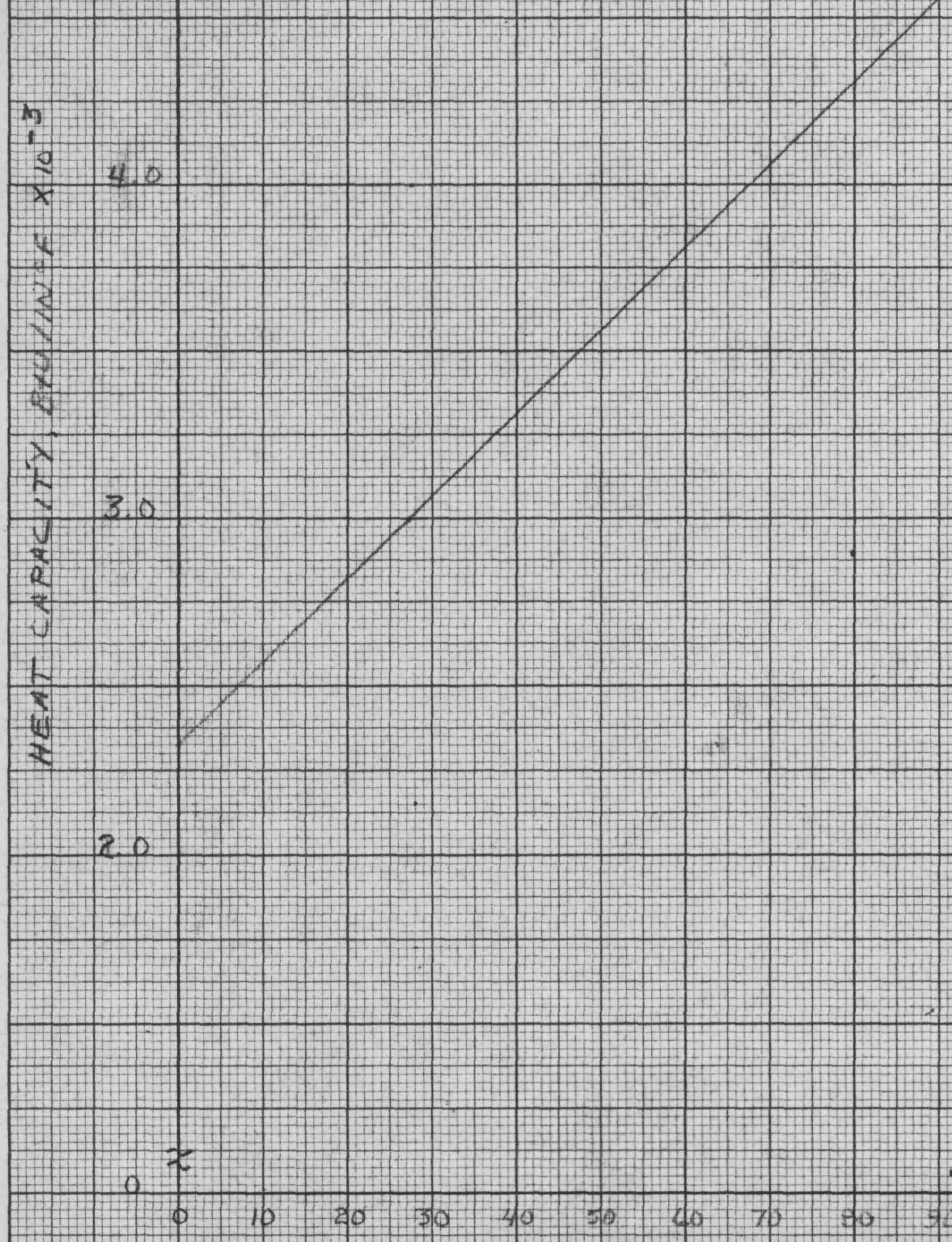

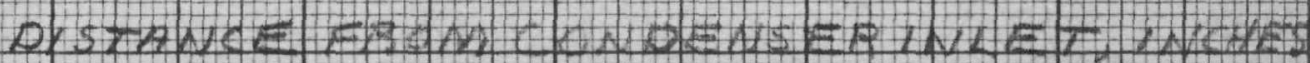




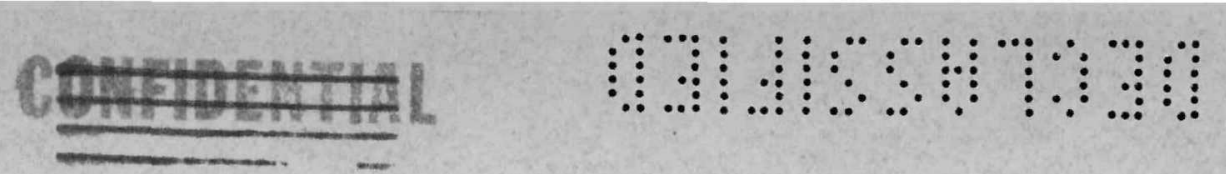

if $\underset{F_{i-j}}{\stackrel{j}{\longrightarrow}}$

NODE

(8)

\begin{tabular}{|l|l|l|l|l|l|l|l|l|l|l|l|l|}
\hline & 2 & 3 & 4 & 5 & 6 & 7 & 8 & 9 & 10 & 11 & 12
\end{tabular}

$\begin{array}{lllllllllll}0.04544 & .045414 & .07846 & .12055 & .08239 & 07703 & .09239 & .09055 & 068446 & .03160\end{array}$

4

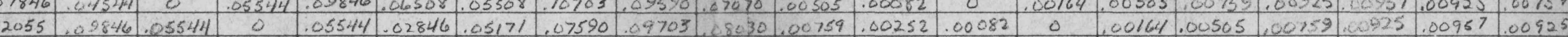

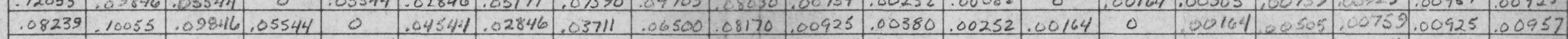

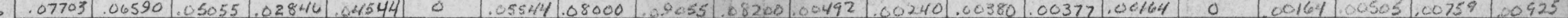

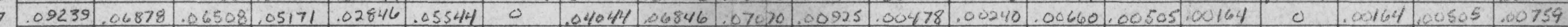

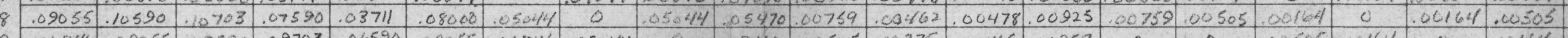

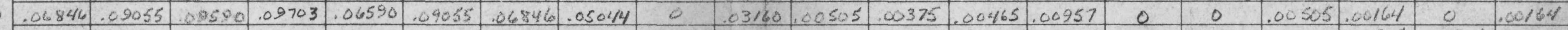

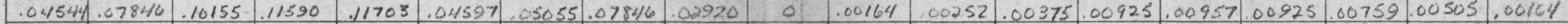

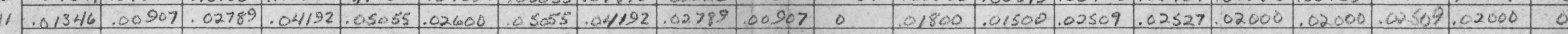

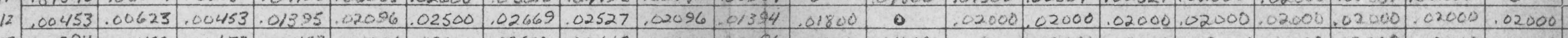

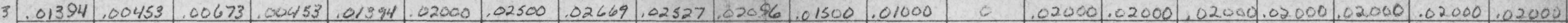

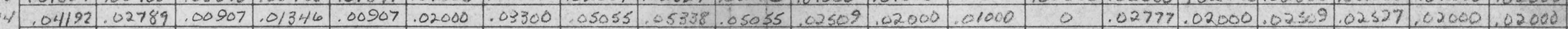

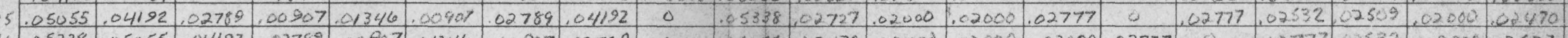

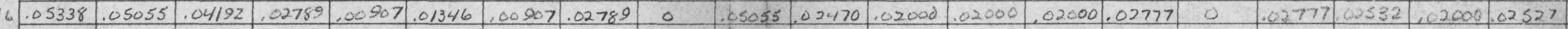

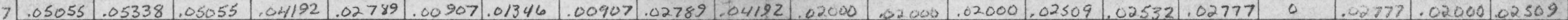

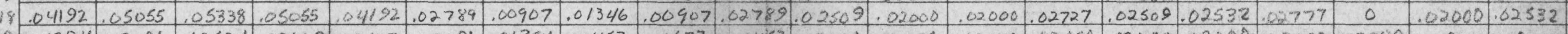

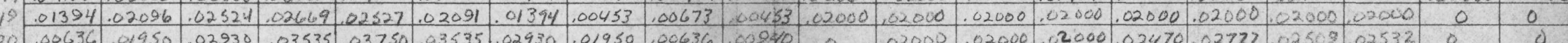

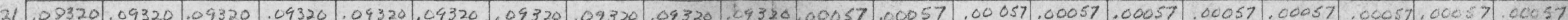

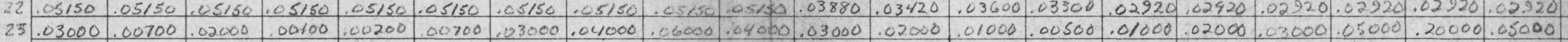

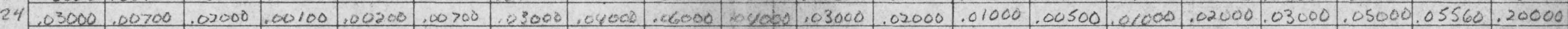

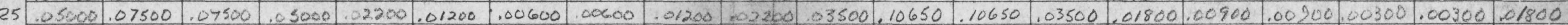

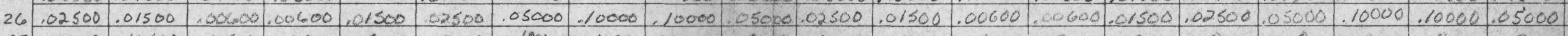

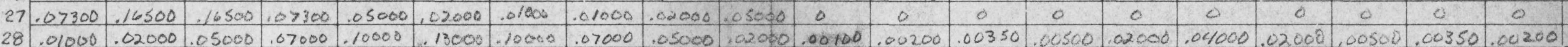

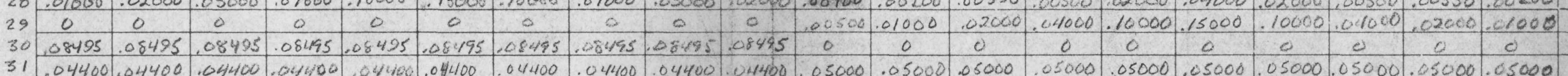

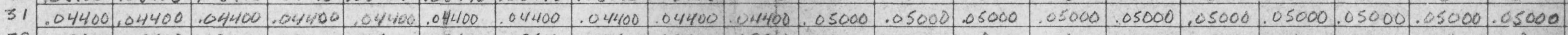

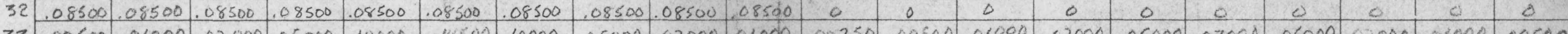

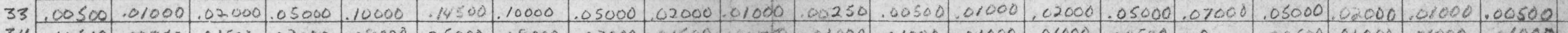

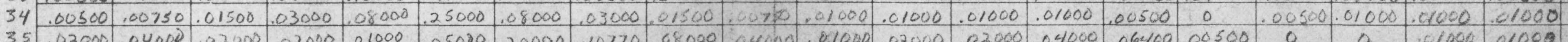

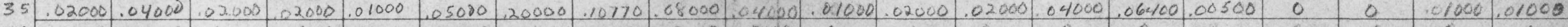

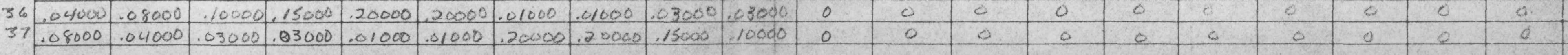

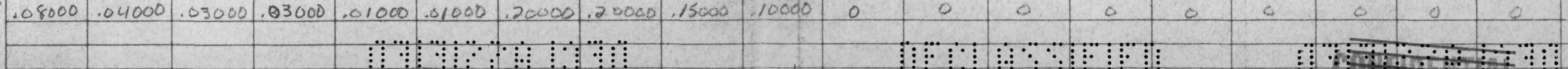


三

\begin{tabular}{|c|c|c|}
\hline $\begin{array}{l}\text { PREPARED or, S. BIC KEL } \\
\text { CHeCKED ar. }\end{array}$ & $\begin{array}{l}\text { ATOMICS INTERNATIONAL } \\
\text { A DIVISION OF NORTH AMERICAN AVIATION. INC. } \\
\text { VIEW FACTORS }\end{array}$ & $\begin{array}{l}\text { PACENO } 76 \text { of } 114 \\
\text { NAA-SR-TDR } 9004 \\
\text { NEPOAT NO. }\end{array}$ \\
\hline Darte $>/ 10 / 63$ & TABLE 5 (CONTINUED) & \\
\hline
\end{tabular}

$i \downarrow F_{i-1}$

\begin{tabular}{|l|l|l|l|l|l|l|l|l}
\hline 21 & 22 & 23 & 24 & 25 & 26 & 27 & 28 & 29 \\
\hline
\end{tabular}

\begin{tabular}{|l|l|l|l|l|l|l|l|l|l|l}
.04393 & .10000 & .00620 & .00620 & .00228 & .00016 & .00095 & .00005 & 0
\end{tabular}

$30 \quad 31$

35 $\begin{array}{lllllllllll}.04393 & .10000 & .00145 & .00145 & .00342 & .00010 & .00214 & .00010 & 0\end{array}$

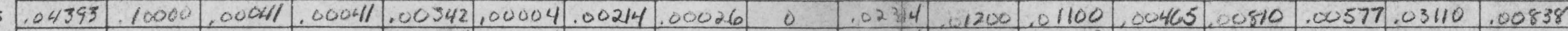

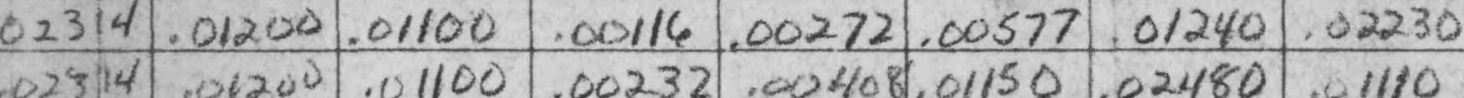

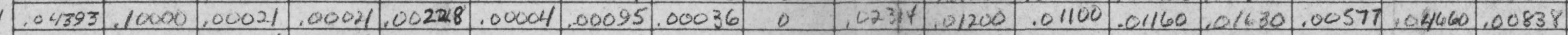

\begin{tabular}{|l|l|l|l|l|l|l|l|l|l|l|l}
5 & .04393 & .10000 & .00041 & .00041 & .00100 & .00010 & .00065 & .00051 & 0
\end{tabular}

$.04393,10000,00145,00145,00055.00016,00026,00067$.

$02314.01200,01100,02320,04350,00288,06220,002279$ $.04393 .10000 .00620 .00620,00027,00032.00013 .00051$

0.234 .01200

$.01100,03370.08160 .01440 .06220 .00279$

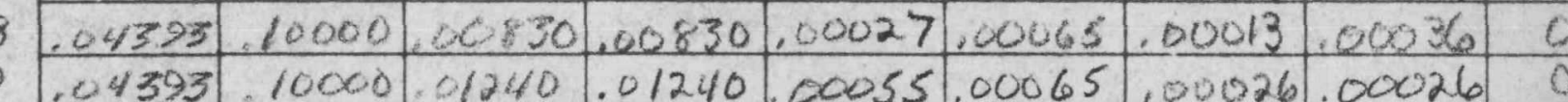

.02314 .01200

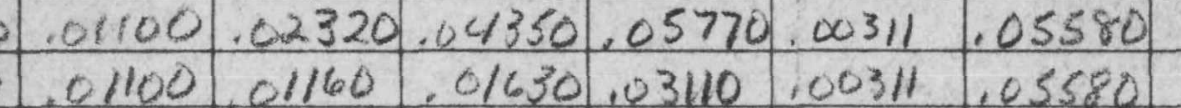

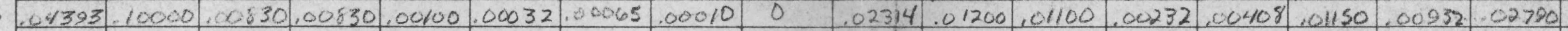

$.02314,01200,01100.00465 .00810 .02311,00932.04120$

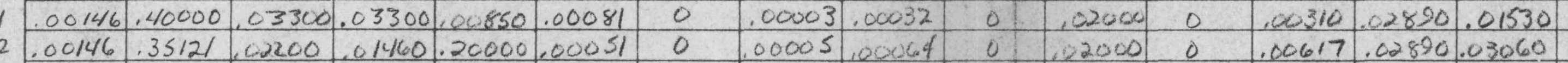

$.00146,37121.01100 \quad 01100 \quad 20000.00021$

.00146 .34121 .00550 .00550 .00850 .000210

\begin{tabular}{|llllllllll}
.00146 & 30000 & .01100 & .01100 & .00437 & .00051 & 0 & .00054 & .00642
\end{tabular}

$\begin{array}{lllllllll}.00146 & 30008 & .02200 & .02200 & .00220 & .00081 & 0\end{array}$

$.00146,30000.03300 .03900 .00073 .00172 \quad 0$

\begin{tabular}{|l|l|l|l|l|l|l|l|}
\hline .00146 & .30000 & .22000 & .06000 & .00220 .00345 & 0 \\
\hline
\end{tabular}

.00054 co6 42

0.102000 0

.00617 .02890 .03060

.0146. 30000 .05004.22000.00437.00172 0 .00005 20064

$\begin{array}{llllll}0 & .03341 & .00091 & .00076 & .00992 .00016 .00035 .00011\end{array}$

\begin{tabular}{c|c|c|c|c|c|c|}
\hline .00835 & 0 & .03200 & 03200 & .05620 & .00067 & 0 \\
\hline
\end{tabular}

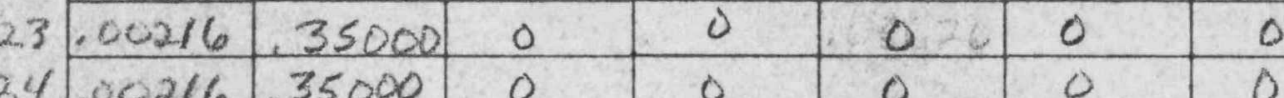

\begin{tabular}{rl|l|l|l}
.00016 & 35000 & 0 \\
.01325 & 29210 & 0
\end{tabular}

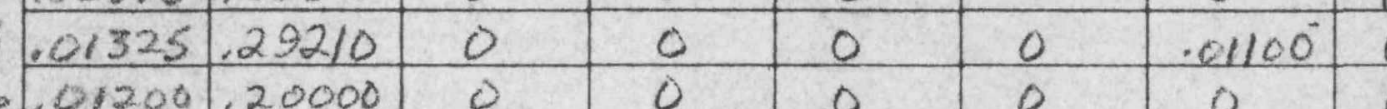

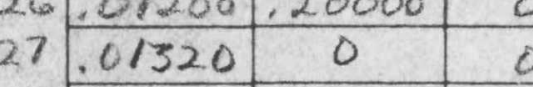

$2.8 .00100 \quad 0$

\begin{tabular}{l|l|l|l|}
29 & 0 & .25000 & 0
\end{tabular}

\begin{tabular}{l|l|l|l|l}
30 & 01045 & .04000 & 0
\end{tabular}

31.00171 .004440

\begin{tabular}{ll|l|l|l}
0 & 0 & 0 & 0 & 0
\end{tabular}

33.01320 .25500 .0

34 \begin{tabular}{l|l|l|}
.01320 & .25500 & .0 \\
\hline .03100 .07620 & .00772 \\
\hline
\end{tabular}

$\begin{array}{cccccc}0 & 0 & 0 & 0 & 0 \\ 0 & 30000 & 0 & 0 & 0\end{array}$

\begin{tabular}{|c|c|c|c|c|c|c|}
.01330 .20000 & 0 & 0 & 0 & 0 & 0 \\
\hline 0 & 0 & 0 & 0 & 0 & 0 & 0 \\
\hline 0 & 0 & 0 & 0 & 0 & 0 & 0 \\
\hline
\end{tabular}

$3 6 \longdiv { 1 0 }$ $\begin{array}{lll}0.00155 & .003862 .000055\end{array}$

02470.02840 .06120

.06180 .01440 .09800

.08650 o .00765

06180.014400

$.02470,028900$

.01230 .02890 .01530

.00627 .02890 .01530

.00730 .03200 .00790

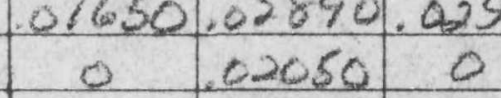

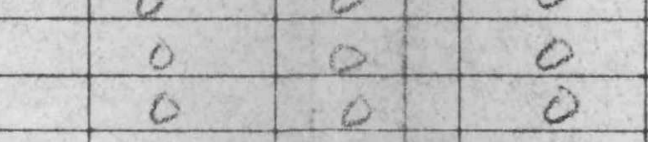

$0 \quad 0.02050 \quad 0$

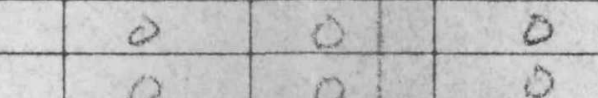

$\begin{array}{lll}0 & 0 & .00566\end{array}$

$\begin{array}{ll}0 & .00600 \\ 0 & .05000\end{array}$

$\begin{array}{cccccccc}0 & 0 & 0 & 0 & .25000 & 101000 & 0 \\ 0 & 0 & 0 & 0 & 25000 & 0 & 0 \\ 0 & 0 & 0 & 0 & 0 & .10005 & 0\end{array}$

$\begin{array}{cccccccc}0 & 0 & 0 & 0 & .25000 & 101000 & 0 \\ 0 & 0 & 0 & 0 & 25000 & 0 & 0 \\ 0 & 0 & 0 & 0 & 0 & .10005 & 0\end{array}$

0

\begin{tabular}{c|cc|c|ccc}
0 & 0 & 0 & 0 & 0 & 0 & .06060 \\
0 & 0 & 0 & 0 & 0 & 0 & .15000 \\
.00550 & .01300 & 0 & 0 & 0 & 0 & .00669
\end{tabular}

$\begin{array}{ll}5 & 0 \\ 0 & 0\end{array}$

.00009

$\begin{array}{cc}0 & 0 \\ .019+10 & .00276\end{array}$ 0

.01

50.08560 .07670

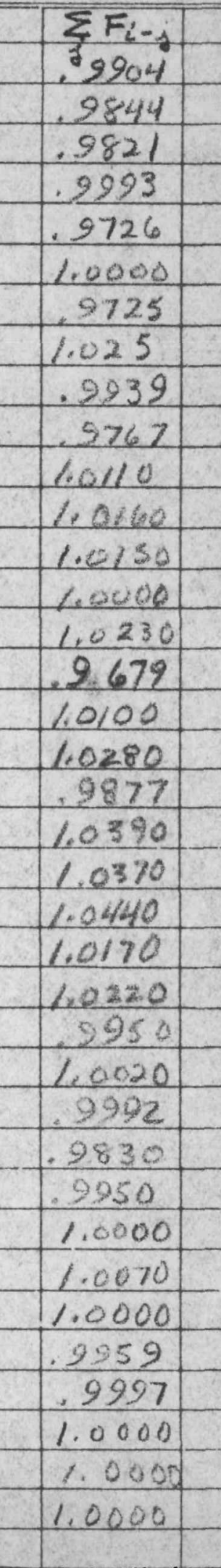

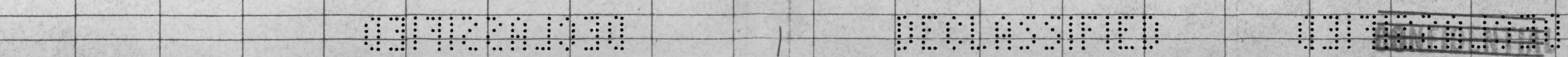


$F_{i j} i$

\begin{tabular}{|c|c|c|}
\hline PREPAREDBY J, BICKEL & $\begin{array}{l}\text { ATOMICS INTERNATIONAL } \\
\text { A DIVISION OF NORTH AMERICAN AVIATION. INC }\end{array}$ & PAGENO 77 of 114 \\
\hline CAECKED OY & INTER CWANGE FACTORS & $\begin{array}{c}\text { NAA-SR-TDR } 9004 \\
\text { REPORT NO. }\end{array}$ \\
\hline DATE, $7 / 10 / 63$ & TABLE $\overline{V L}$ & MODE \\
\hline
\end{tabular}

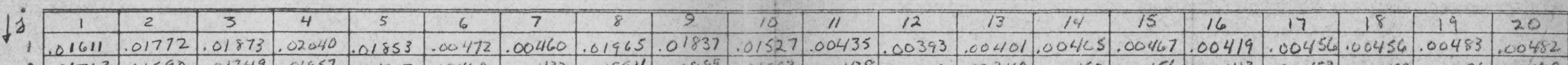

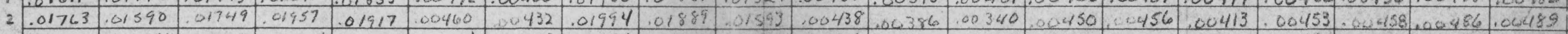

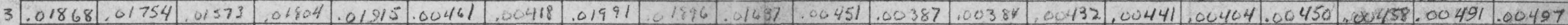

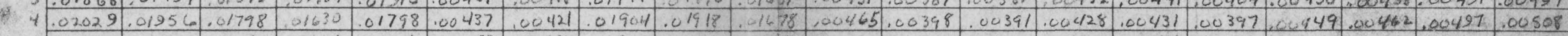

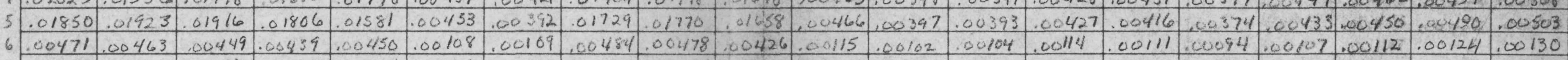

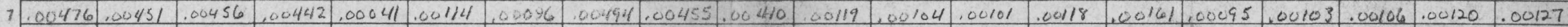

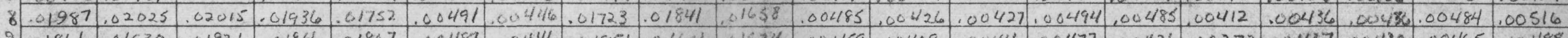

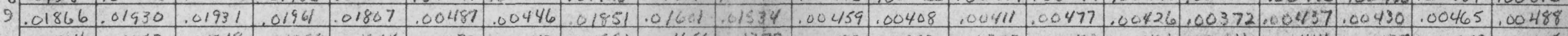

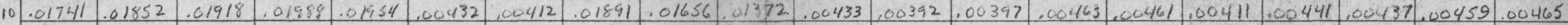

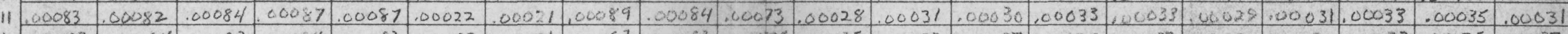

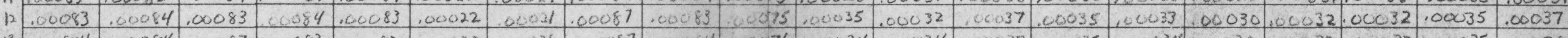

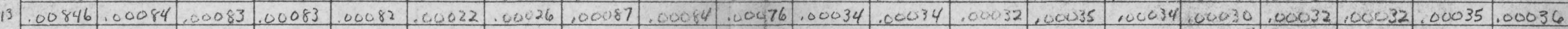

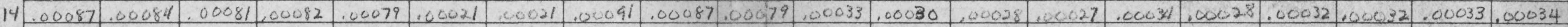

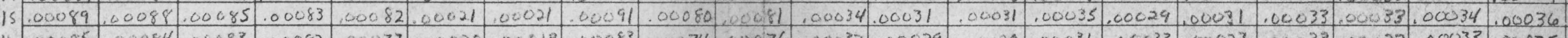

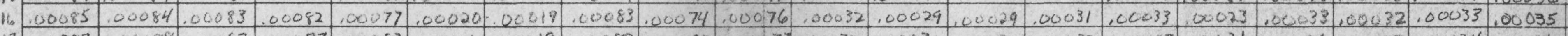

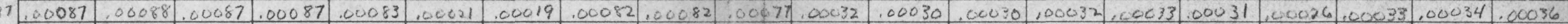

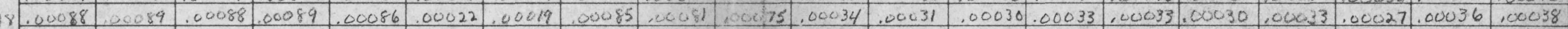

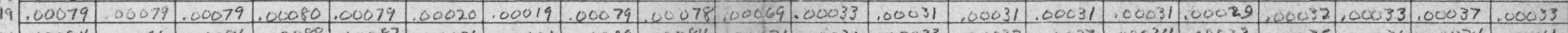

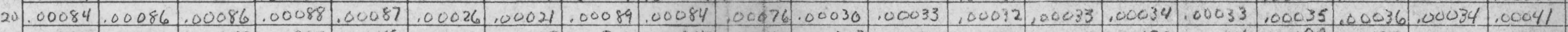

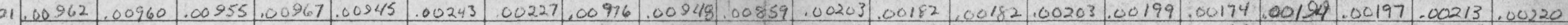

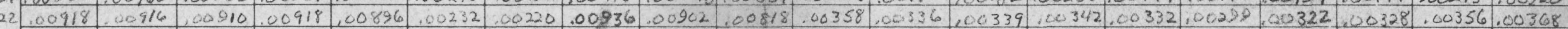

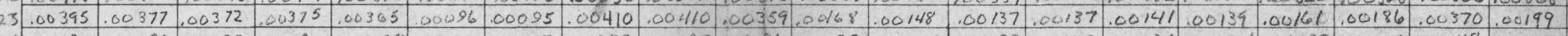

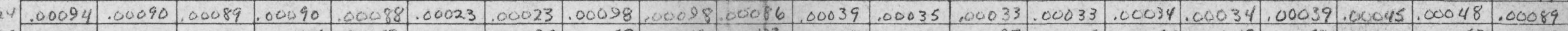

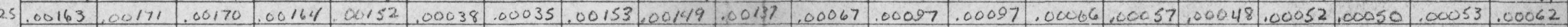

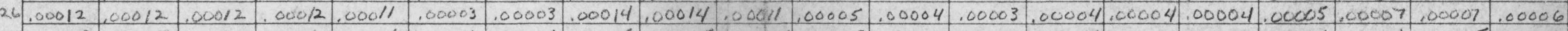

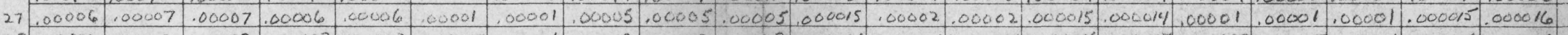
$28, .00002,00002,00002,00002, .00003,000007,0000006,00002,00002,000002,000006.000005, .000005,000006,000007, .000008,0000007,0000006,0000006,0000066$

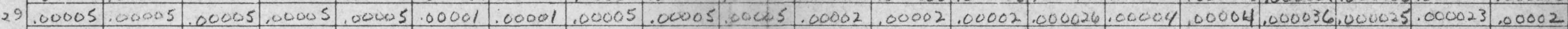

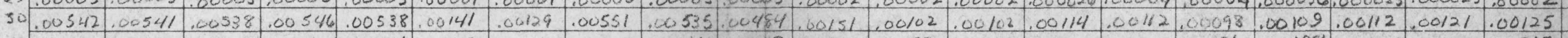

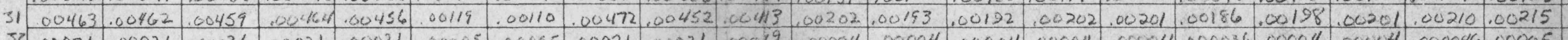

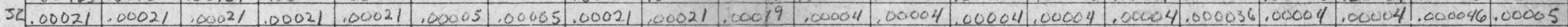

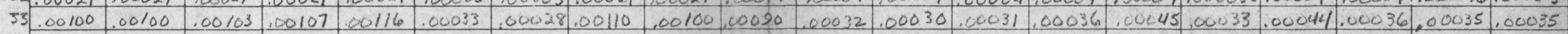

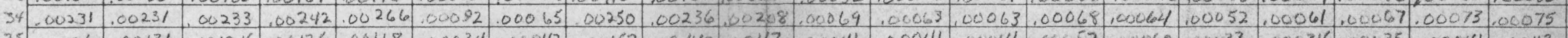

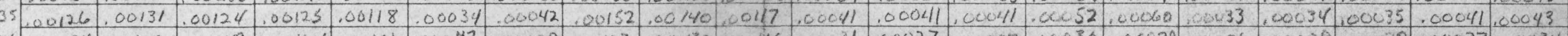

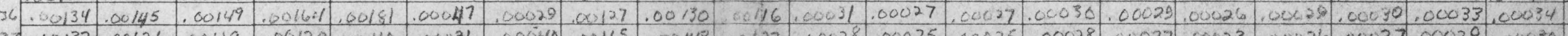

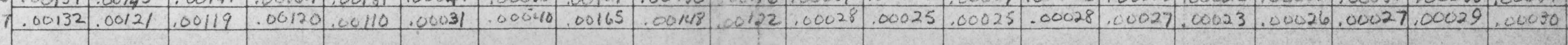

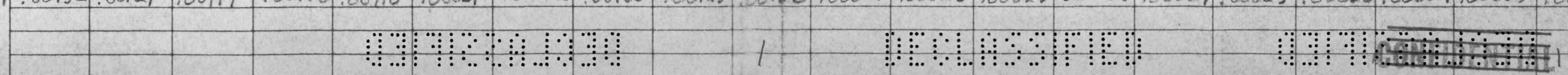




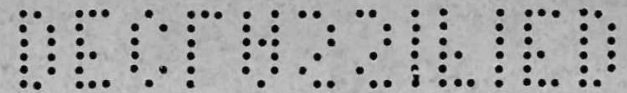

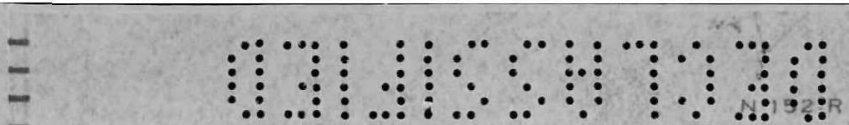

\begin{tabular}{|c|c|c|}
\hline PREAARE QY D. BKKKEL & $\begin{array}{l}\text { ATOMICS INTERNATIONAL } \\
\text { A DIVISION OF NORTH AMERICAN AVIATION INC. } \\
\text { YIËW FAC TORS }\end{array}$ & $\begin{array}{l}\text { PACENO } 78 \text { of } 214 \\
\text { NAA-SR-TDR } 9004\end{array}$ \\
\hline Date $7 / 1 / 163$ & TABLE पI (CONTINUED) & \\
\hline
\end{tabular}

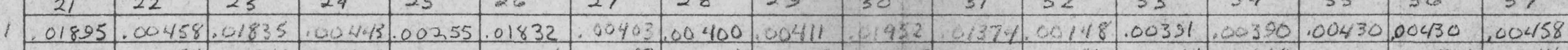

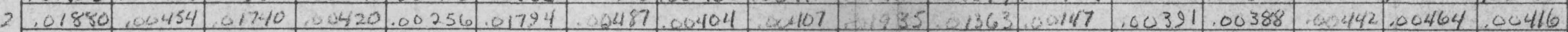

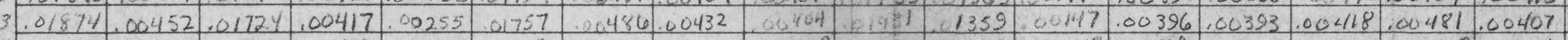

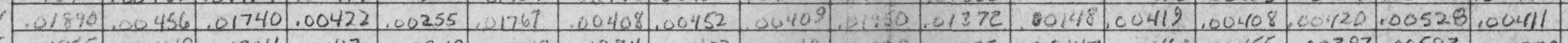

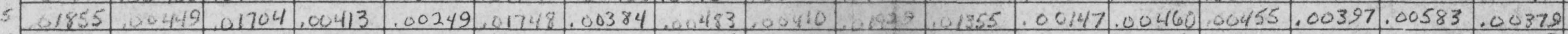

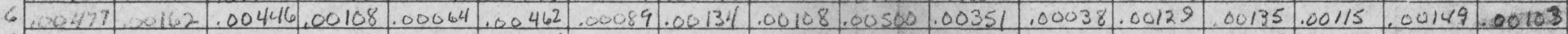

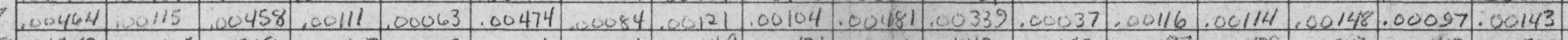

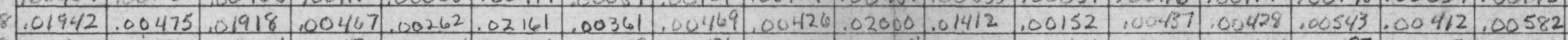
$.01900 \quad .00460 .01934,00470.00254 .02104,00358,00436,000400,01958, .01373,00149.00398, .00404 \quad .00483,00425, .00521$

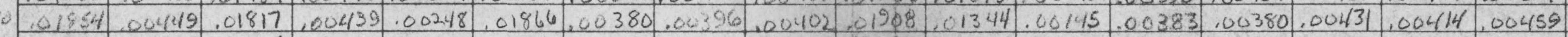

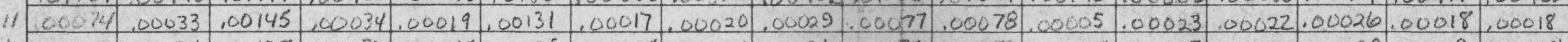

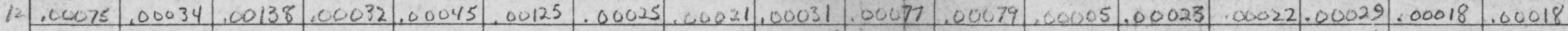
$13, .00075 .00034,00127,00031.00045,00116 \quad .00025,00021.00034,00077.00079 \quad 00006,00025.00022,00029.00018 \quad .00018$

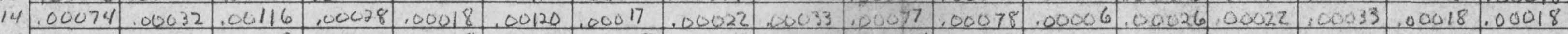

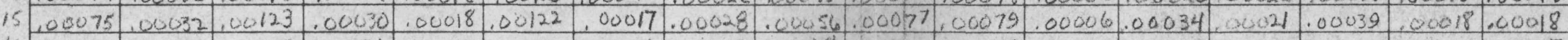

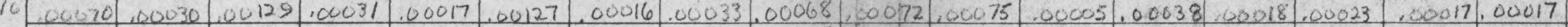

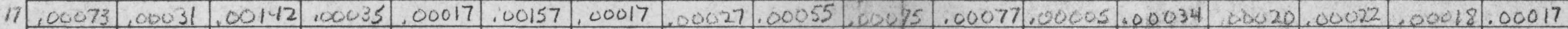

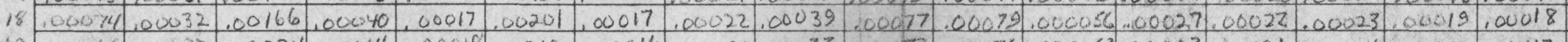

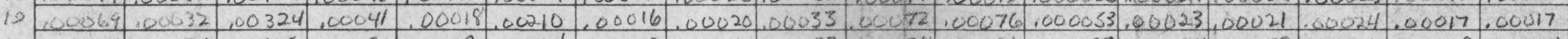

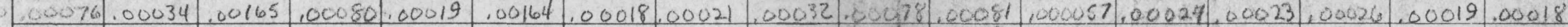

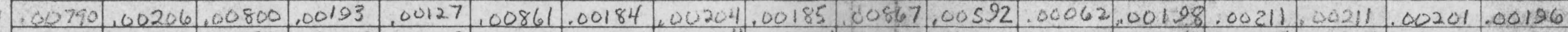

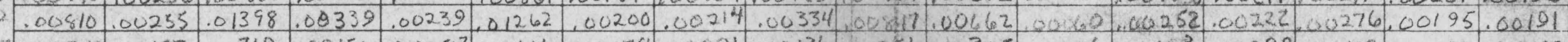

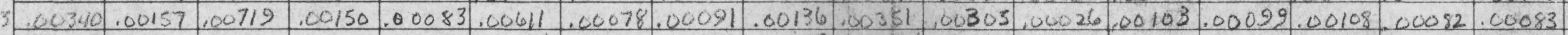
$24.00081 .00037,00147,00042.00020 .00138, .0049,00022,00032.00084, .00072 .00006,00025.00024 .00026,00020.00020$

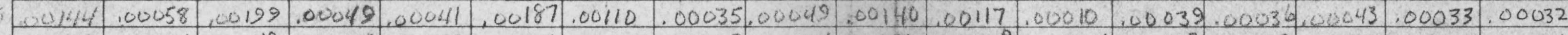

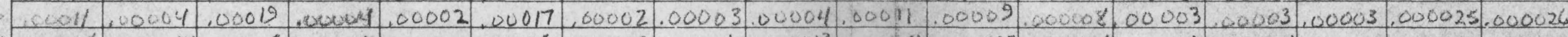

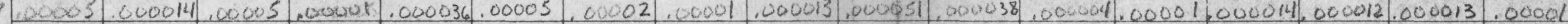
$0,02002,000006,00002,000005,000003.00002 .000004,000009,000009.00002 .000016 .000002,00002.000005 .000006 .000006 .000005$

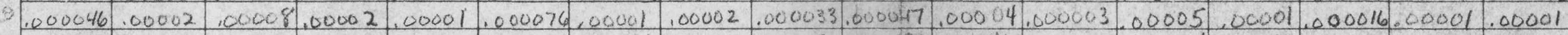

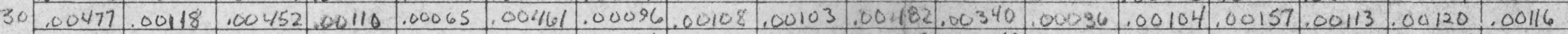
$31.00398 .00134,00005.00147 .00088 .00584 .00091 .00109 .00152 .00415 .00355,00031, .00118 .00130 .00121,00101.00099$

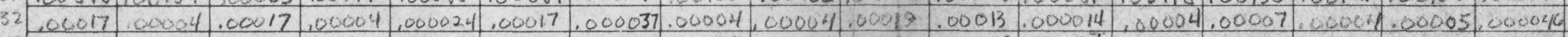

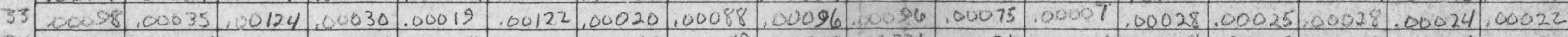

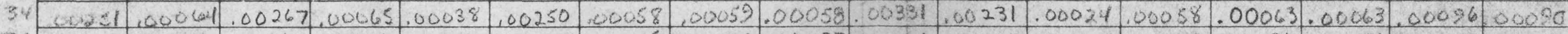

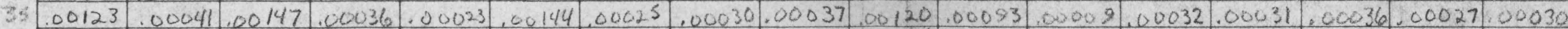

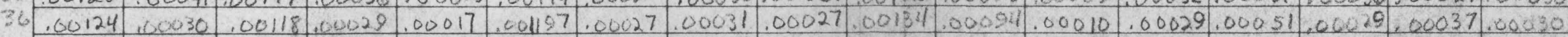

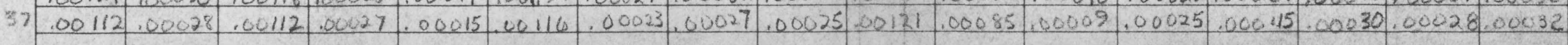

\begin{tabular}{|c|c|c|}
\hline \\
\hline & & \\
\hline & & \\
\hline & & \\
\hline & & \\
\hline & & \\
\hline & & \\
\hline & & \\
\hline & & \\
\hline & & \\
\hline & & \\
\hline & & 1 \\
\hline & & \\
\hline & & \\
\hline & & \\
\hline & & + \\
\hline & & \\
\hline & & \\
\hline & & \\
\hline & & \\
\hline & 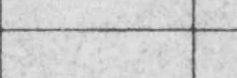 & - \\
\hline & & \\
\hline & & \\
\hline & & \\
\hline & & \\
\hline & & \\
\hline & & \\
\hline & & 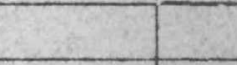 \\
\hline & & 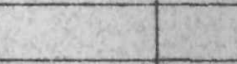 \\
\hline & 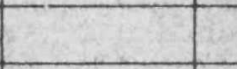 & 1 \\
\hline & 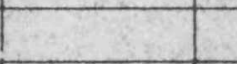 & 5 \\
\hline & & 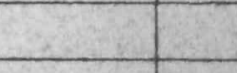 \\
\hline & & \\
\hline & & \\
\hline & & 1 \\
\hline & 1 & 8 \\
\hline अं: & 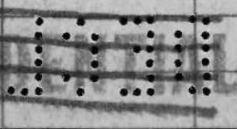 & 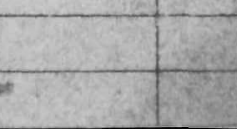 \\
\hline
\end{tabular}


ATOMICS INTERNATIONAL

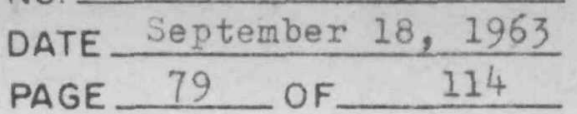

A Division of North American Aviation, Inc.

VII. APPENDIX

A. Interchange Factors

For black bodies,

$$
q_{a-b}=A_{a} F_{a-b}\left(t_{a}^{4}-t_{b}^{4}\right)
$$

where $F_{\text {alb }}$ represents the direct viewfactor from node a to node b. For gray body interchange, the inter-reflections within the system must be considered as well as the direct radiation. This is accomplished by writing an analogous gray body equation of the form

$$
a_{a-b}=A_{a} F_{a-b}\left(t_{a}^{4}-t_{b}^{4}\right)
$$

where the factor if called the overall interchange. factor, is introduced to account for the grayness of the source-sink temperatures. This factor is a function of the geometry (viewfactors) and emissivity or grayness of the surfaces.

Before the solution of this method could be accomplished, it was necessary to determine the viewfactors between all the components included in this analysis. The viewfactors between the $R / C$ nodes, radiation shield, and thermal barrier for the geometry shown in Figure 2 were obtained by utilizing a computer program written for determining the direct viewfactors (Referonce 5). This program only applies to flat surfaces and could not be used to obtain the viewfactors for the components. These viewfactors were calculated whenever possible; however, in most cases, estimations based on the results obtained from the above computer program were made. After determining the viewfactor between a $R / C$ node and a component, the reciprocal law

$$
A_{1} F_{1-2}=A_{2} F_{2-1}
$$

was used to obtain this viewfactor in the opposite direction.

From the resulting viewfactors and by knowing the emissivity of each node, the overall interchange factors between nodes were obtained by utilizing an existing interchange factor code (Reference 6). This program in addition to calculating the interchange factors gives the $\Sigma F$, and $Z F_{\text {, so }}$ so that the resuits may be easily checked. The values of the interchange factors for Case I are listed in Table 6 . These values were included since they provide a means by which the validity of the results contained herein may be checked. 
Although estimations were used in many cases for determining the viewfactors, two checks were used to minimize each viewfactor used in this analysis are given in Table 5.

\section{B. Mean R/C Radiating Temperature}

The mean radiating temperature of the $R / C$ was calculated by writing the heat balance between some node $i$ and the $\mathrm{R} / \mathrm{C}$ nodes $j$, or

$$
\sigma \varepsilon_{i} A_{i}\left[t_{i}^{4}-t_{R C}{ }^{4}\right]=\sigma A_{i} \sum_{j} \widetilde{F}_{i-j}\left(t_{i}{ }^{4}-t_{j}{ }^{4}\right)
$$

where $t_{R C}$ is the mean radiating $R / C$ temperature. Therefore,

$$
\varepsilon_{i} t_{i}^{4}-\varepsilon_{i}{ }^{{ }^{t} R C}{ }^{4}=t_{i}{ }^{4} \sum_{j} \mathcal{F}_{i-j}-\sum_{j} F_{i-j} t_{j}^{4}
$$

Making the approximation that

$$
\begin{aligned}
\varepsilon_{i} & =z_{j} \mathscr{F}_{i-j} \\
t_{\mathrm{RC}} & =\left[\frac{t_{i}^{4} \sum_{j} \mathcal{F}_{i-j}}{\sum_{j} F_{i-j}}\right]^{1 / 4}
\end{aligned}
$$

where $j$ represents only the $R / C$ nodes.

The utility of this calculation is that it gives the capability to compute the radiation heat transfer rates between an enclosed object (source). The only (sink) and anis calculation is the same which was made in the derivation of the mean temperature, namely, $\varepsilon_{i}=\sum_{j} \gamma_{i-j}$

\section{Mean R/C Temperature}

The mean temperature of the $R / C$ was detemined by

$$
i=1
$$


ATOMICS INTERNATIONAL

A Division of North American Aviation, Ine.

OF 114

and represents the true average used (at injection) to compute the required amount of mercury inventory for $\mathrm{R} / \mathrm{C}$ preheat.

\section{Program Description}

A program to solve equations defined herein has been written for the IBM 7094 in the Fortran System.

With an increment of one minute, it operates at a rate of approximately three revolutions or five hours per minute of machine time. Words output is $\leqslant 15$ per revolution or $\leqslant 10$ per hour depending on the number of nodes being taken into account.

Following is a description of pre-data input information necessary, the input data itself, sample data sheets, printed output, and CRT plots.

\section{Data Preparation}

It is essential to the correct running of the program that the node data be entered in proper sequence. It is, therefore, suggested that the user write out his sequence according to the format below before attempting to prepare the data sheets. A sample node sequence follows the format.

$\begin{array}{ll}\text { Node } & \text { Component } \\ 1-10 & \text { R/C nodes } \\ 11-20 & \text { Sub-cooler nodes } \\ 21 & \text { Top } \\ 22 & \text { Bottom } \\ \text { - } & \text { Internal components } \\ \text { - } & \text { NaK nodes } \\ \text { - } & \quad \text { - } \\ \text { XX } & \text { Injection tank storage } \\ & \text { CRU housing } \\ & \text { CRU shaft } \\ & \text { Bracket I - first component } \\ & \end{array}$



OF

Bracket 2 - first component bracketed

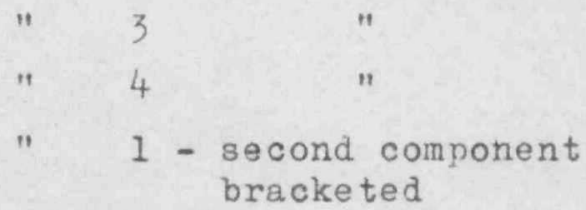

Nodes $1-22$ are always in the same order. The number of radiating internal nodes may be added to, rearranged, etc., but must always follow the bottom (22) node. All internal components classified as NaK nodes must be together and be the last of the internal components listed. This order also applies when preparing data sheets for the interchange factor code by M. P. Berhold. Punched output from the program is used as input to this code. The number of nodes at this point is the total which requires the interchange factor data.

Immediately below the $\mathrm{NaK}$ nodes are the injection storage tank, CRU housing, and CRU shaft followed by the bracket nodes (4) for each component attached to the wall.

$\begin{array}{ll}\text { Sample Case }^{*} \\ \text { 1-10 } & \text { R/C nodes } \\ 11-20 & \text { Sub-cooler nodes } \\ 21 & \text { Radiation shield (top) } \\ 22 & \text { Botton node (top of thermal barrier) } \\ 23 & \mathrm{~N}_{2} \text { tank } \\ 24 & \mathrm{Hg} \text { injection storage tank } \\ 25 & \mathrm{Hg} \text { regulator tank } \\ 26 & \text { Injection line } \\ 27 & \mathrm{Hg} \text { regulator line }\end{array}$

* Node sequence defined here applies to sample data sheets attached. 


\section{ATOMICS INTERNATIONAL}

A Division of North American Aviation, Inc.
DATE September 18, 1963

PAGE 83 OF_ 114

Sample Case (cont'd)

28

CRU exposed bearing line (directly exposed to $\mathrm{NaK}$ loop nodes)

$C R U$ unexposed bearing line

30

Upper vapor riser

31

Lower vapor riser

32

$\mathrm{Hg}$ turbine feed line

33

CRU outer shell

34

Boiler

35

NaK expansion compensator

Hot NaK line

Cold NaK line

38

$\mathrm{Hg}$ injection storage tank

39

CRU housing

40

CRU shaft

41

Hg regulator bracket

42

43

44

45

46

47

48

49

50

51

52

CRU bracket

"

II

"

$\mathrm{Hg}$ injection tank bracket

\section{"}

"

"1

"

" 


\section{ATOMICS INTERNATIONAL}

A Division of North American Aviation, Inc.

DATE September 18, 1963

PAGE $\quad 84$ OF_ 114

Secondly, and prior to filling out the data sheets, if plotting is desired, the user should decide which nodes (by number) are to put on each graph. A maximum of 14 nodes may be plotted in any manner, i.e., all one graph, one per graph, two, three, etc. A sample plot setup is shown below and applies to the case used which is attached.

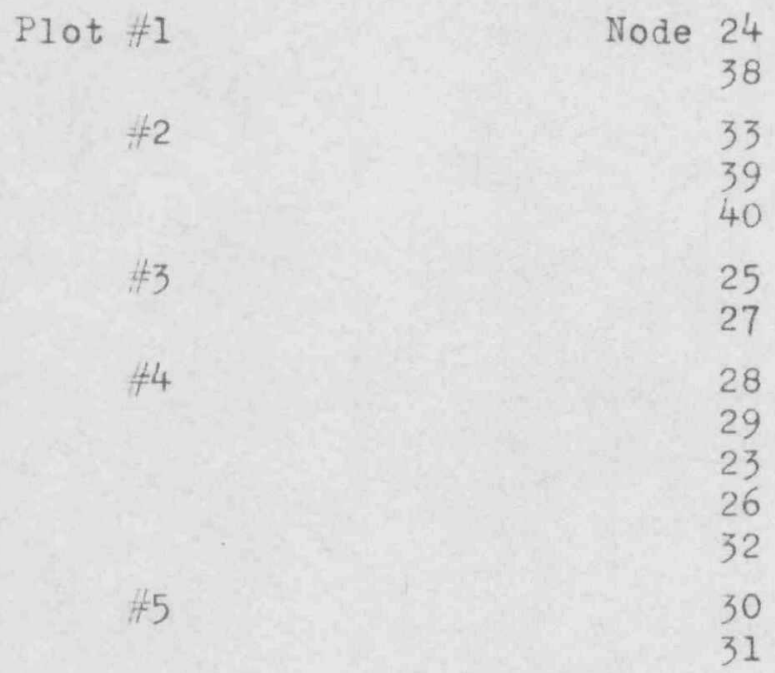

In preparing the data in the IP array, enter a zero for nodes not to be plotted and enter the plot number for those to be plotted. A single node may be placed on one graph only.

For each case, the input data consists of two parts:

1. A title card containing up to 72 alphanumeric characters describing the case.

2. The decimal case data. The program uses the FORTRAN DECRD routine. Each piece of data has an index assigned to it from an array (defined on following pages). The index of the first piece of data on a card is entered to the far right of the first field (using FORTRAN FIXED 10 DIGIT DECIMAL DATA SHEETS). Data are then entered in numerical order by index filling the card. The last card of data in each case must contain a minus in column one.

If the user wishes to run more than one case at a time, it is necessary to have the title card and at least one data card. The user needs only to enter the data that is changing from the previous case. Sample data sheets are attached. 


\section{ATOMICS INTERNATIONAL}

A Division of North American Aviation, Inc.
NO.

DATE September 18, 1963

PAGE $\quad 85$ OF_ 114 \begin{tabular}{lll} 
Numerical & Equation (eq \#) & Program \\
Data Index & Symbol & Symbol \\
\hline
\end{tabular}

1

2

3

4

5

6

7

8

\section{IDORT}

ISORCS

NPASS

NIN

NAKN

IPLOT

NAVGT

INIT

\section{Description}

$=0$, data entered, printed, and plotted as a function of time; $=1$, data as a function of revolution

$=0$, sun-shade orbit; $=1$, constant sun-constant shade orbit

if IDORT $=0$, enter time in even number of hours at end of case; if IDORT $=1$, enter even number of revolutions at end of case

number of internal components which have radiation term requiring interchange factor code data plus top and bottom

number of $\mathrm{NaK}$ components $(\leqslant 10)$

$=0$, no CRT plotting will be done (all data below applicable to plotting need not be entered); $=1$, CRT plotting is desired

node number assigned to component being used as reference node in computing $R$. C average temperature

$=0$, initial temperatures of components are all equal except top; $=1$, initial temperatures vary for some or all components; $=2$, program will pick up last values of previous case (this option allows the user to split the CRT plots of the nodes if desired, this is the only purpose of the option and 


\section{ATOMICS INTERNATIONAL}

A Division of North American Aviation, Inc.
NO.

DATE September 18, 1963

PAGE 86 OF_ 114 \begin{tabular}{lll} 
Numerical Equation $(\mathrm{eq} *)$ & Program \\
Data Index & Symbol & Symbol \\
\hline
\end{tabular}

9

NPLOT

10

NCON2

11

12

13

14

15

16

17

18
INJ

ICRU

ICON

blank

blank

$\operatorname{IBRAC}(1,1)$

$\operatorname{IBRAC}(2,1)$

$\operatorname{IBRAC}(3,1)$

\section{Description}

it is suggested it not be used otherwise as it requires extra computer time)

enter even number of hours or revolution (depending on IDORT) to begin the continuous plots of node temperatures

$=0$, CRU outer shell and injection tank storage are constant; $=1$, CRU constant, injection tank storage varies; $=2$, CRU varies, injection tank storage constant; $=3$, both vary

node number assigned to injection tank

node number assigned to CRU

number of nodes attached to the $\mathrm{R} / \mathrm{C}(\leqslant 5)$

node number assigned to first node bracketed to the $\mathrm{R} / \mathrm{C}$

node number assigned to upper section of $\mathrm{R} / \mathrm{C}$ which component conducts heat to

node number assigned to section of sub-cooler to which component conducts heat 
ATOMICS INTERNATIONAL

A Division of North American Aviation, Ine.
DATE September 18, 196.3

PAGE 87 OF 114
Numerical Equation (eq \#) Program Data Sheet Symbol

19

30

31

32

$\operatorname{IP}(2)$

$\operatorname{IBRAC}(3,5)$

$\operatorname{IP}(I)$

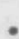

$\operatorname{IP}(60)$

91

$92(\mathrm{mc})_{i}(15)$
DTIME

$\operatorname{AMCRC}(1)$

\section{Description}

same as $\operatorname{IBRAC}(1,1)$ for second bracketed node

$=0$, do not plot node I;

$=$ X, plot on graph X

$=0$, do not plot node 2; $=X$, plot on graph X

(note: a limit of 14 nodes plus the mean temperature will be plotted for each case, thus there should be entered $\leq 14$ values of IP array $\geq 1$ )

time increment for calculations in minutes

product of mass and specific heat for $\mathrm{R} / \mathrm{C}$ nodes

nodes 


\section{ATOMICS INTERNATIONAL}

A Division of North American Aviation, Inc.
DATE September 18, 1963

PAGE $\quad 88$ OF 114
Numerical Equation (eq \#) Program Data Index Symbol Symbol

93 (mc) ${ }_{i+10}^{(16)}$ Symbol $\operatorname{AMCRC}(2)$ $\operatorname{AK}(1)$ $94 \quad * \mathrm{KA}_{1}(15)$ $95 \quad * \mathrm{KA}_{3}(16)$

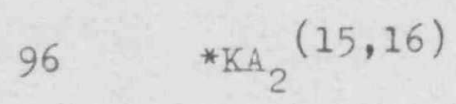
$\operatorname{AK}(3)$

97

98

99

$$
s^{(15,16)}
$$

$\operatorname{ALPHAS}(1)$

$\operatorname{ALPHAS}(2)$

EPSI

100

$$
(15,16)
$$
$\mathrm{s}$

$$
\underbrace{}_{\left(\epsilon_{T}\right)}(15,16)
$$

101

TOR

\section{Description}

product of mass and specific heat for subcooler nodes

product of heat transfer coefficient and crosssectional area for $\mathrm{R} / \mathrm{C}$ nodes

sub-cooler nodes

$R / C$ and sub-cooler nodes vertically

absorptivity to solar radiation: for $\mathrm{R} / \mathrm{C}$ nodes

for subcooler nodes

absorptivity to thermal radiation (emissivity of outside area)

angle of launch in relation to sun if the sunshade orbit is being considered $\left(0^{\circ}\right.$ is directly into sun, $0^{\circ}+$ to $180^{\circ}$ is moving away from the sun, and $180^{\circ}+$ to $360^{\circ}$ is approaching sun)

frequency of $R / C$ and $s u b-$ cooler profile plots (enter in minutes or fractions of revolutions depending on IDORT)

* the $X$ shown in equations is constant and therefore built into the code 
ATOMICS INTERNATIONAL

A Division of North American Aviation, Inc. nit

PAGE
September 18, 1963 OF

\begin{tabular}{lll} 
Numerical & Equation (eq \#) \\
Pata Index & Symbol & Symbol \\
\hline
\end{tabular}

102

TRAMI

103

TRAM2

104

TRAM3

105

TRAM4

106

TRAM5

107

108

CUT

TSLOPE

\section{Description}

note: plot will be done every TOR minutes or revolutions - value has been set on test case such that one set of profiles before temperature ramp is given and in second case following the ramp (second case is continuation of first, see data sheets

time in minutes at which the NaK nodes temperatures are raised by constant specified in array below*

time at which temperature ramp of NaK nodes begins enter in minutes*

time in minutes when temperature ramp of $\mathrm{NaK}$ nodes ends and temperatures become constent again*

startup time of temperature ramp for the top of the $\mathrm{R} / \mathrm{C}$ given in minutes*

termination time for ramp of top in minutes*

rate of increase of top during ramp period - enter in $\mathrm{btu} / \mathrm{hour}$

time in minutes to stop plotting ( time at end of case)

\footnotetext{
* in figuring time, use 107 minutes

(see sample data case)
} 


\section{ATOMICS INTERNATIONAL}

A Division of North American Aviation, Inc.
DATE September 18, 1963

PAGE 20 OF_ 114

$\begin{array}{cll}\begin{array}{l}\text { Numerical } \\ \text { Data Index }\end{array} & \begin{array}{l}\text { Equation }(\text { eq \#) } \\ \text { Symbol }\end{array} & \begin{array}{l}\text { Program } \\ \text { Symbol }\end{array} \\ 111(\mathrm{mc})_{i}(18) & \operatorname{AMC}(1) \\ & (\mathrm{mc})_{i}(18) & \operatorname{AMC}(2)\end{array}$

$(m c)_{i}(24)$

$\operatorname{AMC}(\mathrm{XX})$

$(\mathrm{mc})_{i}(21)$

$(m c)_{i}^{(22)}$

$(\mathrm{mc})_{i}^{(26)}$

$(\mathrm{mc})_{i}(27)$

(mc) ${ }_{i}(28)$

$(m c){ }_{i}(29)$

\section{Description}

product of mass and specific heat for bottom node (node 22)

product of mass and specific heat for first internal node specified (node 23)

Enter in order of nodes user has specified, the mc of each internal node except NaK nodes. Then immediately following the mc of the last internal node, in the same array, enter data as follows:

product of mass and specific heat for injection storage tank

product of mass and specific heat: for CRU housing:

for CRU shaft

for first node of bracket of first component which is attached to $R / C$ (see Figure 6)

for second node of bracket of first component which is attached to $\mathrm{R} / \mathrm{C}$

for third...

for fourth....

for first node of bracket of second component which is attached to $\mathrm{R} / \mathrm{C}$ 


\section{ATOMICS INTERNATIONAL}

A Division of North American Aviation, Inc. OF 114

$\begin{array}{ccc}\begin{array}{l}\text { Numerical } \\ \text { Data Index }\end{array} & \begin{array}{l}\text { Equation } \\ \text { Symbol }\end{array} & \begin{array}{c}\text { Program } \\ \text { Symbol }\end{array} \\ 140 & \left(\mathrm{mc}_{i}\right. & \cdot \\ 141 & \mathrm{~A}_{i}(18) & \text { AMC (30) } \\ 142 & \mathrm{~A}_{i}(18) & \text { AREA(1) }\end{array}$

170

$$
\begin{aligned}
& (E A)_{12}^{(23,24)} \text { AREA }(X X) \\
& (E A)_{12}(20,21) \\
& (E A)_{23^{(21,22)}}
\end{aligned}
$$

$\operatorname{AREA}(30)$

171

$Q^{(18)}$

\section{Description}

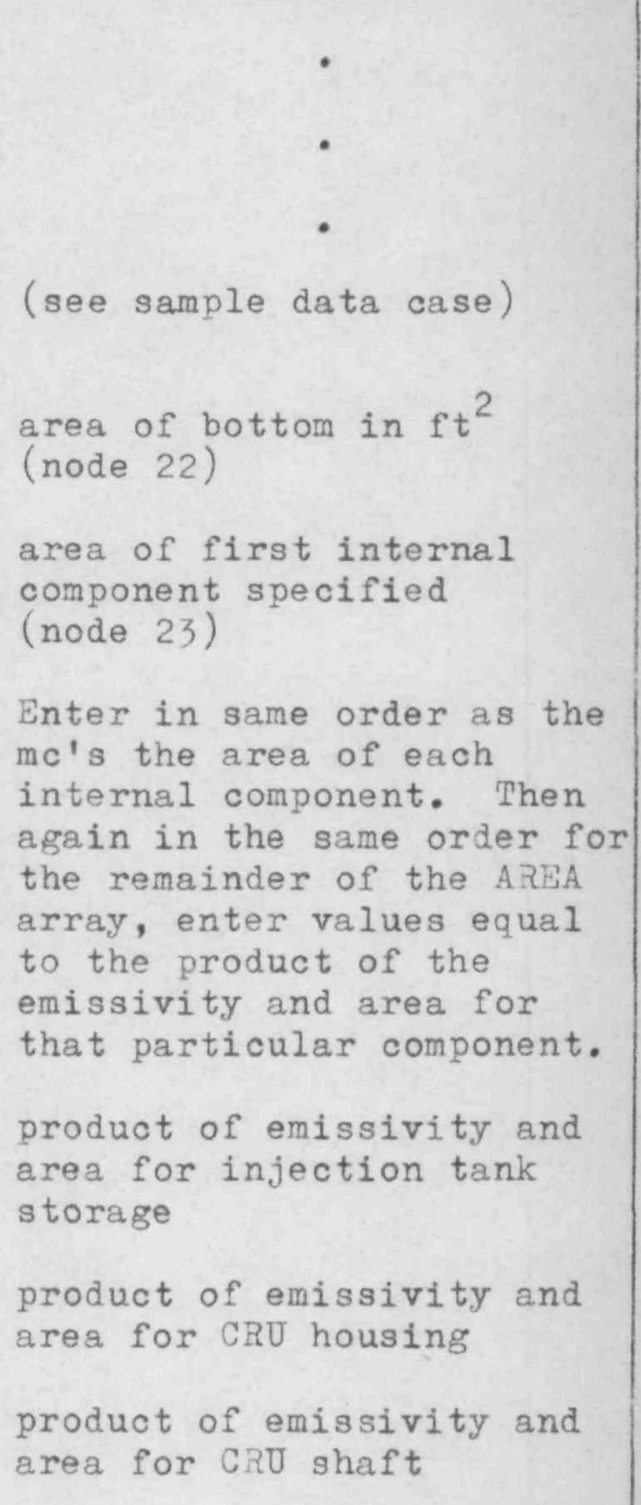

product of emissivity and area for CRU shaft 


\section{ATOMICS INTERNATIONAL}

A Division of North American Aviation, Inc.
DATE September 18, 1963

PAGE 92 OF 114
Numerical Equation (eq \#) Program Data Index Symbol Symbol

172

$\mathrm{QCON}(2)$

173

$2 \operatorname{con}(3)$

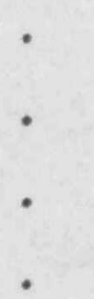

200

$$
\text { 201-2701 } F_{i j}(15,16,18)
$$

2701
FSCRIP

QCON $(30)$ PSenIP

$\mathrm{TI}(1)$

$T I(2)$

\section{Description}

heat being added to first internal component in $\mathrm{btu} / \mathrm{hr}$ if necessary to prevent freezing

heat being added to second...

heat being added to last internal component exclusive of $\mathrm{NaK}$ nodes

these values are punched directly from interchange factor code in proper format (see deck setup)

if $\operatorname{INIT}=0$, TI( 1 ) equals initial temperature of all components except the top; if $I N I T=1$, TI(1) equals initial temperature of first node; if INIT $=2$, the TI array need not be entered at all

if $\operatorname{INIT}=0, T I(2)$ equals initial temperature of the top; if INIT=1, TI(2) equals initial temperature of node 2 .

remainder of array needs to be entered only if INIT $=1$ 
ATOMICS INTERNATIONAL

A Division of North American Aviation, Inc.
Numerical Equation (eq \#) Data Index Symbol
Program Symbol $\mathrm{TI}(3)$ $\operatorname{TI}(60)$
2761

2762

2770

2771

2780

2781

2760

2761

(2771

2781

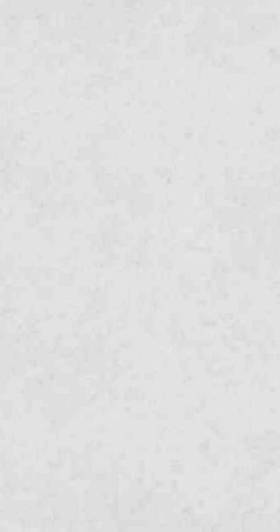

DATE September 18, 1963

PAGE $\quad 93$ OF $\quad 114$ 


\section{ATOMICS INTERNATIONAL}

A Division of North American Aviation, Inc.
DATE September 18, 1963

PAGE $94 \quad$ OF_ 114

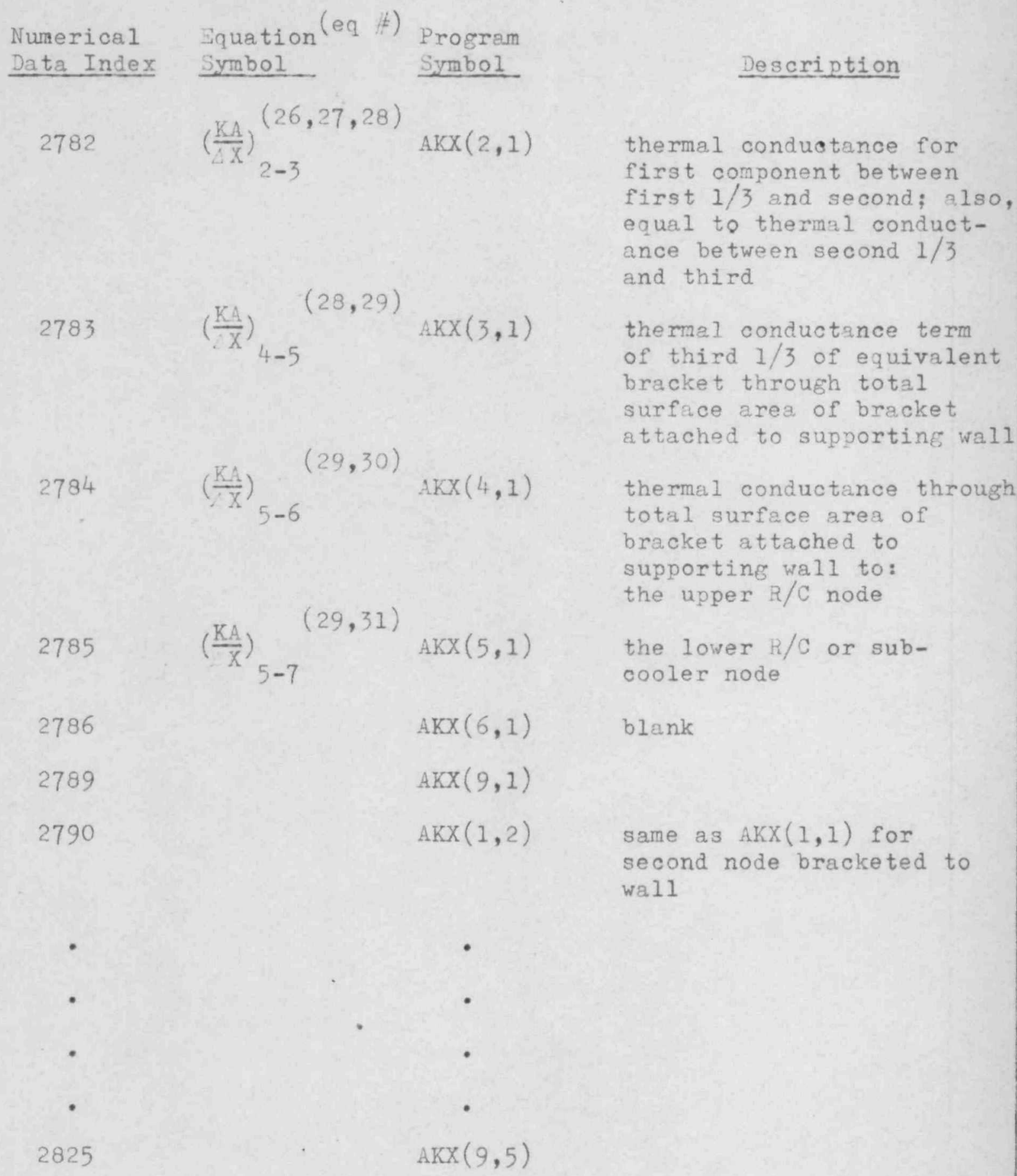




\section{Desk Setup}

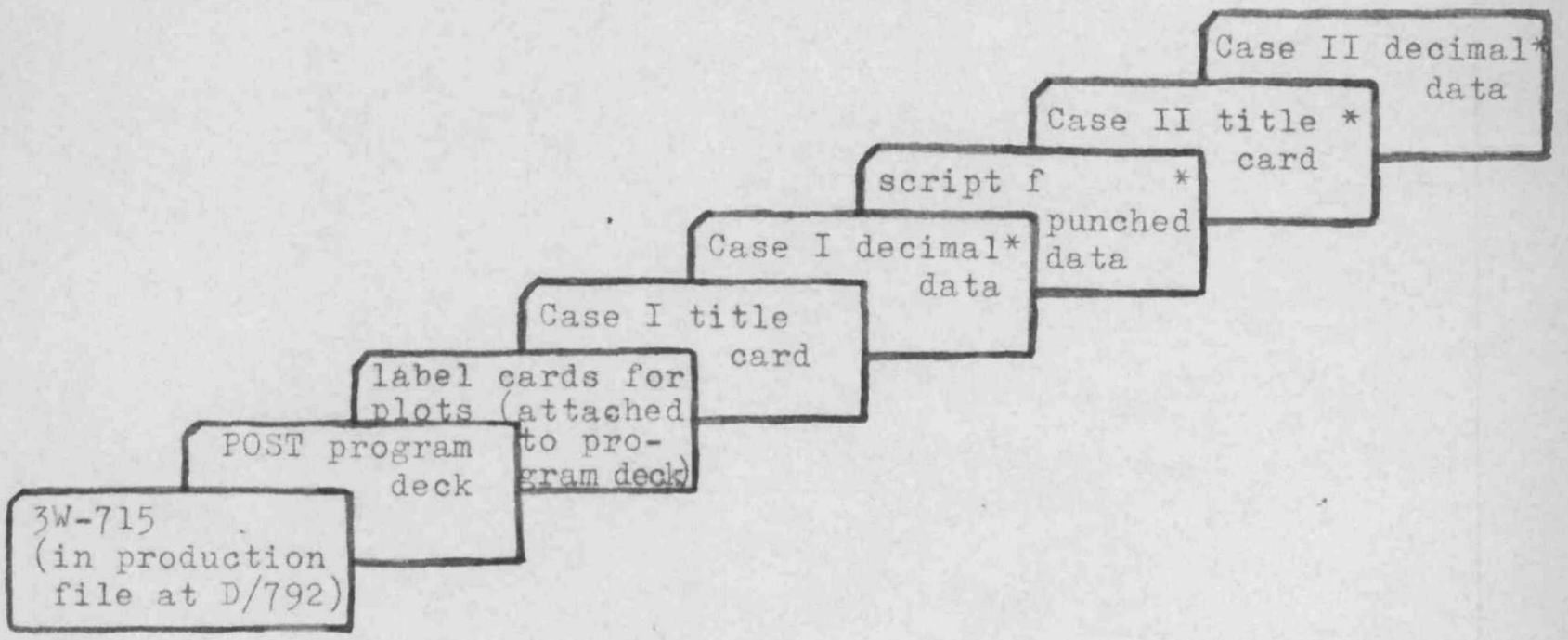

*The script $f$ data has a minus in column one of the last card. Therefore, the user does not need one for the first case and must allow for the script $f$ data deck to follow his decimal data. 
FORTRAN FIXED 10 DIGIT DECIMAL DATA

DECK NO. PASE I PROGRAMMER DATE

PAGE 1 of 10 JOB NO.

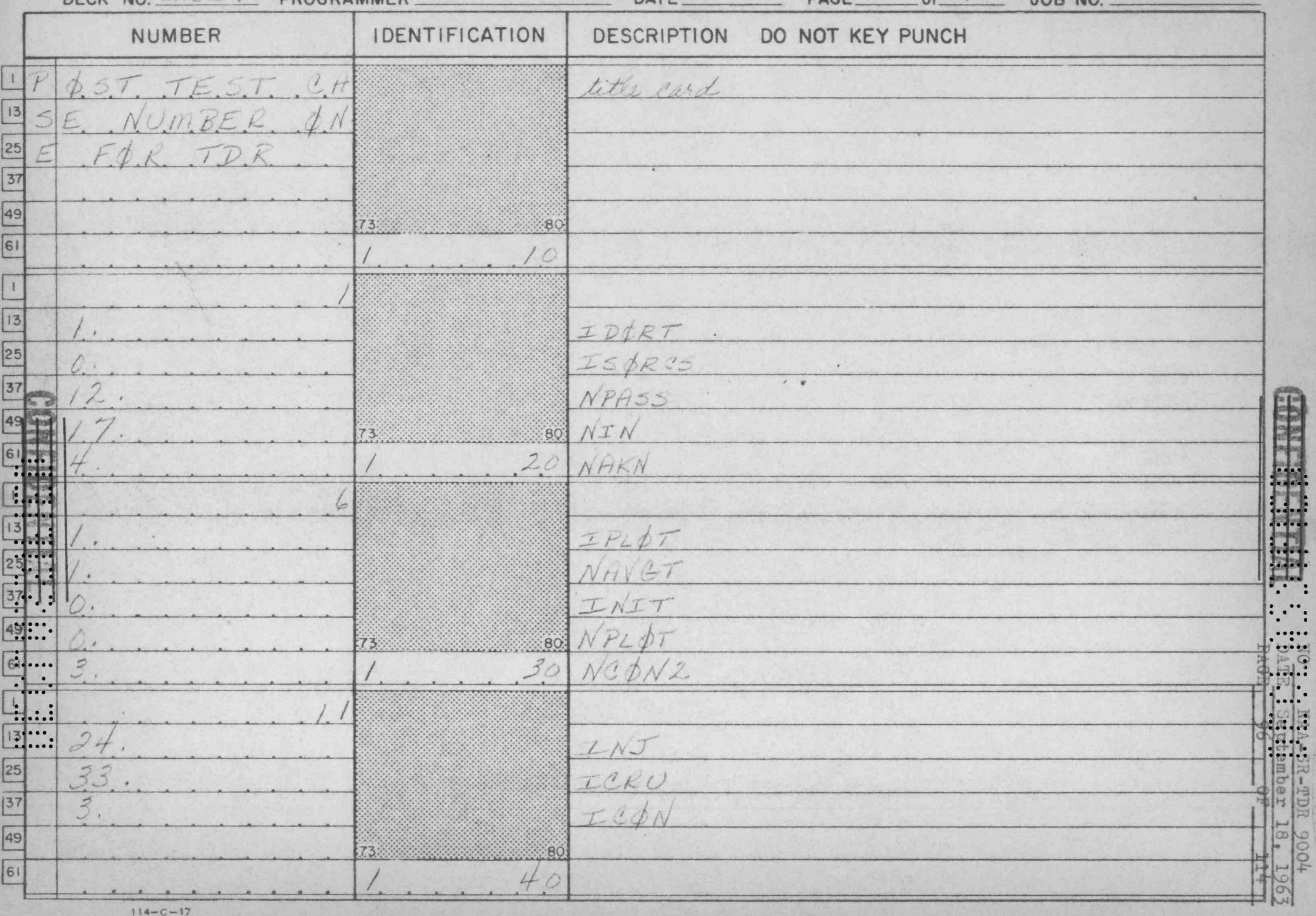




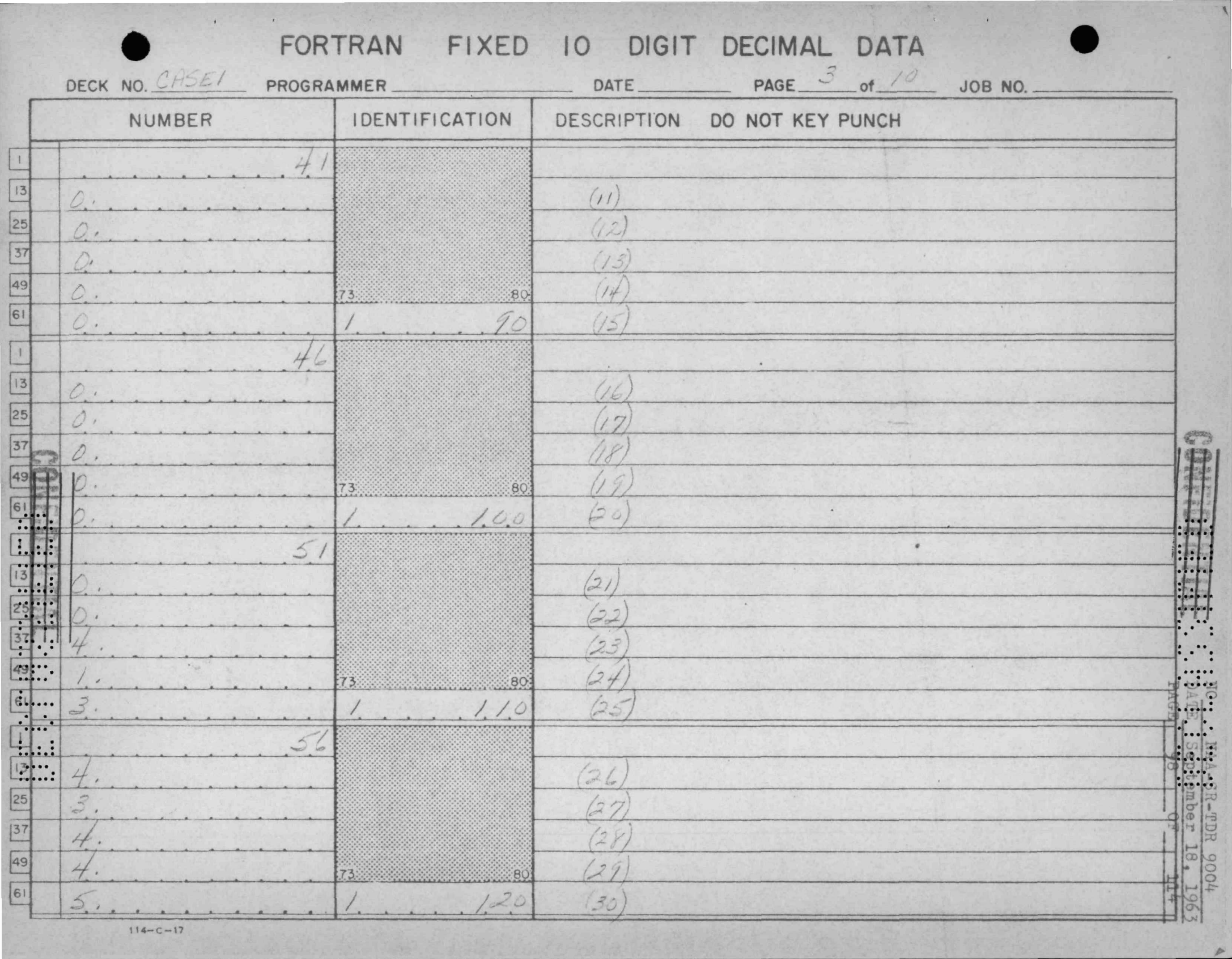




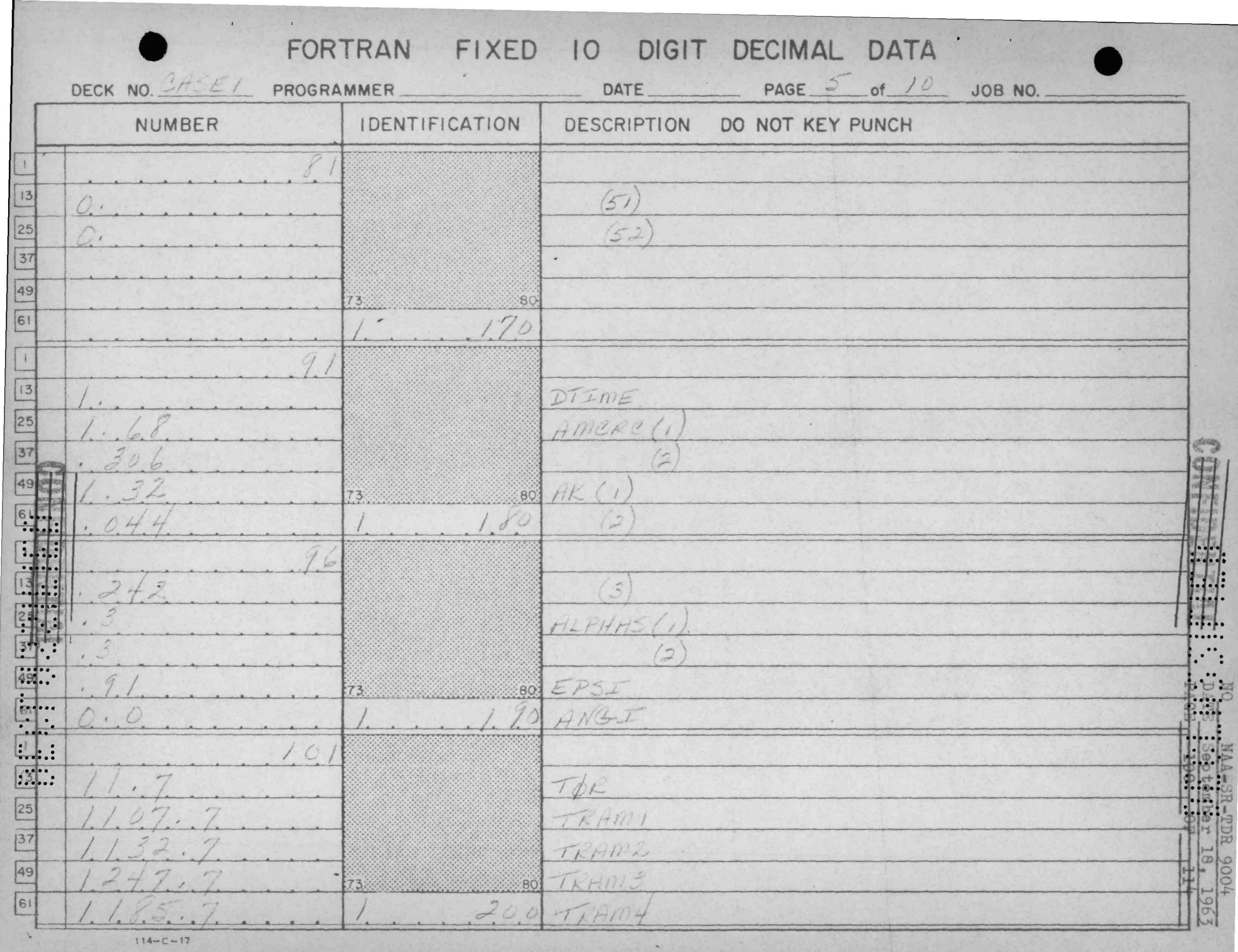




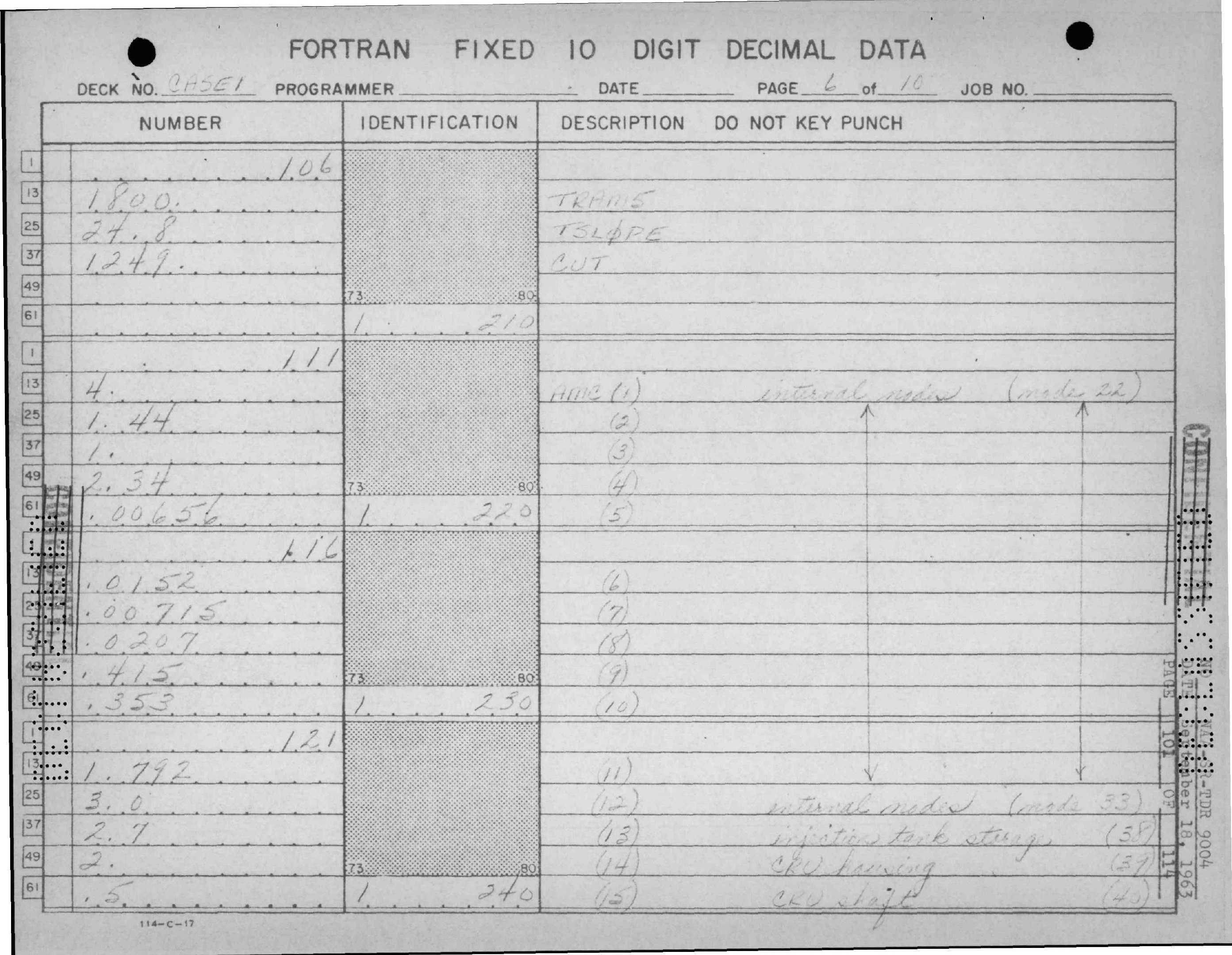




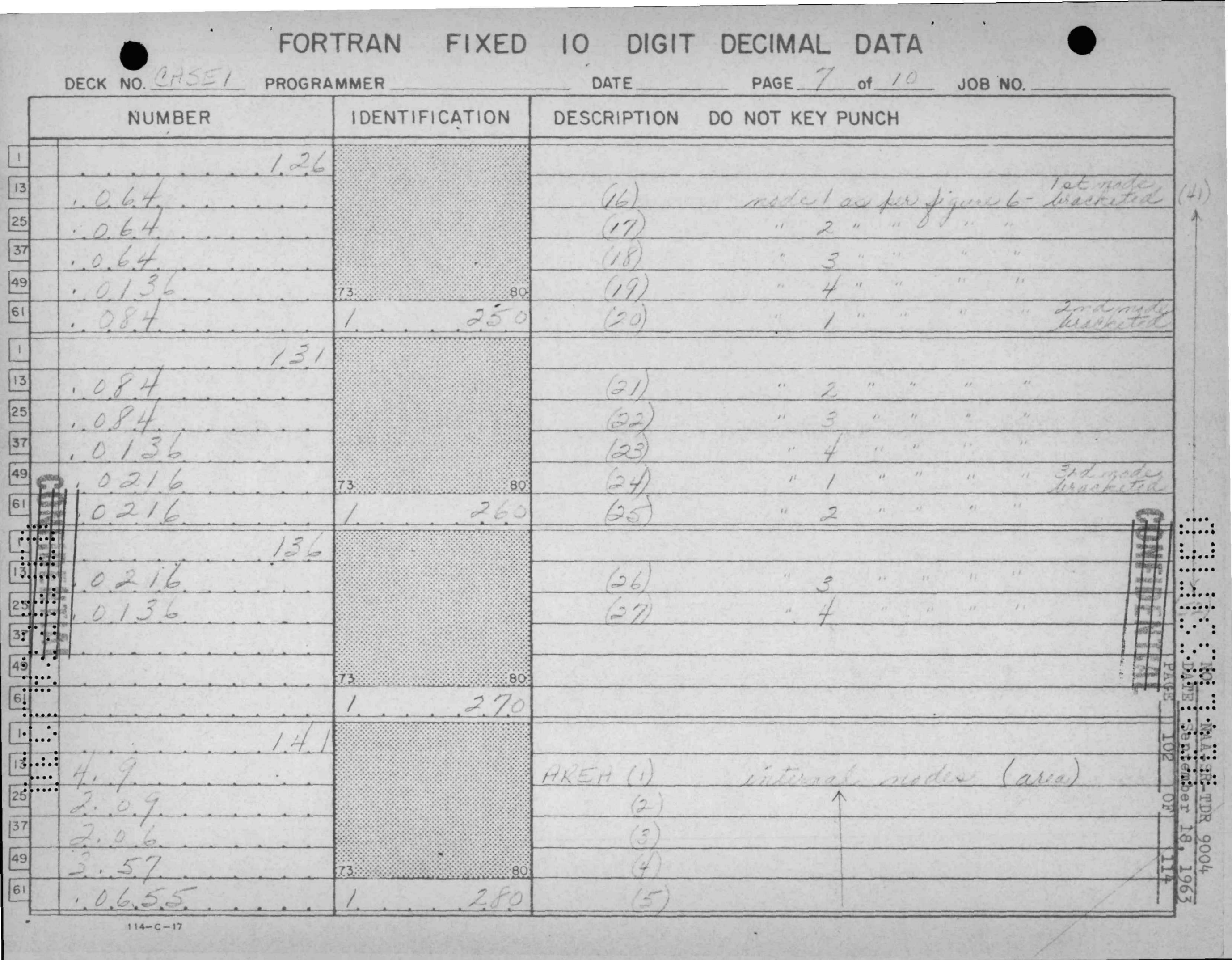




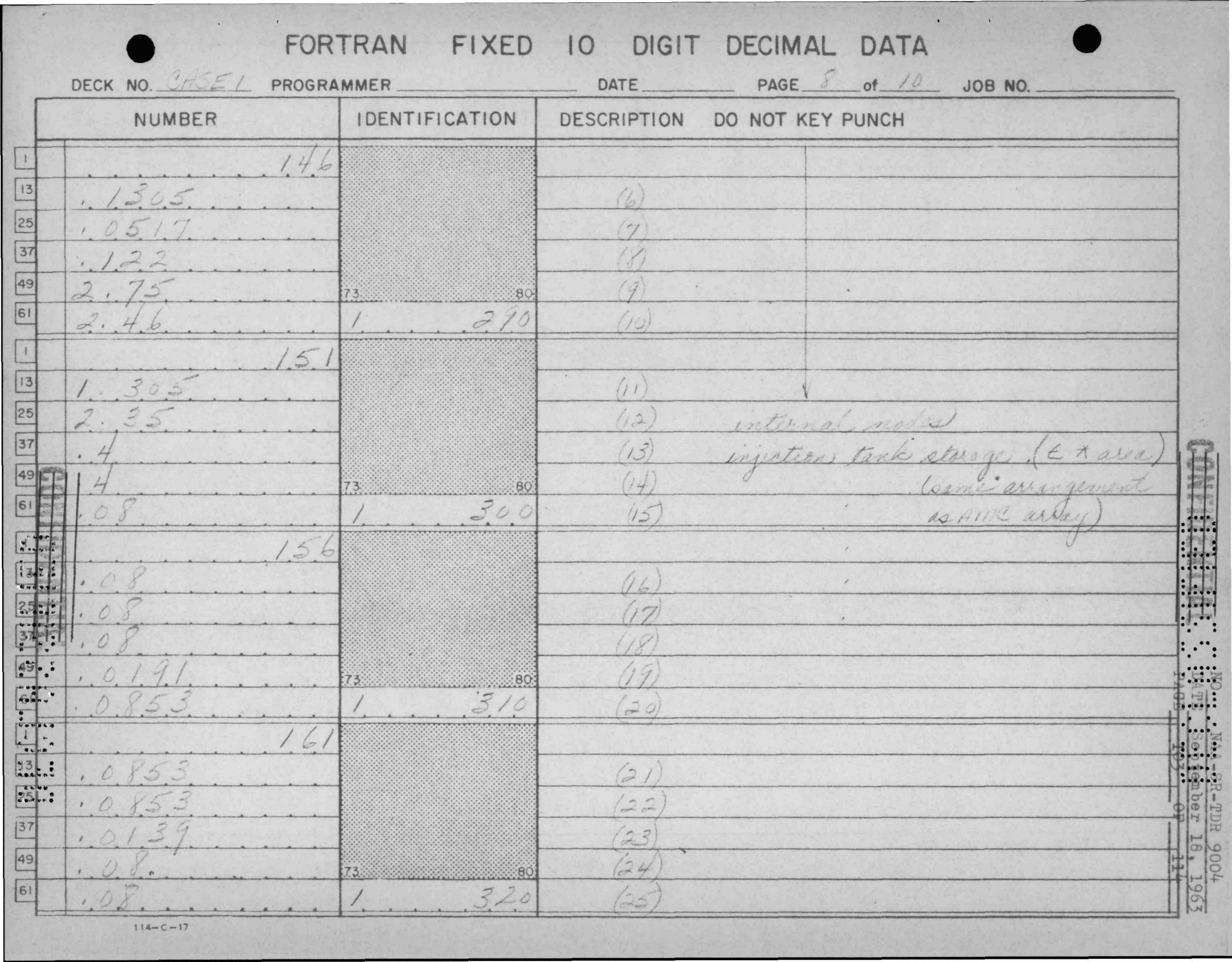




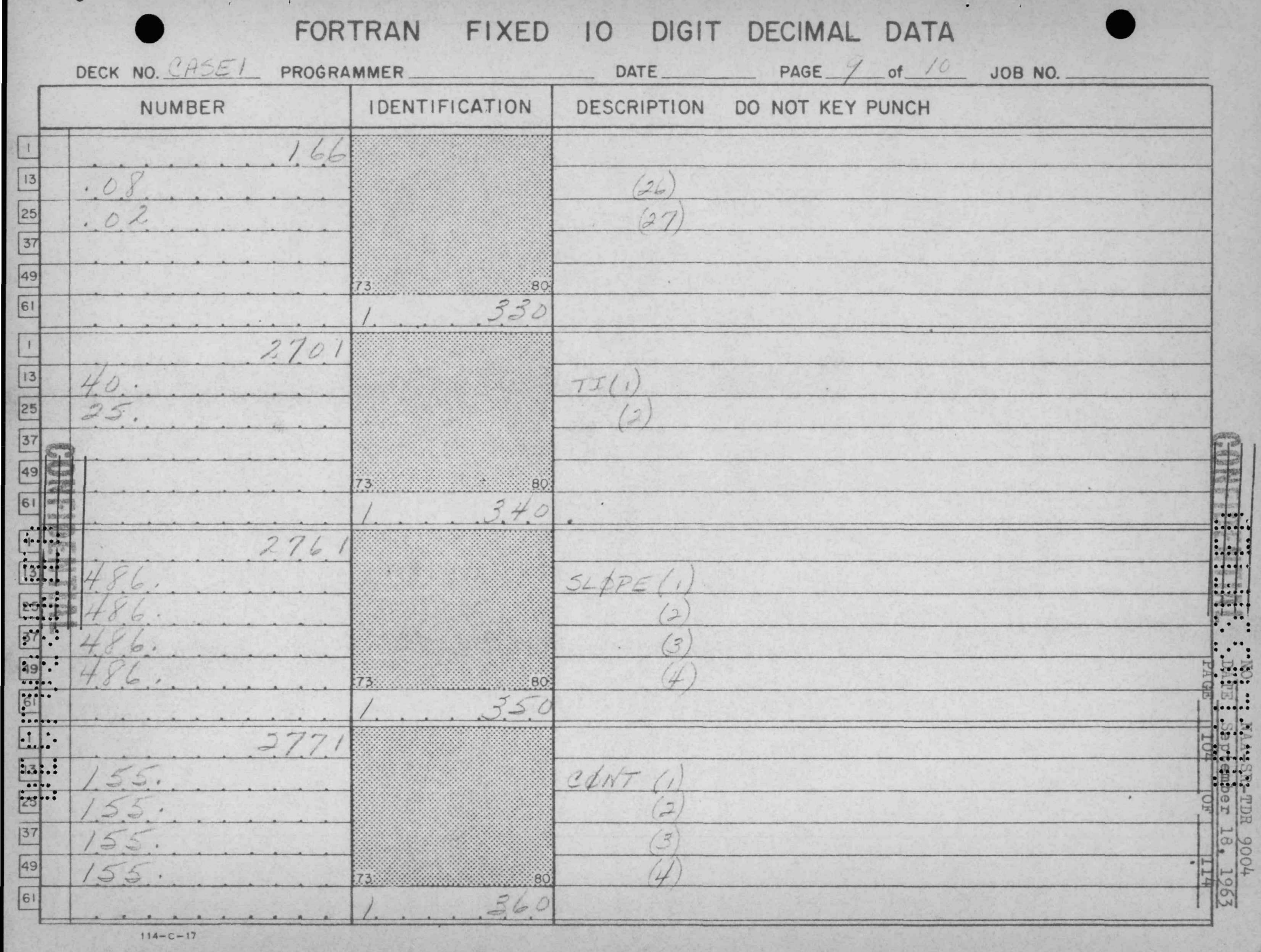




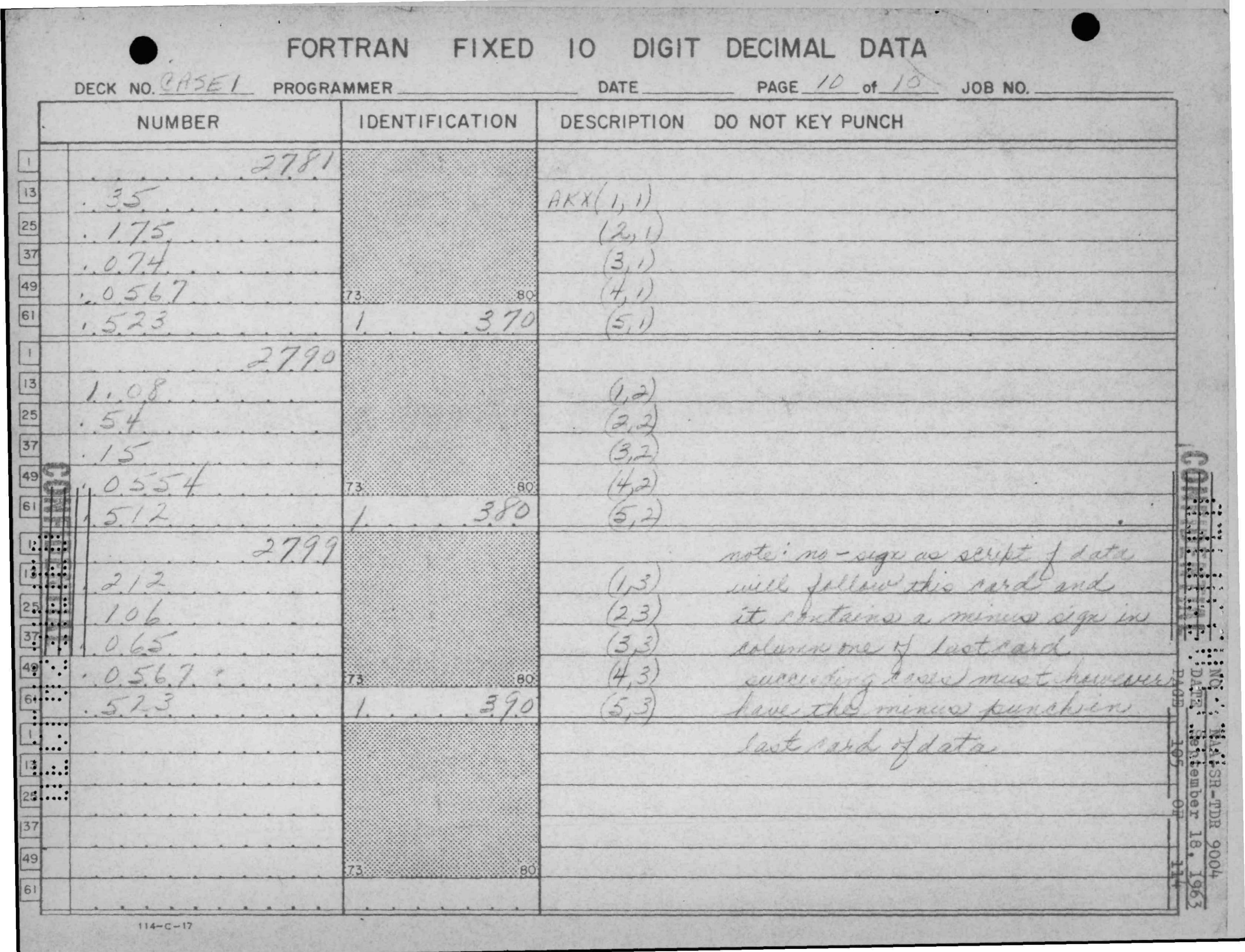




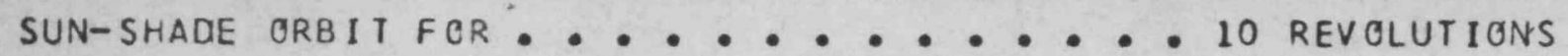

TOTAL NLMBER OF NODES .................. 47

NUMBER CF INTERNAL CONPONENTS

(INCLLOING TOP, BOTTON, AND AAK NODES) . . 17

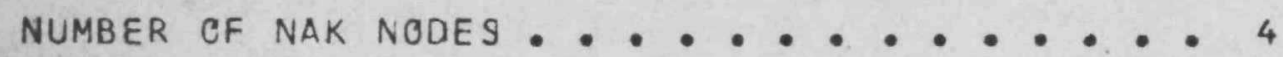

IIME INCREMENT ........................... 01 MINUTES

ABSORBTIVITY TO THERMAL RADIATION

= EMISSIVITY OF OUTSIDE AREA. . . $0.9100 E 00$

ABSORBTIVITY TO SOLAR RADIATION

R/C NOCES .......... 0...3000E-00

SUB-CCOLER NODES:. :.

PRODUCT OF MASS AND SPECIFIC HEAT

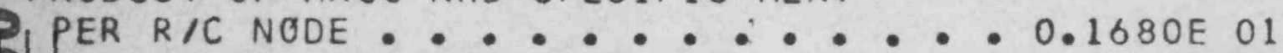

- Per slb-cooler nede : : : : 0.3060 : : 0.00

ato

* RODUCT OF HEAT TRANSFER COEFFICIENT

- AND CRESS-SECTIONAL AREA

4.1.2.\% NOCES HORIZONTALLY...... 0. 0.1320E 01

3 "SUंB-CCOLER NODES HORIZONTALLY. * $0.1440 E-00$

- 1.jic to SUb-COOLER NODES VERTICALLY. 0.2420E-00

$\rightarrow \cdot$

O..... ITAL POSITION AT TINE $=0.0 . . .0$.

DEGREES

:IiN.ITIAL TEMPERATURE OF TOP .... $0.2500 E$ O2 DEGREES

$\because \because$ :

TIGMPERATURE OF TOP INCREASES AT . . 0.2480 E 02 BTU/HR

$\because$ OPOM $0.1198 \mathrm{E} 04$ TC:: 0.1800 E 04 MINUTES

:.....

$\therefore$

$\vdots . .: \vdots$

…... 
TEST CASE OF POST INCLUDING RAD. AND CEND. TERMS FOR INTERNAL NODES

INTER̃IOR NODE DATA

MASS TINES SPECIFIC HEAT

AREA

$0.4900 E 01$

$0.4000 E 01$

$0.1440 E 01$

$0.3700 E 01$

$0.2340 E$ OI

$0.6560 E-02$

$0.1520 E-01$

$0.7150 E-02$

$0.2070 E-01$

$0.4150 E-00$

$0.3530 E-00$

$0.1792 E \quad O 1$

$0.3000 E 01$
0.2090 E 01

0.2060 E Ol

0.3570 E OI

$0.6550 E-01$

$0.1305 E-00$

$0.5170 E-01$

$0.1220 E-00$

$0.2750 E 01$

0.2460 E 01

$0.1305 E$ Ol

0.2350 E 01
HEATER

0.
0.
0.
0.
0.
0.
0.
0.
0.
0.

NAK NOLE DATA

TEMPERATURE INCREASES BY CONSTANT AT $0.1120 E 04$ P

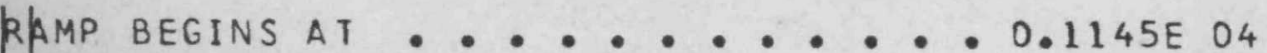

ANO BECGMES CONSTANT AGAIN AT: $\because 0^{\circ} 1260 E 04$

NODE CONSTANT RATE OF INCREASE

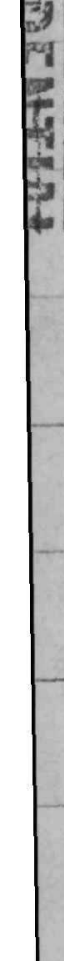

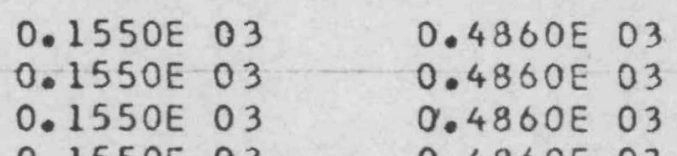

$0.1550 E 03 \quad 0.4860 E 03$

$\because \because$

$\because \ldots$.

i.....

$\therefore \therefore$

¿...:

:....: 
MIN REV ANG AVG RAD TENPERATURE OF NODES IN CEGREES FAHRENHEIT

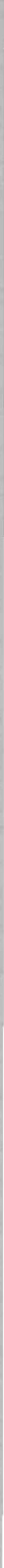


$$
\text { PAGE } 109 \text { OF } 114
$$

\section{Method of Predicting the Temperature Extremes of any Component}

The computer results obtained from the foregoing analysis were used to derive a method of predicting the temperature as a function of time of any component, valve, section of pipe, etc., contained in the PCS. Since this method is based on computer results, the only mode of heat transfer considered was by internal radiation.

The heat loss by radiation from a body of Area A, emissivity E, and surface temperature Ts to the surroundings at a temperature $\mathrm{Ta}$ is given by

$$
q_{r}=\sigma A E\left(T_{S}{ }^{4}-T_{a}{ }^{\gamma}\right)
$$

Even though this heat loss of radiant energy is proportional to the 4t power of the temperatures, a radiation coefficient ( $h r$ ) may be defined on the besis of the linear temperature difference, or

$$
q_{r}=A \operatorname{hr}\left(T_{s}-T_{a}\right)
$$

From this definition, a time constant $\frac{m c}{h_{r} E A}$ is obtained. "Iso, by equating the above equations

$$
h_{r}=\operatorname{Er}\left(T_{s}+T_{a}\left(T_{s}^{2}+T_{a}^{2}\right)\right.
$$

Obviously hr is a function of the source and sink temperature as well as the surface emissivity. The sink temperature for any FCS component is effectively the mean $R / C$ temperature since the sink and source temperatures both vary and an analytic determination of the radiation coefficient is difficult.

For this reason, a pseudo time constant difined as $\gamma=\frac{m c}{E A}$ was introduced and the relationship between this constant and the real time constant was determined from the results of the foregoing analysis. This relationship is shown by Graph 42 which is a plot of the real time constant versus the pseudo time constant.

By calculating the value of the psuedo time constant for any component in question, the real time constant can be obtained by referring to this graph. Once the real time constant is known, the temperature change of any component as a function of time may be determined from

$$
t=t_{0}-\left(t_{0}-t_{m}\right)\left(1-e^{-T / \gamma}\right)
$$

prior to sensible heat. 
where: to - initial component temperature at launch $=40^{\circ} \mathrm{F}$

$t_{m}$ - mean temperature at which a component reaches thermal equilibrium with surroundings $\left(-65^{\circ} \mathrm{F}\right)$

$T$ - time from launch, to point at which the temperature $(t)$ of the component is derived prior to startup

$\gamma$ - real time constant

A second plot was made from the results of this program which gives the change in terperature from the period between sensible heat generation and mercury injection as a function of $\varepsilon \mathrm{A} / \mathrm{mc}\left(\frac{1}{\gamma^{\prime}}\right)$. This plot had a maximum deviation of $\pm 20^{\circ} \mathrm{F}$ and this large of a variation was only experienced with $\varepsilon A / m c$ greater than 1.2 .

EX: This method is best illustrated by an example. Assume a component has the following properties:

$$
\begin{aligned}
& \text { mass }=10 \mathrm{lbs} \\
& \text { specific heat }=.10 \frac{\mathrm{BTU}}{1 \mathrm{~b}^{\circ} \mathrm{F}} \\
& \text { emissivity }=.05 \\
& \text { surface area }=2 \mathrm{ft}^{2}
\end{aligned}
$$

The pseudo time constant is

$$
\gamma^{\prime}=\frac{m c}{\varepsilon A}=\frac{(10)(.095)}{(.05) \cdot 2)}=9.5
$$

Referring to Graph 42, the real time constant is 18.8 hours. If the time from vehicle launch to startup is 20 hours ( $\approx 9$ hours minimum) the temperature of the component at the initiation of the startup sequence is

$$
\begin{aligned}
& t=t_{0}-\left(t_{0}-t_{m}\right)\left(1-e^{-T / r}\right) \\
& t=40-105\left(1-e^{2.718 .8}\right) \\
& t=-28.6{ }^{\circ} \mathrm{F}
\end{aligned}
$$

Taking the reciprocal of the pseudo time constant $\left(\gamma^{\prime}\right)$ and referring to graph 43 , the components change in temperature from sensible heat to injection is $26^{\circ} \mathrm{F}$, or the temperature of the component at injection is $-2.6^{\circ} \mathrm{F}$. 


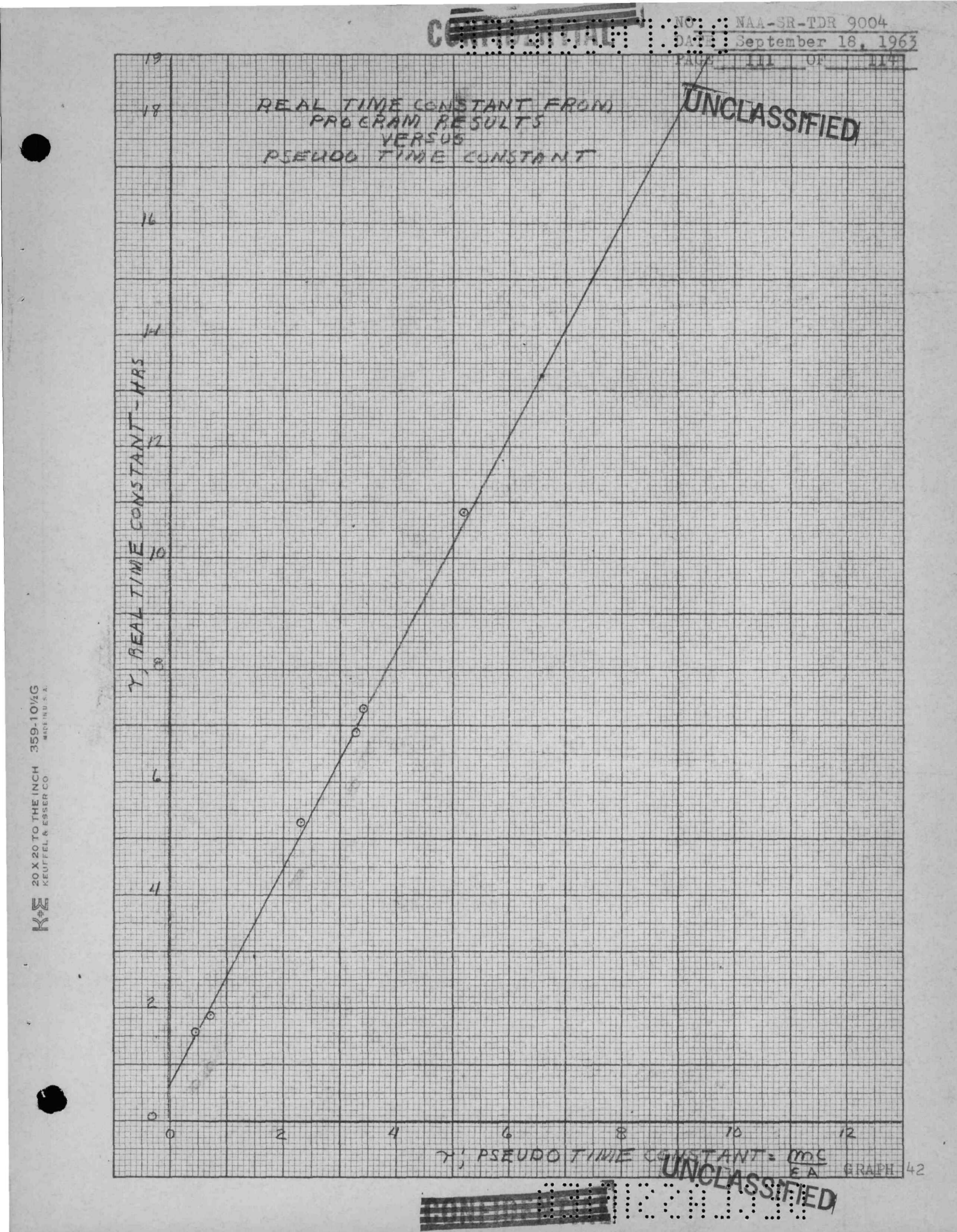


ATOMICS INTERNATIONAL

A Division of North American Aviation, Inc. DATE September 18,1263 SS/F/ED

REFEREIICES

1. Berman, D., TDR 6747, "SiAP-2 Prestartup System Temperature

2. Treuenfels, E., TDR 9961, "Radiator-Condenser Analysis."

3. James, L., TDR 8302, "SNAP-2 Orbital Startup with a Thermoelectric NaK pump."

4. Treuenfels, E., TDR 8306, "SNAP-2/10A Shield Temperatures."

5. Toupo, K., NAA-SID 62-393, "A General Computer Program for the Determination of Radiant-Interchange Configuration Factors." 6. Berhold, P., and Gresho, P., "Interchange Factor Code,"
(Not Published) 